

\section{DISCLAIMER}

This report was prepared as an aceount of work sponsorodby United States Government. Neither the bnited Statesugevern menthortany

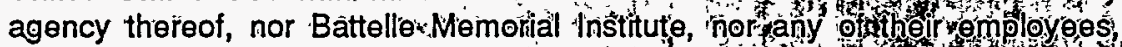

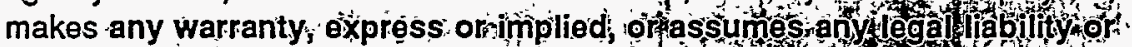
responsibility for the accuracy, compléten ess, of usefulnessitof fany

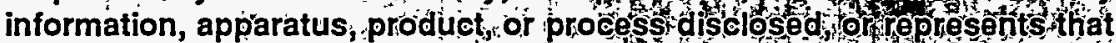

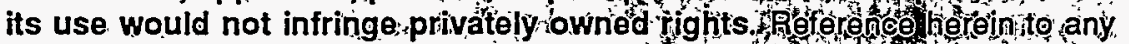
specific commercial product, process, or senvice by ptradoiname, tiad mairk, manufacturer, or otherwise does not necessabily constifute op imely uts endorsement, recommendation, or favoritig by the UUnitod States Govern ment or

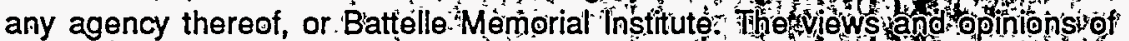

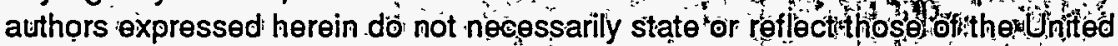
States Government or any agency thereof.

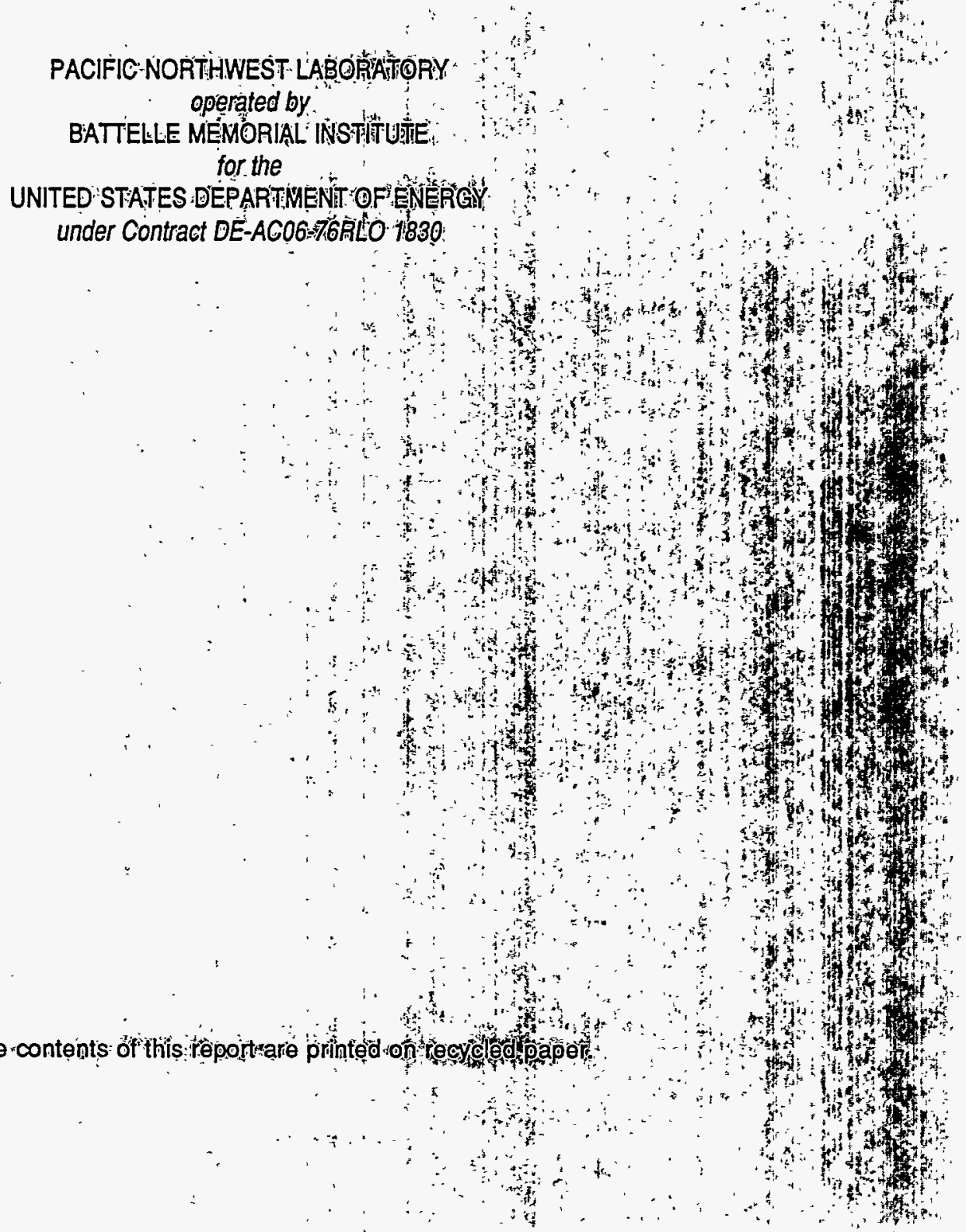


Field Monitoring and Evaluation of a Residential Gas-Engine-Driven. Heat Pump

\author{
Volume 1 - Cooling Season
}

J. D. Miller

September 1995

Prepared for

the U.S. Department of Energy

Federal Energy Management Program

under Contract DE-AC06-76RLO 1830

Pacific Northwest Laboratory

Richland, Washington 99352 



\section{Preface}

The Federal govemment is the largest single energy consumer in the United States;

consumption approaches 1.5 quads/year of energy ( 1 quad $\left.=10^{15} \mathrm{Btu}\right)$ at a cost valued at nearly $\$ 10$ billion annually. The U.S. Department of Energy (DOE) Federal Energy Management Program (FEMP) supports efforts to reduce energy use and associated expenses in the Federal sector. One such effort, the New Technology Demonstration Program (NTDP), seeks to evaluate new energysaving U.S. technologies and secure their more timely adoption by the U.S. government.

Pacific Northwest Laboratory (PNL) ${ }^{(a)}$ is one of four DOE national multiprogram laboratories that participate in the NTDP by providing technical expertise and equipment to evaluate new, energy-saving technologies being studied and evaluated under that program.

This two-volume report describes a field evaluation that PNL conducted for DOE/FEMP and the U.S. Department of Defense (DoD) Strategic Environmental Research and Development Program (SERDP) to examine the performance of a candidate energy-saving technology-a gasengine-driven heat pump. The unit was installed at a single residence at Fort Sam Houston, a U.S. Army base in San Antonio, Texas, and the performance was monitored under the NTDP. Participating in this effort under a Cooperative Research and Development Agreement (CRADA) were York International, the heat pump manufacturer, Gas Research Institute (GRI), the technology developer; City Public Service of San Antonio, the local utility; American Gas Cooling Center (AGCC); Fort Sam Houston; and PNL.

(a). Pacific Northwest Laboratory is operated for the U.S. Department of Energy under Contract DE-AC06-76RLO 1830 by Battelle Memorial Institute. 


\section{Summary}

Through its Office of Federal Energy Management Program (FEMP), the U.S. Department of Energy (DOE) provides technical and administrative support to Federal agency programs directed at reducing energy consumption and cost in Federal buildings and facilities. One such program is the New Technology Demonstration Program (NTDP).

In this context, NTDP is a demonstration of a U.S. energy-related technology at a Federal site. Through a partnership with a Federal site, the utility serving the site, a manufacturer of an energyrelated technology, and other organizations associated with these interests, DOE can evaluate new technologies. Through the results of the program, Federal agency decision makers have more hands-on information with which to validate a decision to utilize a new technology in their facilities. The partnership of these interests is secured through a Cooperative Research and Development Agreement (CRADA).

The purpose of the Fort Sam Houston/Triathlon demonstration is to evaluate the performance and cost-effectiveness of the Triathlon gas heat pump (GHP) in the Federal sector. This is done by measuring the performance of the candidate unit and comparing it to the measured performance of conventional HVAC systems currently in the residences at the base. The energy consumption, thermal measurements, and maintenance records will be primary elements in the life-cycle cost analysis of potential savings from the candidate unit.

The NTDP project at Fort Sam Houston (San Antonio, Texas) features a 3-ton gas-engine- . driven heat pump. A single-cylinder, four-stroke, 5-hp engine fueled by natural gas drives the heat pump's compressor. A distinctive feature of the technology is an inherent load-matching capability. The heat pump can vary engine speed and blower fan speed, and thereby dynamically control capacity to balance with thermal loads. This balance reduces cycling and the associated thermal losses and equipment wear. The unit also produces added heating capacity through engine-waste heat recovery. The Triathlon GHP is manufactured by York International.

Three test houses at the Fort were used for the field comparison of the Triathlon against conventional residential heating, ventilating, and air-conditioning (HVAC) systems. The houses were chosen to have identical structural design and solar exposure and to be occupied by families with one or two children. Two of the houses currently have HVAC systems that represent the best available at the Fort. This includes pulse-combustion fumaces and air conditioners with scroll compressors. A third house represents the worst case, with the oldest of the Fort's conventional air conditioners and furnaces. These HVAC systems bracket the range of equipment performance currently at the Fort and typically found in many other residential installations at Federal facilities.

Baseline measurements on the three comparison units started in August 1993. One of the comparison units was replaced with the Triathlon GHP in June 1994. Side-by-side monitoring of the 
Triathlon GHP and the two remaining comparison systems continued through June 1995. Monitoring of the Triathlon GHP continues through the end of December 1995.

Performance maps, based on field data, were developed for the existing residential furnaces and air conditioners monitored at Fort Sam Houston. These maps present a common basis for comparisons between the GHP and the existing equipment. The comparisons are done by projecting (mapping) the field-measured characteristics of the comparison units onto the actual loads and operating conditions seen by the GHP. This approach supplements a pre/post-measure evaluation by decoupling the measured equipment performance from the effects of different envelope characteristics, occupant behavior, and weather. Details of the technical approach used in the evaluation, including instrumentation and methodology, are presented in this volume.

Findings from the summer-cooling test have demonstrated the Triathlon GHP to be a reliable system for Fort Sam Houston. There were no forced outages during the test, giving the unit a $100 \%$ reliability record:

Throughout the cooling test season, the GHP operated at performance levels anticipated by the manufacturer. This test unit showed normal operating behavior relative to a computer simulation of the GHP. The cooling-season test results demonstrated GHP performance levels slightly above those established in the Phase I Field Test program conducted by the unit's developers. The GHP demonstrated a thermal coefficient of performance (COP) of 1.128 and a cost-equivalent test-period energy efficiency ratio (TP_EER) ${ }^{(\mathrm{a})}$ of $12.23 \mathrm{kBtu} / \mathrm{kWh}$. An electric air conditioner would require a TP_EER of 12.23 to have the same overall operating costs as the GHP (based on San Antonio residential fuel prices).

The occupants concluded that the GHP provided good comfort with acceptable levels of operating noise. Monitoring of indoor humidity during cooling operation showed nearly identical average humidity levels (and associated comfort) by the Triathlon and comparison air conditioners during the summer test.

The GHP has shown potential to reduce cooling-energy costs over more conventional air conditioners. In a normal San Antonio summer, the GHP uses $41.5 \mathrm{kcf}$ of gas and $864 \mathrm{kWh}$ of electricity. This amount of fuel costs $\$ 227$ (based on San Antonio residential prices) and corresponds to a savings of $\$ 111$ to $\$ 139$ over the three comparison air conditioners in this field

(a) TP_EER should never be directly compared with SEER or EER. EER and SEER are based on chamber measurements of capacity and consumption. EER is a direct presentation of chamber performance at rating conditions. SEER is based on chamber measurements and standard procedures that estimate the dynamic performance of the unit over an entire season of national average conditions. TP_EER is an indicator of actual field efficiency as subject to operating conditions seen in the field test. Generally, field conditions for a TP_EER are more severe than those used in calculating a SEER (e.g., a retum temperature of $80^{\circ} \mathrm{F}$ is assumed in SEER calculations). As a result, TP_EER measurements will generally be significantly lower than SEER ratings. 
test. The savings relative to the best of the comparison units (10.45 SEER) was $\$ 111$ (32.9\%). 



\section{Abbreviations, Acronyms, and Initialisms}

AGCC American Gas Cooling Center

ANSI , American National Standards Institute

ARI Air-Conditioning and Refrigeration Institute

ASHRAE American Society of Heating, Refrigerating and Air-Conditioning Engineers, Inc.

Btu British thermal unit

CDD cooling degree-day

COP coefficient of performance

CRADA Cooperative Research and Development Agreement

DAS data acquisition system

DoD U.S. Department of Defense

DOE U.S. Department of Energy

EER energy efficiency rating (ratio)

FEMP Federal Energy Management Program

GHP gas heat pump

GRI Gas Research Institute

HVAC heating, ventilating, and air conditioning

k thousand

kWh kilowatt-hour

M million

NCDC National Climatic Data Center

NTDP New Technology Demonstration Program

PNL Pacific Northwest Laboratory

RTD resistance temperature device

SEER seasonal energy efficiency rating

SERDP Strategic Environmental Research and Development Program

TP_EER test-period energy efficiency ratio

TRY Test Reference Year 



\section{Contents}

Preface $\ldots \ldots \ldots \ldots \ldots \ldots \ldots \ldots \ldots \ldots \ldots \ldots \ldots \ldots \ldots \ldots \ldots$

Summary $\ldots \ldots \ldots \ldots \ldots \ldots \ldots \ldots \ldots \ldots \ldots \ldots \ldots \ldots \ldots \ldots \ldots$

Abbreviations, Acronyms, and Initialisms $\ldots \ldots \ldots \ldots \ldots \ldots \ldots \ldots \ldots$ vii

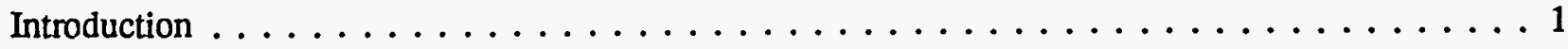

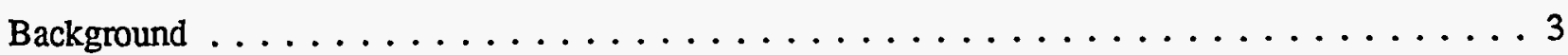

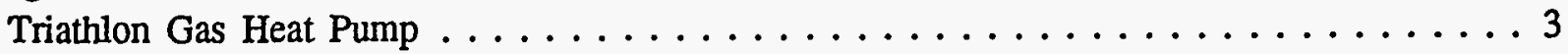

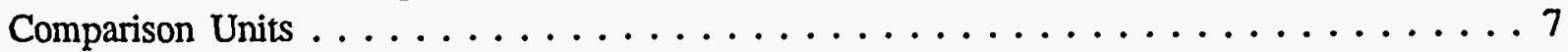

Demonstration site $\ldots \ldots \ldots \ldots \ldots \ldots \ldots \ldots \ldots \ldots \ldots \ldots \ldots \ldots$

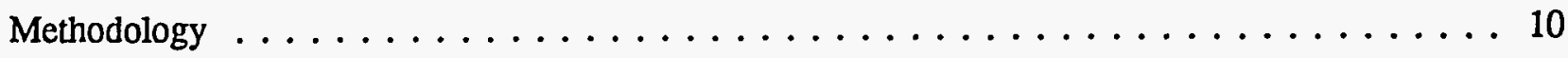

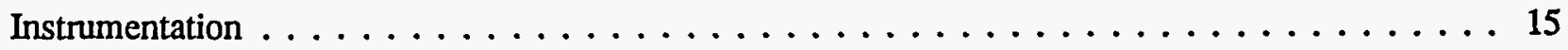

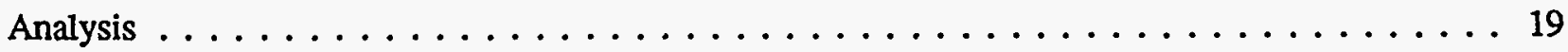

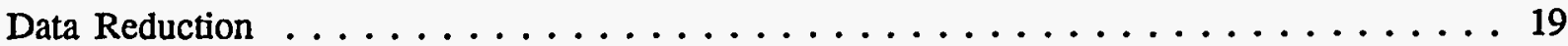

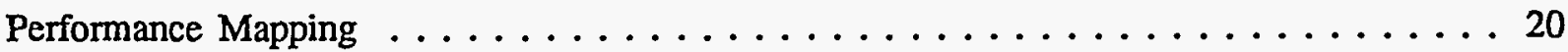

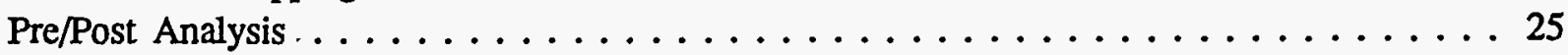

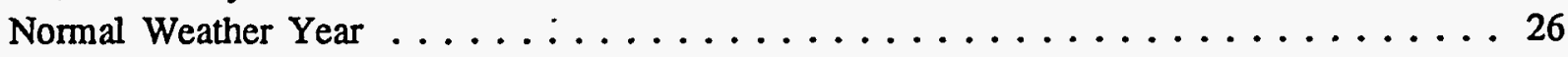

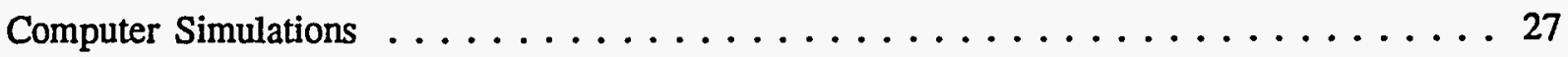

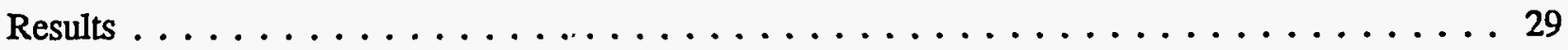

Unit and Instrumentation Maintenance and Other Events During Testing . . . . . . . 29

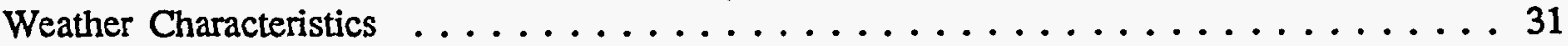

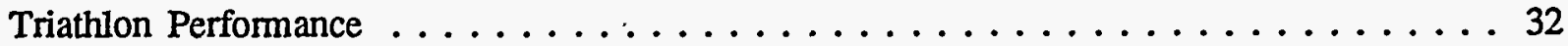

Comparison Units Performance . . . . . . . . . . . . . . . . . 32

Comparison Units Projected Performance $\ldots \ldots \ldots \ldots \ldots \ldots \ldots$

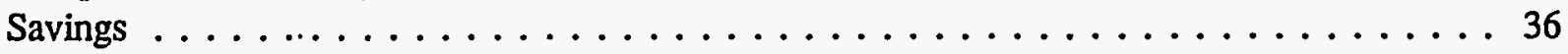

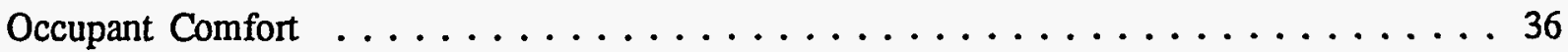

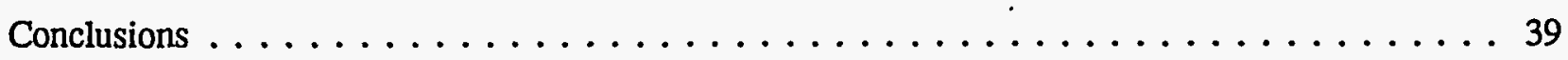

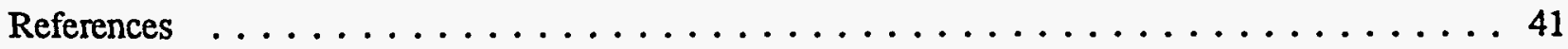

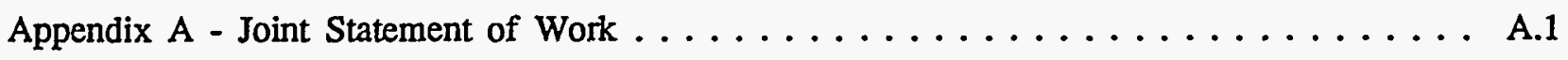

Appendix B - Instrumentation Details for Gas Heat Pump Monitoring . . . . . . . . . . B.1 
Appendix C - Performance Check by Computer Simulation $\ldots \ldots \ldots \ldots \ldots \ldots$ Appendix D - Additional Field Data on Triathlon $\ldots \ldots \ldots \ldots \ldots \ldots \ldots$ Appendix E - Fuel Price Calculations $\ldots \ldots \ldots \ldots \ldots \ldots \ldots \ldots \ldots \ldots \ldots \ldots$ 


\section{Figures}

1 Front View, Triathlon GHP Outdoor Unit (Engine and Compressor) With Weather-Monitoring Sensors Mounted on House to Left of Unit $\ldots \ldots \ldots \ldots$

2 Side View, Triathlon GHP Outdoor Unit, Showing Gas, Refrigerant, Glycol, Electric Power, and Monitoring Instrumentation Lines . . . . . . . . . 4

3 Triathlon GHP Outdoor Unit With Back Panel Removed $\ldots \ldots \ldots \ldots$

4 Triathlon GHP Outdoor Unit With Side Panel Removed $\ldots \ldots \ldots \ldots \ldots$

5 Triathlon GHP Indoor Unit With Condensate Tipping Bucket Meter (Near Box) and Duct Instrumentation $\ldots \ldots \ldots \ldots \ldots \ldots \ldots \ldots \ldots$

6 Test House 1 at Fort Sam Houston, San Antonio, Texas $\ldots \ldots \ldots \ldots$

7 HVAC Capacity Monitoring Instrumentation Used in Baseline Measurements . . . . 16

8 Baseline and Triathlon Data Acquisition Systems at Test House $1 \ldots \ldots \ldots 17$

9 Regression on Manufacturer's Steady-State Total Capacity Data . . . . . . . . 21

10 Regression of Relative Capacity With Duty Cycle for Unit $2 \ldots \ldots \ldots \ldots \ldots 22$

11 Regression of Relative Capacity With Duty Cycle for Unit $3 \ldots \ldots \ldots 22$

12 Triathlon Total Load Time Series $\ldots \ldots \ldots \ldots \ldots \ldots \ldots \ldots \ldots \ldots \ldots \ldots$

13 Measured and Self-Mapped Energy Use Time Series From Unit $2 \ldots \ldots \ldots \ldots$

14 Regression of Daily Total Load Against Outdoor Temperature, House 1, 1994 Cooling Season Test (Triathlon Installed) . . . . . . . . . . . . 25

15 Regression of Daily Total Load Against Outdoor Temperature, House 1, 1993 Cooling Season Test (Baseline) . . . . . . . . . . . . . . . . . . 26

16 Distribution of Outdoor Operating Temperatures at House 1 During 1993

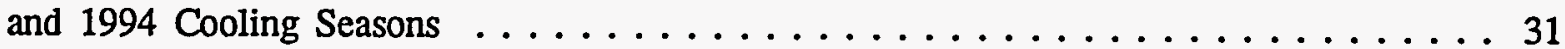


17 Distribution of Indoor Operating Relative Humidity $\ldots \ldots \ldots \ldots \ldots$

18 Distribution of Indoor Operating Temperature $\ldots \ldots \ldots \ldots \ldots \ldots$

\section{Tables}

1 Manufacturers' Rated Performance of Test Units $\ldots \ldots \ldots \ldots \ldots \ldots$

2 Fort Sam Houston Test House Occupancy History . . . . . . . . . . . . . 9

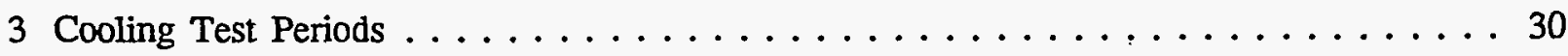

4 Commissioned Performance Periods $\ldots \ldots \ldots \ldots \ldots \ldots \ldots \ldots$

5 Triathlon GHP 1994 Cooling-Season Test Performance . . . . . . . . . . . . . 33

6 Comparison Units Performance in 1993 Test Season $\ldots \ldots \ldots \ldots \ldots$. . . . . . . 34

7 Comparison Units Performance in 1994 Test Season $\ldots \ldots \ldots \ldots$

8 Commissioned Performance of Comparison Units Projected Onto 1994 Loads and Operating Conditions of Triathlon Unit . . . . . . . . . . . 36

9 Normal Year Savings by Triathlon Unit Relative to Comparison Units . . . . . . . 36 


\section{Introduction}

The purpose of the New Technology Demonstration Program (NTDP) is to install and evaluate new U.S.-developed energy technologies at Federal facilities and evaluate their performance. Through the results of the program, Federal agency decision makers have more hands-on information with which to consider a new technology and validate any decision to utilize it in their facilities. The NTDP seeks to identify new energy-saving technologies, determine which have the broadest application in, and benefit to, the Federal sector, and then shorten the deployment time for those technologies that prove beneficial to the Federal market by providing a demonstration of the energy savings potential and the cost-effectiveness of these new technologies in the Federal sector. The NTDP supports Federal facilities in their effort to meet goals established in Executive Order $12902^{(a)}$ and the Energy Policy and Conservation Act. ${ }^{(b)}$

The purpose of the Fort Sam Houston/Triathlon demonstration is to evaluate the performance and cost-effectiveness of the Triathlon gas heat pump (GHP) in the Federal sector. This is done by monitoring the performance of the candidate unit and comparing it to that of the conventional HVAC systems currently in the residences at the base. The energy consumption, thermal measurements, and maintenance records will be primary elements in life-cycle cost analysis of potential savings from the candidate unit (see Joint Statement of Work in Appendix A).

The NTDP project at Fort Sam Houston (San Antonio, Texas) features a 3-ton gas-enginedriven heat pump. A single-cylinder, four-stroke, 5-hp engine fueled by natural gas drives the heat pump's compressor (Harnish et al. 1991). A distinctive feature of the technology is an inherent load-matching capability. The heat pump can vary engine speed and blower fan speed, and thereby dynamically control capacity to balance with thermal loads. This balance reduces cycling and the associated thermal losses and equipment wear. The unit also produces added heating capacity through engine-waste heat recovery. The Triathlon GHP is manufactured by York International.

Baseline measurements on three comparison units at the Fort started in August 1993. One of the comparison units was replaced with the Triathlon GHP in June 1994. Side-by-side monitoring of the Triathlon and the two remaining comparison units continued through June 1995 . Monitoring of the Triathlon GHP continues through the end of December 1995.

(a) "Each agency shall develop and implement a program with the intent of reducing energy consumption by 30 percent by the year 2005 , based on energy consumption per-gross-square-foot of its buildings in use, to the extent that these measures are cost-effective."

(b) "Not later than January 1,2005, each agency shall, to the maximum extent practicable, install in Federal buildings owned by the United States all energy and water conservation measures with payback periods of less than 10 years. .." 
This volume is the first of a two-volume report on the Fort Sam Houston/Triathlon demonstration. Volume 1 describes the cooling performance of the Triathlon GHP during the 1994 cooling-season test relative to three comparison air conditioners. Emphasis is given to describing the methodology used in the cooling analysis (and to be used in the heating analysis) and to describing the instrumentation used in the monitoring. Although operating cost comparisons are made, the life-cycle cost analysis is presented in Volume 2. Volume 2 presents results from monitoring during the heating season, additional information on features of the Triathlon, and lifecycle cost analysis for Fort Sam Houston and other Federal facilities in the United States. 


\section{Background}

\section{Triathlon Gas Heat Pump}

The Triathlon GHP is a heat pump with a compressor driven by a natural-gas-fired engine. By contrast, an electric air conditioner has a compressor driven by an electric motor. The GHP single-cylinder, four-stroke, 5-hp engine was developed by Briggs \& Stratton. Annual maintenance involves changing the oil, oil filter, air filter, and spark plug. . It has heavy-duty pistons, hydraulic valve lifters, water cooling, and pressurized oil lubrication. Lean-bum combustion enhances efficiency and minimizes emissions. Endurance tests of the engine indicate a lifetime in excess of $40,000 \mathrm{~h}$, or 10 to 15 years of typical heat pump use. Engine noise is $65 \mathrm{db}$ at $3 \mathrm{ft}$, approximately the same as that of the most advanced electric heat pump. The outdoor and indoor sections of the GHP are shown in Figures 1 through 5.

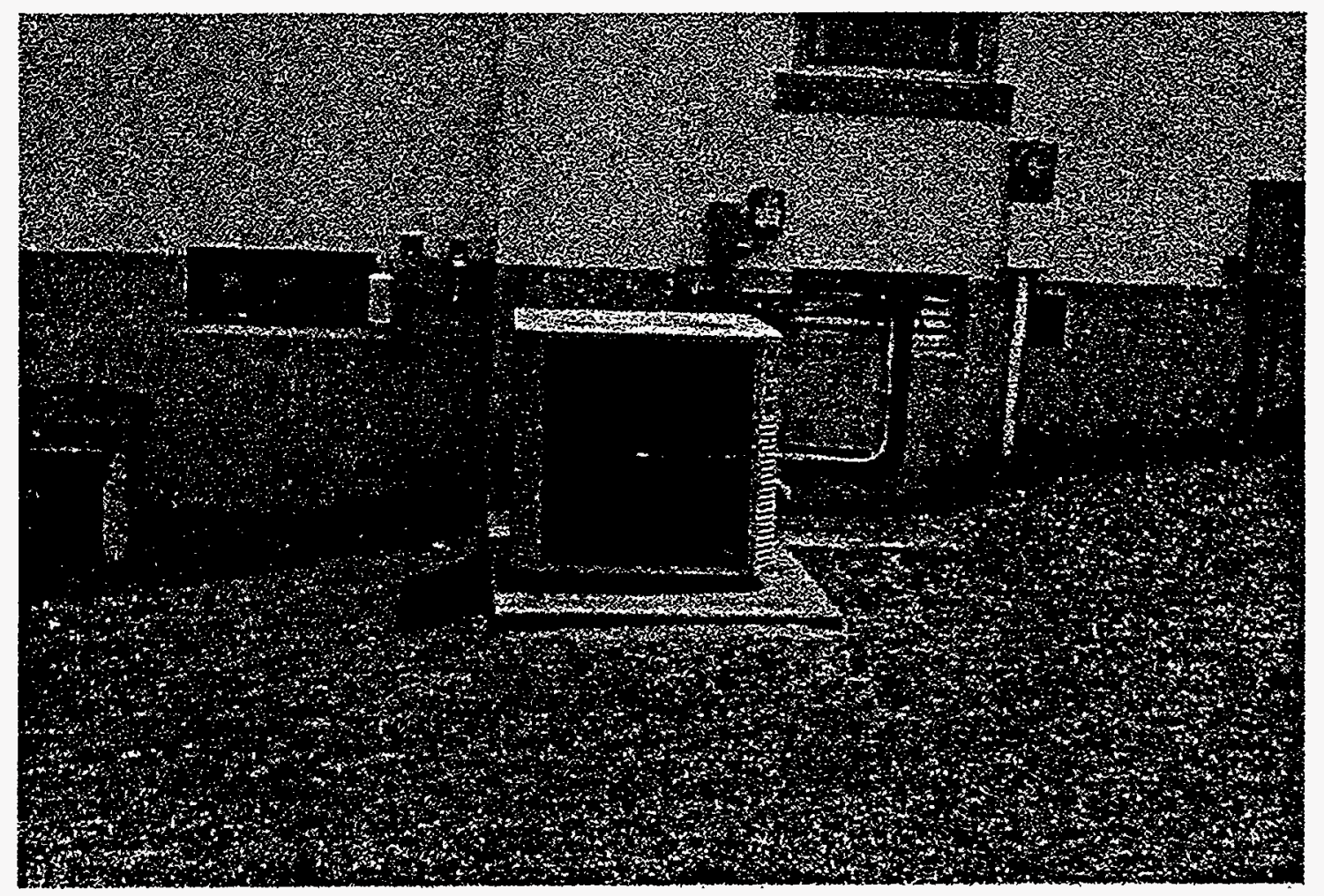

Figure 1. Front View, Triathlon GHP Outdoor Unit (Engine and Compressor) With Weather-Monitoring Sensors Mounted on House to Left of Unit 


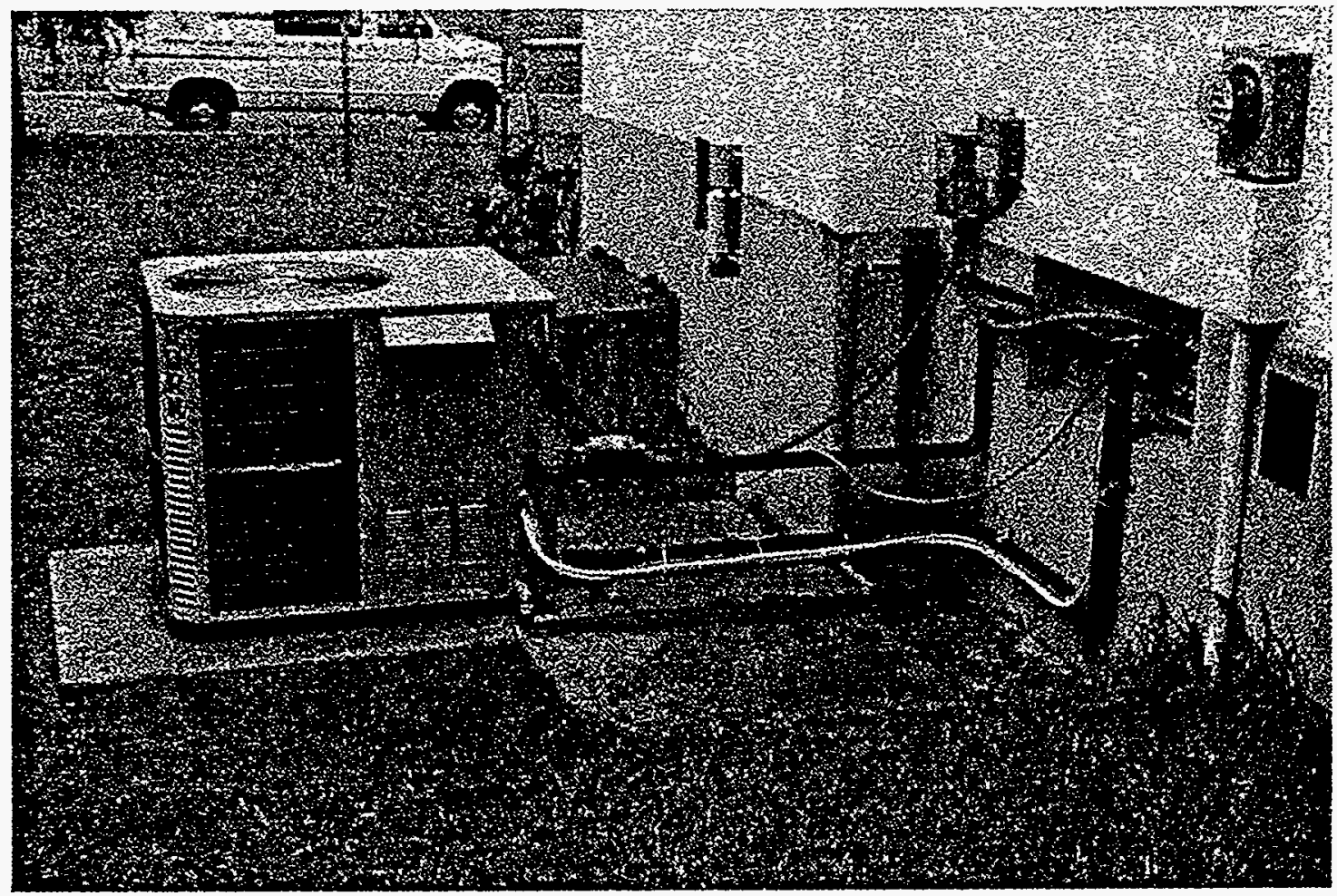

Figure 2. Side View, Triathlon GHP Outdoor Unit, Showing Gas, Refrigerant, Glycol, Electric Power, and Monitoring Instrumentation Lines

The primary advantage of the GHP is lower operating cost. According to the Gas Research Institute (GRI), "The annual cost to operate the gas heat pump can be up to $50 \%$ less than a gas furnace/electric-air-conditioner combination or an electric heat pump." (GRI 1993). A secondary advantage is improved occupant comfort from less variation of temperature and humidity in the house. This improvement results from the GHP's variable-speed operation and electronic controls. The heat pump can vary engine speed and blower fan speed, thereby dynamically controlling capacity to balance with thermal loads. This balance reduces cycling and the associated thermal losses and equipment wear, it tends also to reduce summertime humidity levels in the house.

In the heating season, the GHP provides supply-air temperatures warmer than conventional heat pumps because of waste-heat recovery from the engine. The waste heat is delivered via a waterglycol loop to a separate radiator in the indoor unit. This feature eliminates the uncomfortably cool supply air produced by electric heat pumps during defrost cycles and periods of low outdoor ambient temperatures. The heat recovery also improves heating capacity. Compared to electric heat pumps, the gas heat pump has nearly twice the heating capacity at $0^{\circ} \mathrm{F}$. Recovered heat can also be used for domestic hot water heating. On summer days, it can meet up to $100 \%$ of water heating needs. 


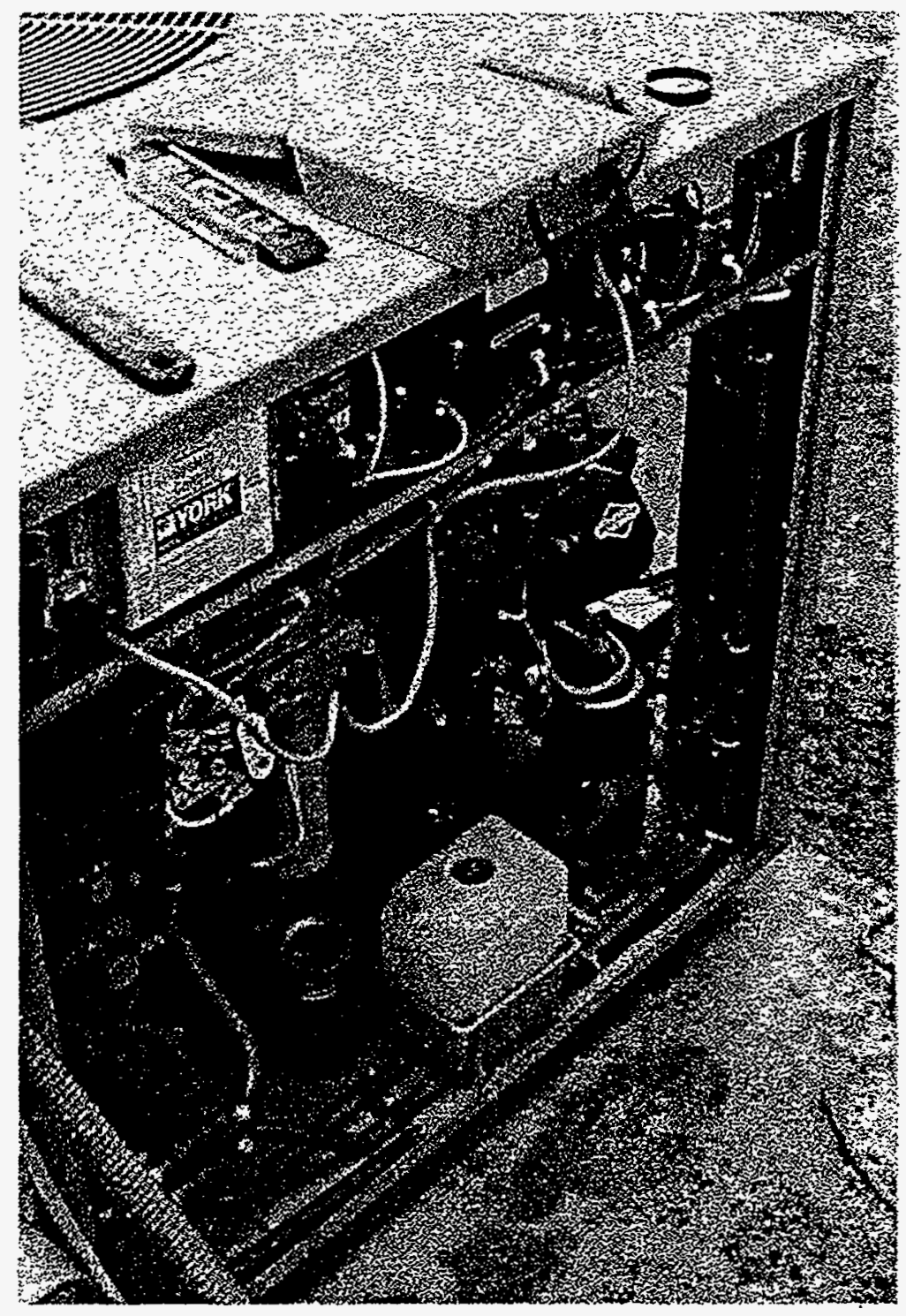

Figure 3. Triathlon GHP Outdoor Unit With Back Panel Removed

When supplemental heat is required, the GHP meets the added load with a gas-fired auxiliary boiler (heating COP, 0.82; capacity, $65 \mathrm{kBtu} / \mathrm{h}$ ). The boiler is contained in the outdoor unit and circulates hot fluid to the water-glycol radiator contained in the indoor unit. In extreme cold, the system controls shut down the heat pump and the auxiliary boiler is the sole source of heating. Outdoor temperatures below $5^{\circ} \mathrm{F}$ trigger a heat pump shutdown. As temperatures rise above $5^{\circ} \mathrm{F}$, the heat pump is released from the shutdown mode. 


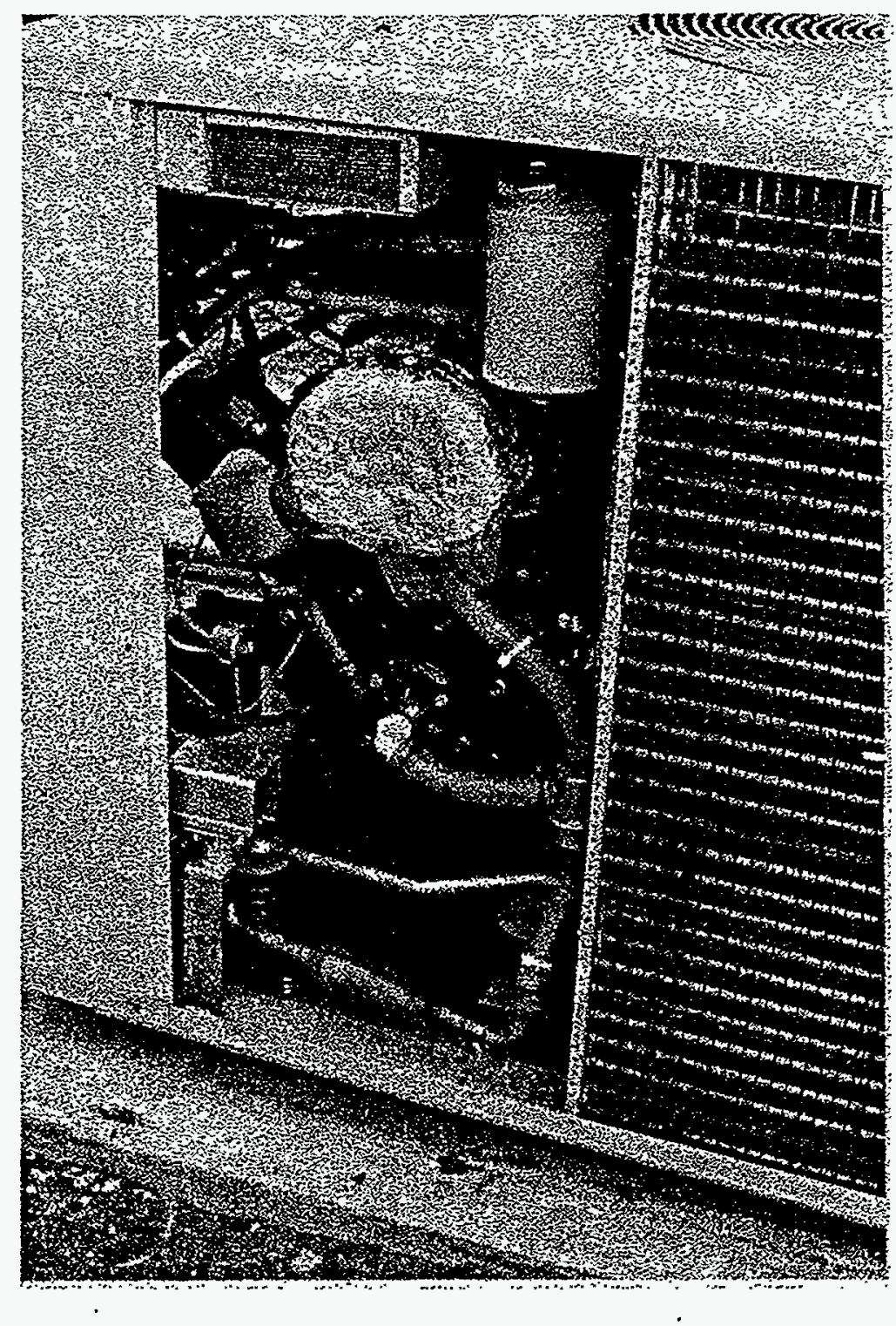

Figure 4. Triathlon GHP Outdoor Unit With Side Panel Removed

The mechanical power of the engine can also be used to drive a generator to produce electricity. This power can be used to drive the heat pump fan and blower or to maintain certain critical home base power needs. ${ }^{(a)}$

(a) This feature was not evaluated in this demonstration. 


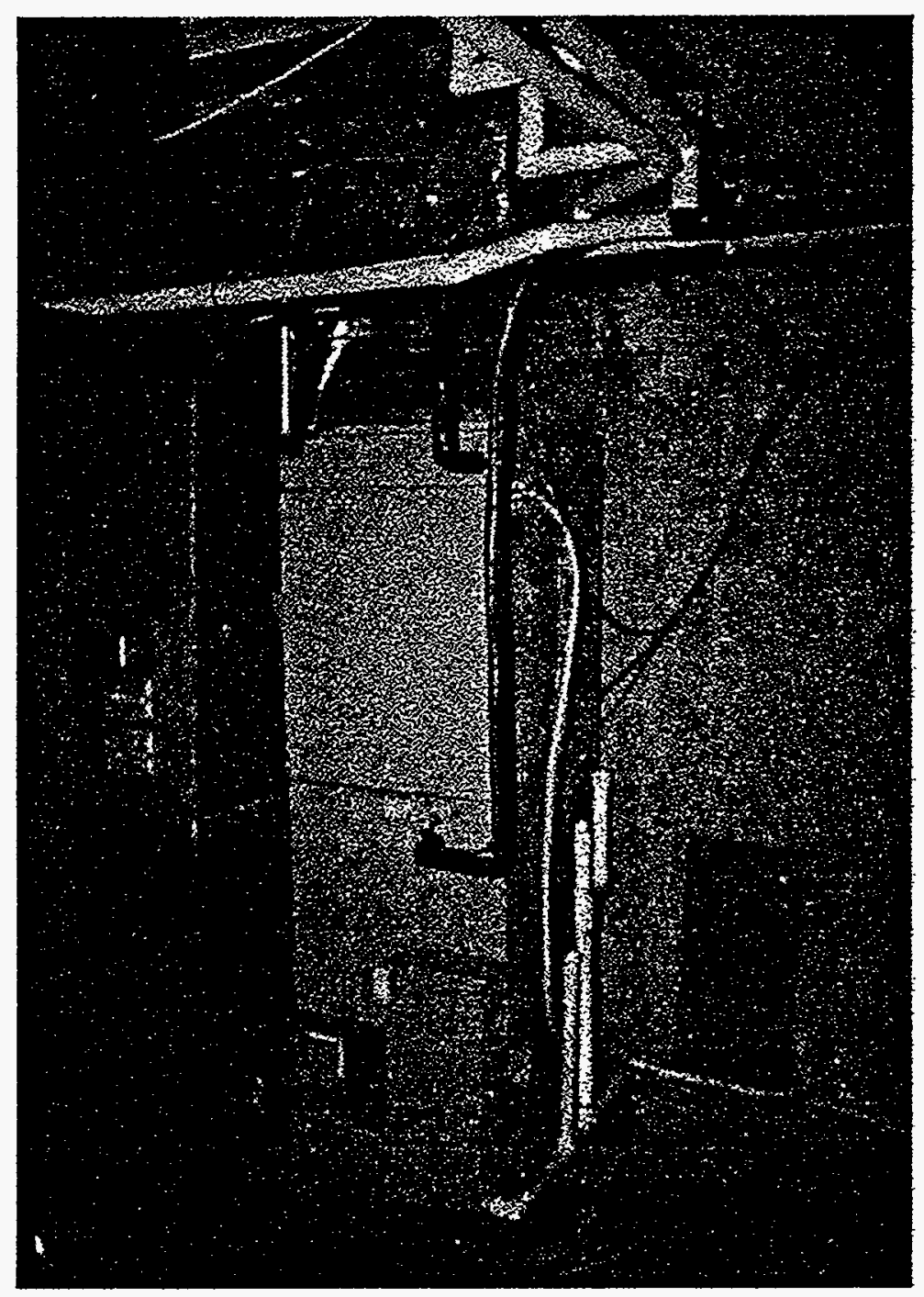

Figure 5. Triathlon GHP Indoor Unit With Condensate Tipping Bucket Meter (Near Box) and Duct Instrumentation

Early field tests indicate an average coefficient of performance (COP) of 1.3 for heating and 1.1 for cooling (York International and Battelle 1993). These results, on an energy cost basis, are as good as, or better than, the comparable figures for the most advanced electric equipment.

\section{Comparison Units}

Table 1 lists the manufacturers' performance specification for the Triathlon and the air conditioners against which it was compared. Units 1 and 2 were manufactured in 1991, used scroll compressors, and 
Table 1. Manufacturers' Rated Performance of Test Units

\begin{tabular}{|c|c|c|c|c|c|}
\hline & $\begin{array}{c}\text { Compressor } \\
\text { Type }\end{array}$ & $\begin{array}{l}\text { Date } \\
\text { Built }\end{array}$ & $\begin{array}{l}\text { Capacity, } \\
\text { kBtu/h(a) }\end{array}$ & $\operatorname{EER}^{(\mathbf{a})}$ & SEER \\
\hline Triathlon & Reciprocating & 1993 & 38.8 & --- & $16.2^{(b)}$ \\
\hline Unit 1 & Scroll & 1991 & 33.8 & 9.53 & 10.45 \\
\hline Unit 2 & Scroll & 1991 & 33.8 & 9.53 & 10.45 \\
\hline Unit 3 & Reciprocating & 1975 & 40 & 7.5 & ---- \\
\hline
\end{tabular}

(a) Noted in terms of Air-Conditioning and Refrigeration Institute (ARI) conditions.

(b) Cost-equivalent SEER obtained through chamber measurements and calculations as outlined in ANSI Standard Z21.40.4 and using local San Antonio residential prices for natural gas and electricity.

were the same model. Unit 3 represented the oldest of the existing units at the base and used a reciprocating compressor.

\section{Demonstration Site}

The demonstration was done in the single-family residential area of the Fort where many identical $1500-\mathrm{ft}^{2}$ homes are occupied by officers and their families. The three test houses are approximately 45 years old, stucco on masonry construction, one story in height with a partially below-grade basement and with the remainder of the house over a crawl space. The HVAC systems are installed in the unconditioned basements. All units have individual gas meters that are owned and read by City Public Service of San Antonio. A typical test house is shown in Figure 6. The occupancy history for the test houses is shown in Table 2. 


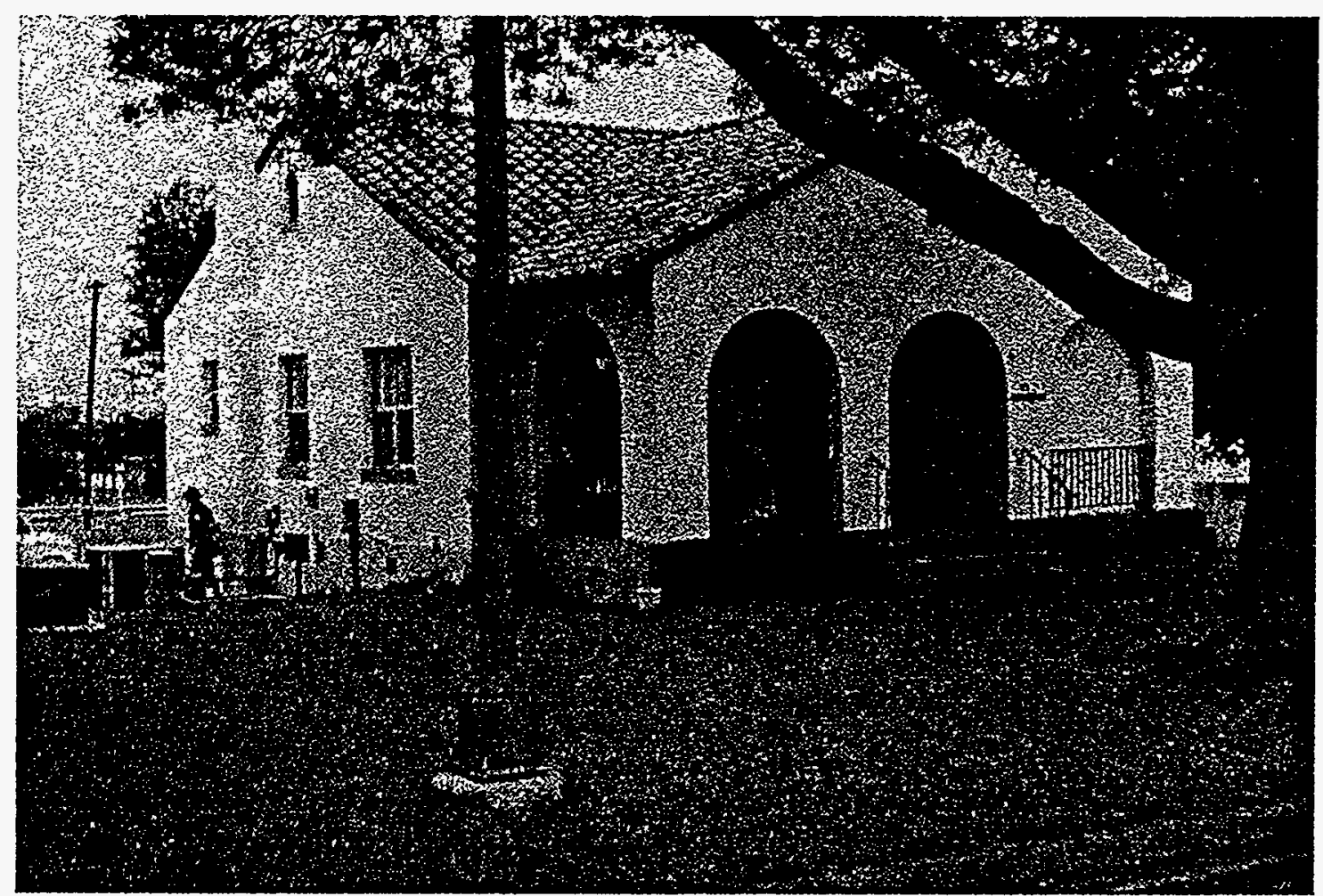

Figure 6. Test House 1 at Fort Sam Houston, San Antonio, Texas

Table 2. Fort Sam Houston Test House Occupancy History

\begin{tabular}{|c|c|c|c|}
\hline Address & Period & Adults & Children \\
\hline \multirow{3}{*}{$\begin{array}{l}764 \text { Chaffee } \\
\text { (Unit } 3 \text { site) }\end{array}$} & 09/15/94-06/12/95 & 2 & 1 \\
\hline & 08/13/94-09/14/94 & Vacant & \\
\hline & $11 / 15 / 91-08 / 12 / 94$ & 2 & 2 \\
\hline \multirow{3}{*}{$\begin{array}{l}766 \text { Chaffee } \\
\text { (Unit } 2 \text { site) }\end{array}$} & $02 / 24 / 94-06 / 12 / 95$ & 2 & 0 \\
\hline & $12 / 30 / 93-02 / 23 / 94$ & Vacant & \\
\hline & $10 / 21 / 91-12 / 30 / 93$ & 2 & 1 \\
\hline \multirow{3}{*}{$\begin{array}{l}842 \text { Chaffee } \\
\text { (Unit } 1 \text { site) }\end{array}$} & $01 / 26 / 94-06 / 12 / 95$ & 2 & 2 \\
\hline & $12 / 01 / 93-01 / 25 / 94$ & Vacant & \\
\hline & $04 / 15 / 93-11 / 30 / 93$ & 2 & 2 \\
\hline
\end{tabular}





\section{Methodology}

Ideally, a performance comparison of two HVAC units is done side-by-side under identical operating conditions. While this can be achieved under steady-state testing in the laboratory, dynamic field conditions in houses with occupants are difficult to control so as to yield equivalent side-by-side conditions. A pre/post assessment ${ }^{(2)}$ approach offers some advantages in that the house and possibly the occupants remain the same during the two phases of the test. However, changes in weather and occupant behavior lead to changes in operating conditions and equipment loading that can be addressed only partially with weather normalization techniques.

To address these potential problems, a hybrid approach is taken in this demonstration. The approach includes

- a weather-normalized pre/post comparison of energy usage

- performance mapping of the existing units followed by a projection of their maps onto the load records from the installed candidate unit.

A performance map is a form of empirical model that is used to predict a system's (unit and thermostat) response to a time series of load and operating conditions. The loads and conditions recorded from monitoring the candidate unit drive the performance maps of the existing unit. The result is a prediction of the existing unit's energy usage under the conditions and loads of the candidate unit. Performance mapping offers advantages over the pre/post and side-by-side comparisons in that changes in weather, loading, and operating conditions are addressed. The key component of the map is a regression-based characterization of part-load performance.

Maps should be capable of projecting to a wide range of operating and loading conditions. With air conditioners, where capacity depends on ambient conditions, this capability can be achieved through mapping relative to manufacturers' steady-state performance data. Doing so minimizes the need for a broad range of baseline conditions. Essentially, the ratio of the measured total capacity to a fit of the manufacturer's steady-state total capacity data is correlated with the duty cycle. Duty cycle is defined as the blower fractional on-time during a cycle relative to the sum of the on-time and the prior off-time. With the furnace, the capacity is not strongly dependent on operating conditions; therefore, the capacity map is absolute and only a function of a duty cycle. Equation (1) shows the functional form of the air-conditioner maps.

(a) A pre/post evaluation is a comparison of some measurable performance parameter during two time periods. Pre denotes the period before installation of the candidate measure; post is the period after the installation. 


$$
\begin{aligned}
& C=C_{s g}\left(T_{o d b}, T_{i d b}, T_{i w b}, \dot{V}\right) C_{p I}(x) \\
& P=P_{s s}\left(T_{o d b}, T_{i w b}, \dot{V}\right) P_{c f}
\end{aligned}
$$

where $\mathrm{C}=$ part-load total capacity, Btu/h

$\mathrm{C}_{\mathrm{ss}}=$ manufacturer's steady-state total capacity, Btu/h

$\mathrm{C}_{\mathrm{pl}}=$ air-conditioner part-load factor (function of duty cycle)

$\mathrm{x}=$ duty cycle

$\mathrm{T}_{\text {od }}=$ outdoor dry-bulb temperature, ${ }^{\circ} \mathrm{F}$

$\mathrm{T}_{\text {ld }}=$ indoor dry-bulb temperature, ${ }^{\circ} \mathrm{F}$

$\mathrm{T}_{\text {two }}=$ indoor wet-bulb temperature, ${ }^{\circ} \mathrm{F}$

$\mathrm{V}=$ volumetric flow rate of evaporator fan, $\mathrm{cfm}$

$\mathrm{P}=$ compressor power consumption, $\mathrm{kW}$

$\mathrm{P}_{\mathrm{ss}}=$ manufacturer's steady-state data on compressor power, $\mathrm{kW}$

$P_{\triangleleft}=$ empirically-based correction factor to $P_{s s}$.

Equation (2) shows the form for the furnace.

$$
H=H_{s s} H_{p I}(x)
$$

where $\mathrm{H}=$ part-load furnace output capacity, Btu/h

$\mathrm{H}_{\mathrm{ss}}=$ manufacturer's steady-state output capacity, Btu/h

$\mathrm{H}_{\mathrm{pl}}=$ furnace part-load factor (function of duty cycle)

$\mathrm{x}=$ duty cycle.

The maps are implemented through use of a time-series record of load and conditions in which the candidate unit runs. For each time increment in the series, the load balance in Equation (3) is solved to determine what run time (duty cycle) is necessary to satisfy the load at the recorded conditions. The equation is solved through iteration because the capacity is dependent on the partload functions, which are nonlinear with respect to duty cycle and make closed-form solutions unavailable. If the estimate of run time is smaller than minimum run times seen during periods of low load (from the baseline data), the load is not acted on but added to the next period. This keeps the simulation from artificially low loading. The mapping technique can be tested by comparing the map against its own baseline load and energy record and requiring that the map's estimate of energy consumption equal the actual measured energy total in the baseline data.

$$
\begin{aligned}
& L_{c}=x C(x) \\
& L_{b}=x H(x)
\end{aligned}
$$

where $\mathrm{L}_{\mathrm{c}}=$ total cooling load, Btu/h

$\mathrm{L}_{\mathrm{h}}=$ heating load, Btu/h. 
With run time estimated, the unit's energy consumption is estimated through Equation (4). The compressor's power draw is calculated from an empirically-based correction to a fit of the manufacturer's data on compressor power [P in Equation (1)]. The power. draw from the condenser fan and supply fan is determined from average field measurements $\left(P_{\text {fans }}\right)$. For the furmace, gas consumption is calculated using an empirically determined correction factor to the manufacturers steady-state input capacity, $\mathrm{H}_{\text {id }}$ in Equation (4):

$$
\begin{aligned}
& E_{c}=x\left(P+P_{\text {fans }}\right) \\
& E_{h}=x H_{i s s} H_{i c f}
\end{aligned}
$$

where $\mathrm{E}_{\mathrm{c}}=$ electricity consumed by air conditioner, $\mathrm{kWh}$

$\mathrm{P}=$ compressor power consumption, $\mathrm{kW}$

$\mathrm{P}_{\text {tans }}=$ condenser and supply fan power consumption, $\mathrm{kW}$

$E_{\mathrm{h}}=$ fuel consumed by furnace, Btu

$\mathrm{H}_{\mathrm{iss}}=$ manufacturer's steady-state input capacity, Btu/h

$\mathrm{H}_{\mathrm{lt}}=$ correction factor to $\mathrm{H}_{\mathrm{iss}}$.

To complement the performance mapping, a pre/post comparison is done in the house that received the Triathlon unit. A zero-load-outdoor temperature is found for the monitoring periods before and after the installation of the unit. These temperatures serve as the basis for cooling degree-day (CDD) calculations. The CDD number for the pre- and post-period then serves to form a correction factor that accounts for changes in weather and occupant behavior (e.g., thermostat setting). The projected energy use is then calculated as shown in Equation (5):

$$
E=\left(C D D_{\text {post }} / C D D_{\text {pre }}\right) E_{\text {pre }}
$$

Three test houses at the Fort were chosen to support the hybrid approach. The houses have identical structural design and solar exposure and are occupied by families with one or two children. Energy records were checked to see that the houses are typical of other similar houses at the Fort and that the existing HVAC systems have capacities similar to that of the 3-ton Triathlon unit. Two of the houses currently have HVAC systems that represent the best available at the Fort. This includes pulse-combustion furnaces and air conditioners with scroll compressors. A third house represents the worst case, with the oldest of the Fort's conventional air conditioners and furnaces. These HVAC systems bracket the range of equipment performance currently at the Fort.

Baseline data collection (begun in August 1993) continued until the new gas-engine-driven heat pump was installed in June 1994 at house 1. Data collection on the Triathlon and the two remaining comparison units then continued through June 1995 . This allows pre/post comparison 
between the best case and the candidate in the installation house, and mapping from all three comparison units to the candidate load and conditions record.

At the end of the comparative-monitoring period, the occupants at house 1 were interviewed. The questions were designed to determine occupant comfort (thermal and acoustic), operating convenience, and general level of acceptance of the new technology. A summary of the interview is presented in the Results section of this volume: 


\section{Instrumentation}

Baseline monitoring in support of the hybrid assessment approach involved measurements of system outputs (capacity), system inputs (energy consumption), and operating conditions. All measurements in the airstream (return-air psychrometric and sensible capacity) are conditionally sampled to produce an average over periods of output (supply fan is on). Measurements of conditions outside the airstream, such as conditioned space, basement, and outdoor condenser temperatures, are based on continuous sampling. Data loggers at the three test houses produced a record of measurements at 15-minute intervals. All averages are based on 5-second sampling intervals. The records were downloaded daily to a computer at PNL in Richland, Washington, for storage and analysis.

Operating conditions are characterized by temperature measurements in the retum airstream, in the basement duct, and outside (sun-shielded) near the condenser. Platinum resistance temperature devices (RTDs) are used for the absolute temperature measurements. Humidity in the retum airstream is measured with solid-state polymer film sensors calibrated using saturated salt solutions.

Sensible capacity (differential temperature) is measured with a 24-gauge type-T thermopile using six junction pairs. Six junctions are placed upstream of the furnace filter on a single support rod followed by six junctions downstream of the evaporator coils on two support rods (Figure 7). Volumetric flow rate of the supply air-handler is determined with a heat injection test using a 5-kW heating coil commonly used as a backup heat source for heat pump systems. Flow rate is determined for the high-speed blower mode associated with air-conditioner operation and the low-speed blower mode associated with furnace operation. Latent capacity (condensate flow) is recorded by counting contact closures from a calibrated tipping bucket rain gauge. Barometric pressure is measured with a variable-capacitance ceramic sensor. Supply fan speed (in revolutions per minute) is recorded with an optical sensor that counts the passes of a piece of reflective tape attached to the far side of the fan rotor. Cycling data is recorded as a count of the times the supply fan turns on during the 15-minute logger period.

Electric energy use is measured with current transformers at the compressor, condenser fan, and supply fan. Contact closures from a reed switch on an inline gas meter are counted to record volumetric flow of natural gas to the fumace.

When Unit 1 was replaced by the Triathlon in June 1994, additional instrumentation was added to accommodate the Triathlon's variable airflow and to monitor critical internal components and systems. Because of variable flow rates, independent logger averages of $\Delta T$ (temperature drop across the cooling coils) and $V$ (volumetric flow rate) at the indoor coil do not properly represent the changing system capacity. Instead, the product, $V \Delta T$, must be averaged over the period the supply fan runs. This requires a real-time multiplication capability in the data logger and a realtime volumetric flow rate measurement. The new logger was a personal-computer-based 


\section{Duct Instrumentation}

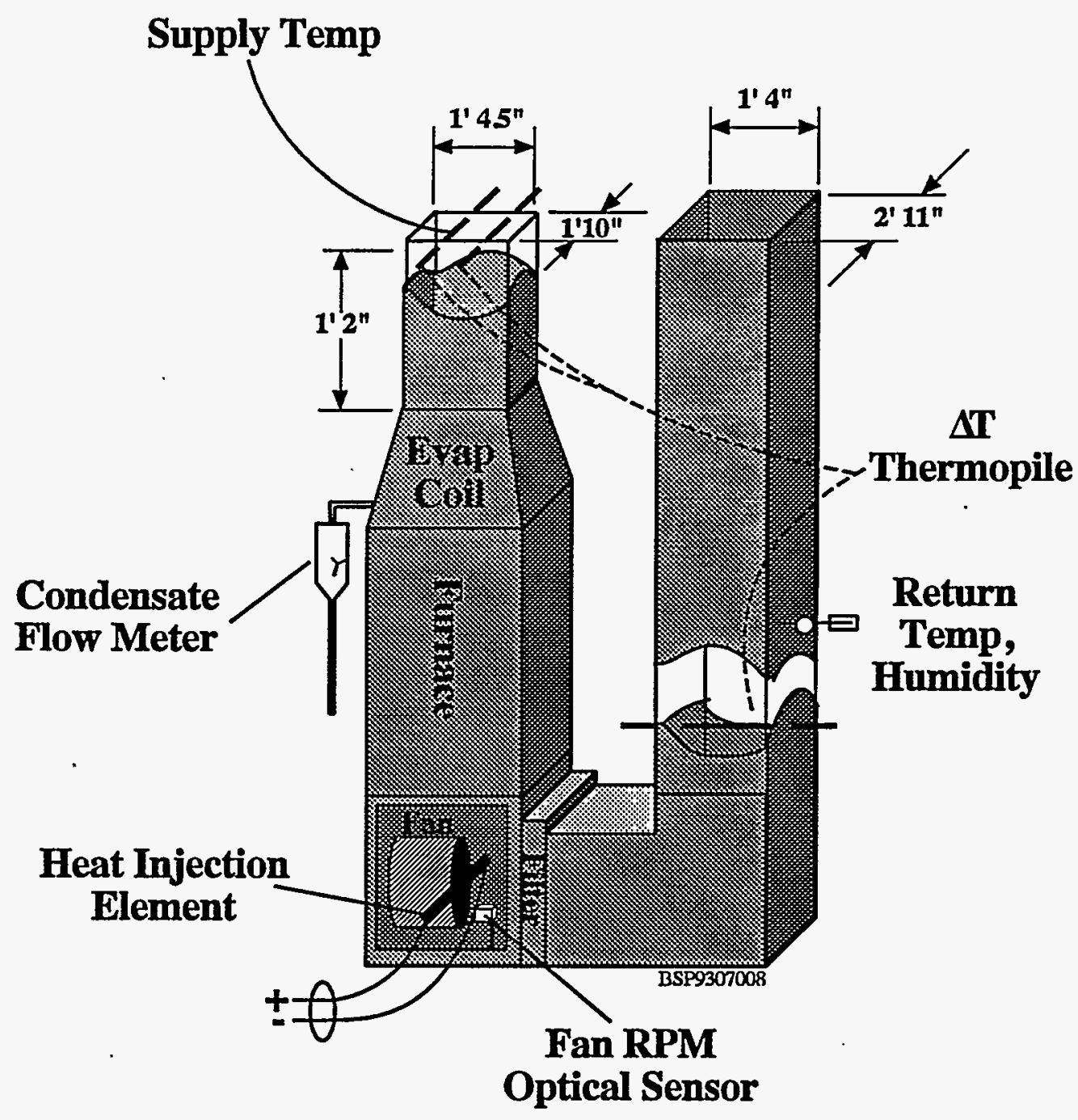

Figure 7. HVAC Capacity Monitoring Instrumentation Used in Baseline Measurements

system with conditional sampling capabilities and real-time cross-channel math processing. A laboratory-based correlation along with a site calibration is used to determine $V$ from fan power and speed data. See Appendix B for detailed descriptions of the instrumentation for the gas-engine heat pump and a schematic diagram with sensor locations. The data acquisition system used on the Triathlon is located on the right-hand side in Figure 8. The system used on the comparison units is pictured on the left-hand side in Figure 8. 


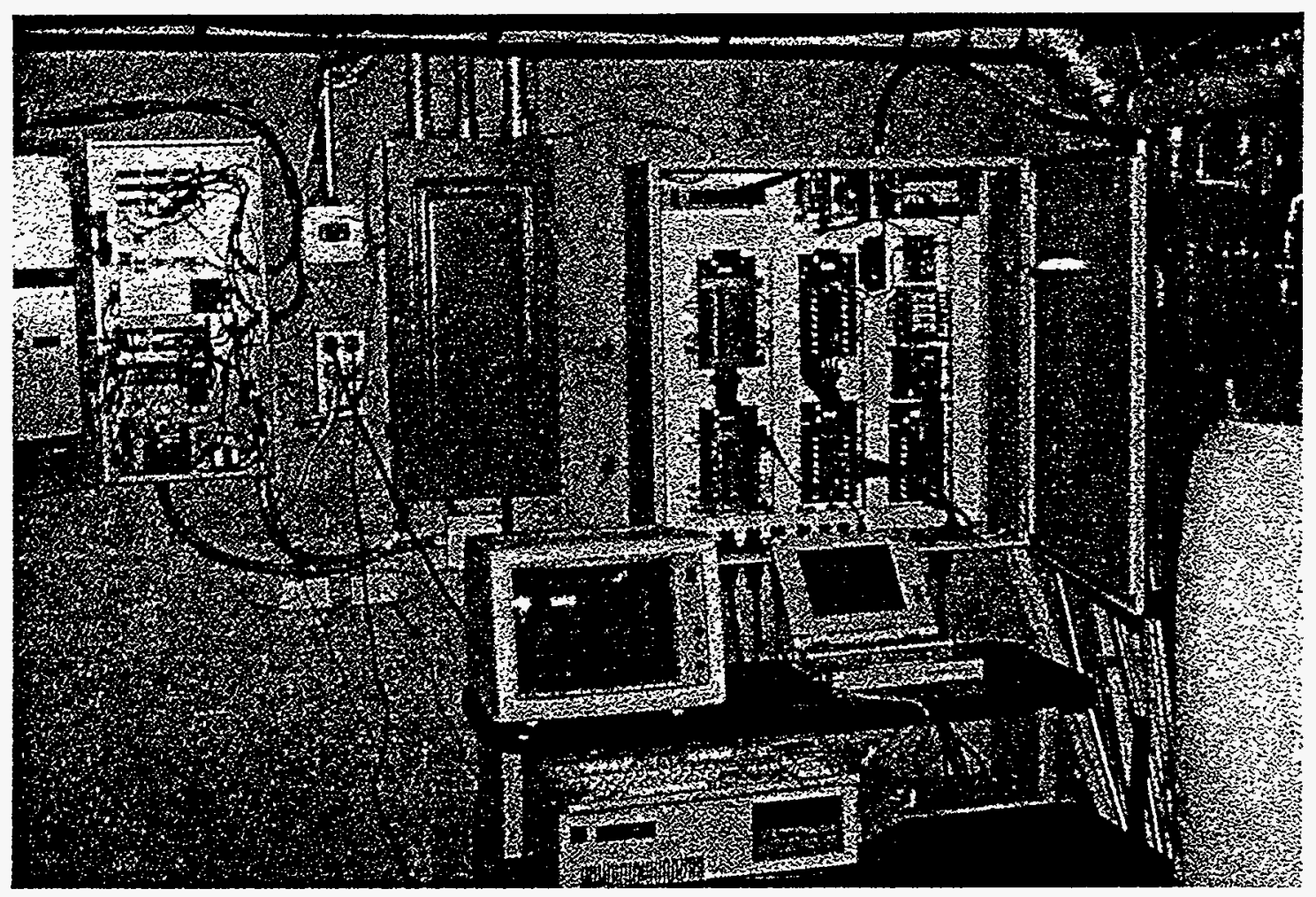

Figure 8. Baseline and Triathlon Data Acquisition Systems at Test House 1 



\section{Analysis}

\section{Data Reduction}

Analysis begins with interpretation of raw sensor measurements made at the field sites. The field measurements on the HVAC systems can be classified as inputs (gas and electricity consumption), outputs (sensible and latent cooling), and operating conditions.(return and outdoor).

Sensible and latent capacity are calculated with Equation (6) (ASHRAE 1989). In the sensible calculation, it is assumed that the supply air fan runs at a constant speed and provides approximately constant volumetric flow. In other words, the fan by design provides constant volumetric flow; it is assumed that neither accumulation of dust in the fumace filter nor possible changes in the outlet dampers by the occupants will affect volumetric flow. The corresponding mass flow was calculated using a psychrometric routine for specific volume, which included corrections for barometric pressure, temperature, and moisture. Pressure data were not available from the site sensor prior to June 1994 but were integrated from an online public database (on the Internet) of hourly San Antonio weather from the National Climatic Data Center (NCDC). These sea-level-referenced pressures were then corrected for site elevation.

$$
\begin{aligned}
& S=60 \dot{V} \Delta T \rho\left(P_{b}, T_{i d b}, T_{i w b}\right) C_{p} \\
& C_{p}=0.24+0.444 W \\
& L=\dot{m}_{\text {cond }}\left(h_{g}\left(T_{i d b}\right)-h_{c o n d}\right) \\
& h_{g}=1061+0.444 T_{1 d b}
\end{aligned}
$$

where $S=$ sensible cooling capacity, Btu/h

$V=$ supply airflow rate, $\mathrm{cfm}$

$\Delta \mathrm{T}=$ temperature differential across evaporator coils, ${ }^{\circ} \mathrm{F}$

$\rho=$ air density, $\mathrm{lb}$ air $/ \mathrm{ft}^{3}$

$\mathrm{P}_{\mathrm{b}}=$ barometric pressure, in. $\mathrm{Hg}$

$\mathrm{T}_{\text {l由 }}=$ dry-bulb temperature of retum air, ${ }^{\circ} \mathrm{F}$

$\mathrm{T}_{\mathrm{iwb}}=$ wet-bulb temperature of return air, ${ }^{\circ} \mathrm{F}$

$c_{p}=$ specific heat of air, Btu/lbm ${ }^{\circ} \mathrm{F}$

$\mathrm{W}$. = humidity ratio of return air, $\mathrm{lb}$ water/lb dry air

$\mathrm{L}=$ latent cooling capacity, Btu/h

$\dot{\mathrm{m}}_{\text {cond }}=$ condensate flow rate, $\mathrm{lb} / \mathrm{h}$

$h_{\mathrm{g}}=$ specific enthalpy of saturated water vapor, Btu/lbm water

$h_{\text {cond }}=$ specific enthalpy of condensate at $50^{\circ} \mathrm{F}, \mathrm{Btu} / \mathrm{lbm}$ water. 
The efficiency of the furnace was calculated using natural gas heating values as shown in Equation (7) where the factor $1020 \mathrm{Btu} / \mathrm{ft}^{3}$ is the value (for standard conditions) used throughout the analysis. This value was reported by City Public Service of San Antonio for June 1994. This equation is used with the gas meter's volumetric flow records to account for variations in density from pressure and temperature. The house gas-line temperature was estimated from a temperature measurement inside the gas submeter (Triathion) or on the surface of the gas line (comparison units).

$$
H_{v}=1020 \frac{\left(P_{s i t e}+\Delta P\right)}{P_{s t}} \frac{T_{s t}}{T_{\text {Iine }}}
$$

where $\mathrm{H}_{v}=$ heating value of natural gas, $\mathrm{Btu} / \mathrm{ft}^{3}$

$P_{\text {stie }}=$ barometric pressure at the site, in. $\mathrm{Hg}$

$\Delta \mathrm{P}=$ house line pressure above atmospheric, in. $\mathrm{Hg}$

$\mathbf{P}_{\mathrm{st}}=$ standard pressure, 29.921, in. $\mathrm{Hg}$

$\mathrm{T}_{\mathrm{st}}=$ standard temperature, $518.7,{ }^{\circ} \mathrm{R}$

$\mathrm{T}_{\text {line }}=$ temperature of gas in house line, ${ }^{\circ} \mathrm{R}$.

In analyzing field capacity data taken from fixed-interval data loggers, consideration must be given to the relationship between the logging interval and the cycling characteristics of the equipment. Ideally, the field data logger should have the capability of recording a time stamp at the beginning and end of each HVAC cycle. This type of sampling, triggered by events, clearly supports mapping by duty cycle. However, fixed-interval-logger periods must be chosen carefully so as to collect enough data to resolve the elements of each cycling event. If the logger intervals chosen are too long, multiple cycles will be lumped in one logger interval and will be indistinguishable.

Single HVAC system cycles divided by logger time boundaries can be reassembled and placed in the period where the event terminates. This is done with logic filters that act on the record of cycle counts, run time, and energy usage. Consumptions, outputs, and run times are totaled for the cycle. In addition to the unit's performance, duty cycle is calculated and recorded. This is defined as the blower fractional on-time during a cycle relative to the sum of the on-time and the preceding off-time.

\section{Performance Mapping}

An initial step in performance mapping of the air-conditioner data from the comparison units is the regression of the manufacturers' steady-state total-capacity data against flow rate, retum, and outdoor conditions [see Figure 9 and $\mathrm{C}_{\mathrm{ss}}$ in Equation (1)]. Also, the manufacturers' data on compressor power is regressed to give a relationship for compressor power draw as a function of conditions $\left[\mathrm{P}_{\mathrm{ss}}\right.$ in Equation (1)]. 


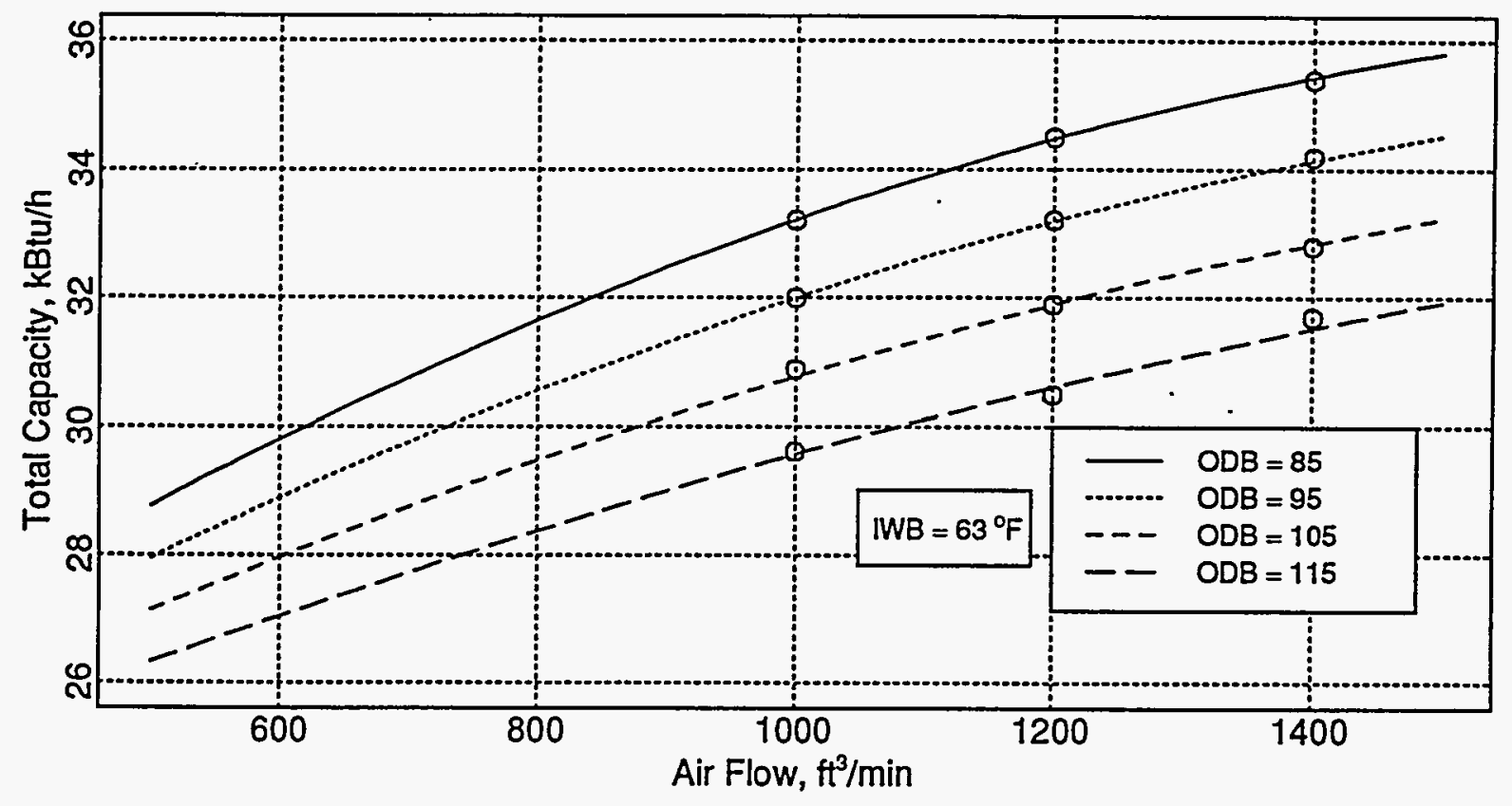

Figure 9. Regression on Manufacturers' Steady-State Total Capacity Data

The remaining component in the map $\left[C_{p}(x)\right.$ in Equation (1)] is determined by regressing the relative capacity of the unit against duty cycle. Relative capacity is defined as the ratio of the field measured capacity during a cycle to the manufacturer's steady-state capacity at the measured operating conditions. Here the field-measured capacities are those that result from the logic filters described above. The results of these regressions are illustrated for Units 2 and 3 in Figures 10 and 11 , respectively. These plots show the reductions in capacity with decreasing duty cycle that result from cycling losses.

The final step in preparing for the mapping calculations is to prepare the load time series that represents the cooling load on the house in which the Triathlon was installed. This time series serves as input to the map-load balance [Equation (3)]. To prepare the representative time series, the raw time series of the Triathlon cooling output is smoothed with a box-car routine. This is essentially a running average (composed of nine 15 -min periods). that removes the cycling variations and produces a smooth time series that preserves the variations in the building load. A segment of the Triathlon load series (smoothed and raw) is shown in Figure 12.

Before actually mapping to the Triathlon load series, a check is made to see how well a unit's map can predict its own measured energy use. This self-mapping exercise serves as a general check on the technique and gives confirmation of the specific correlations done in developing the maps. This is done by mapping onto the unit's own smoothed-load time series. The results of the self-mapping test for Unit 2 are illustrated in Figure 13. This shows the excellent agreement, throughout the diumal swings of 10 days in June, between the actual energy consumption 


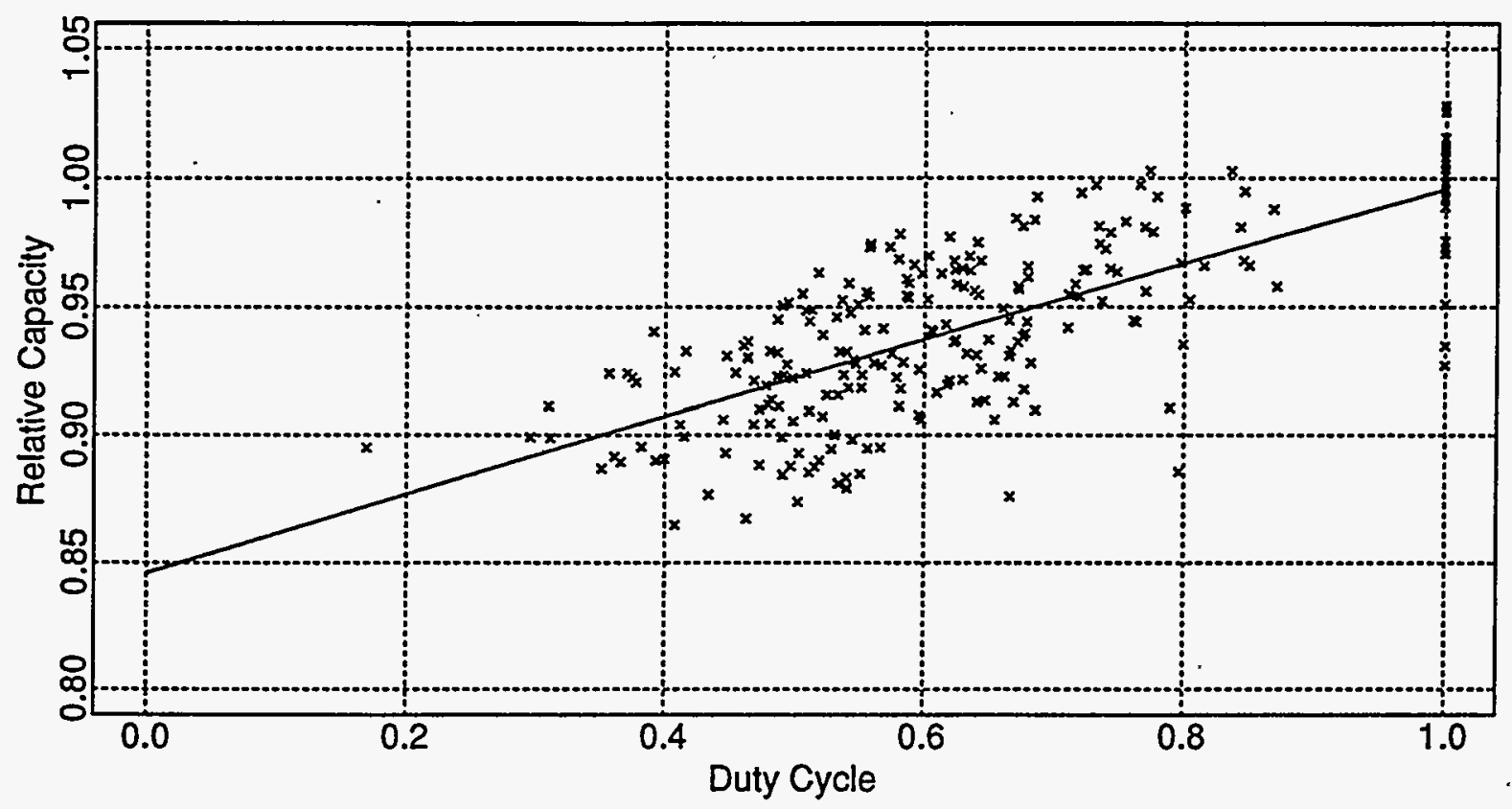

Figure 10. Regression of Relative Capacity With Duty Cycle for Unit 2

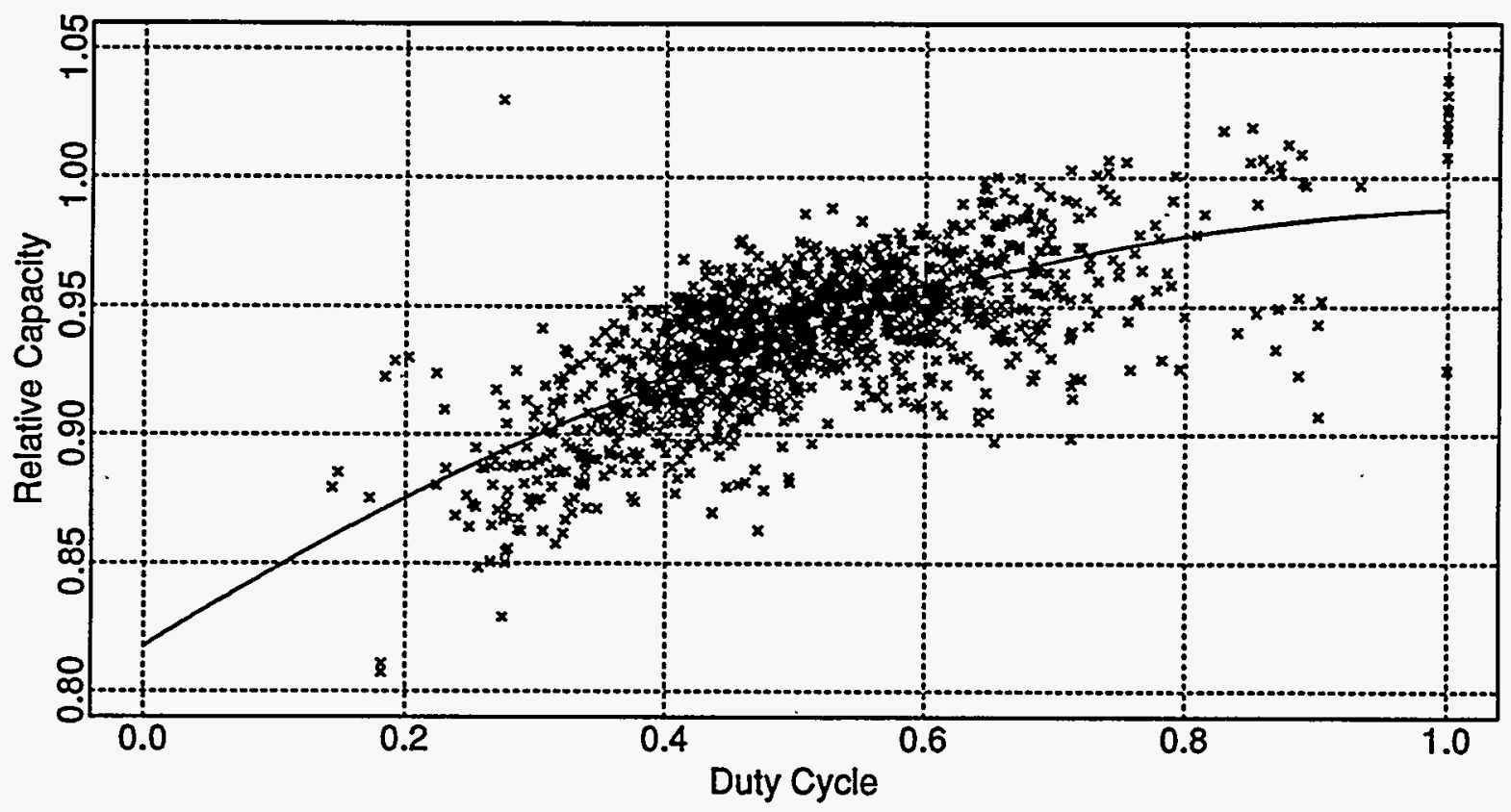

Figure 11. Regression of Relative Capacity With Duty Cycle for Unit 3 


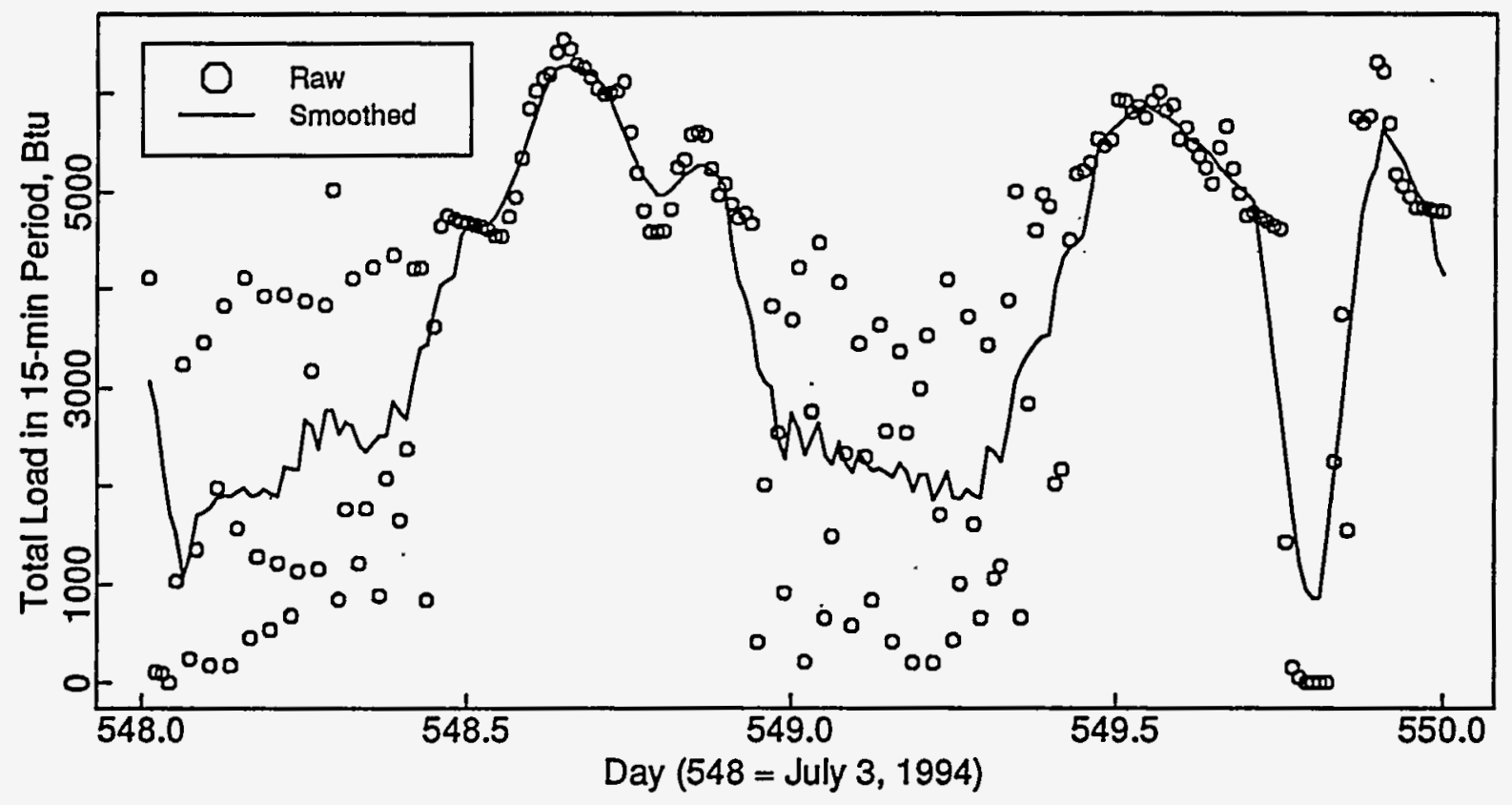

Figure 12. Triathlon Total Load Time Series

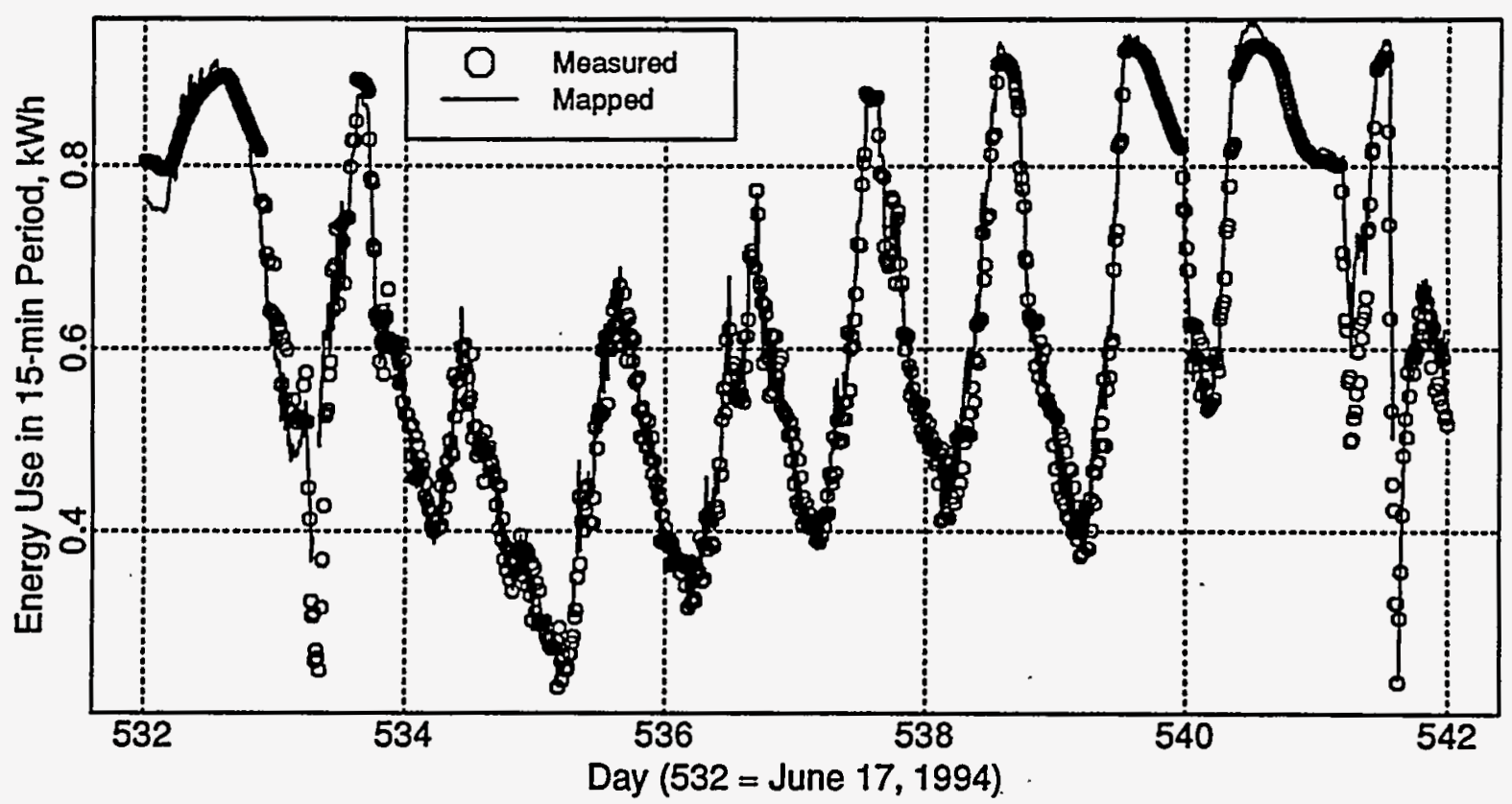

Figure 13. Measured and Self-Mapped Energy Use Time Series From Unit 2 
(smoothed) and the predictions from the mapping. If the time series are totaled over the time basis used for developing the part-load curves, the self-mapping result differs from the actual measured energy consumption by less than $0.2 \%$ for both Units 2 and 3 . 


\section{Pre/Post Analysis}

To complement the mapping analysis, a pre/post analysis is applied to the baseline energy consumption recorded for Unit 1 in 842 Chaffee (before the installation of the Triathlon). As described in the methodology section, the pre/post comparison is made by adjusting the baseline data with CDD correction factor. The factor is the ratio of the CDDs for the pre- and postperiods where the base temperature for the CDD calculation is determined from the zero-load floating point for the house.

Plots of daily average load and outdoor temperature are shown in Figures 14 and 15 . The $\mathrm{x}$ axis intercept of these plots indicates the zero-load floating point $\left(67.0^{\circ} \mathrm{F}\right.$ in $1994,65.3^{\circ} \mathrm{F}$ in 1993$)$. Differences in the floating point can be caused by changes in the occupant thermostat set point and differences in the solar gains. The slope is nearly the same for both plots and indicates structural characteristics that impact heat transfer, driven by the outdoor temperature (such as conduction through the walls and air infiltration), have remained the same from the pre- to the post-period. The calculation of CDD in 1994 for the house with the Triathlon was 1783.1 (base $67.0^{\circ} \mathrm{F}$ ); in 1993, it was 847.5 (base $65.3^{\circ} \mathrm{F}$ ). This results in a pre-period to post-period correction factor of 2.10 .

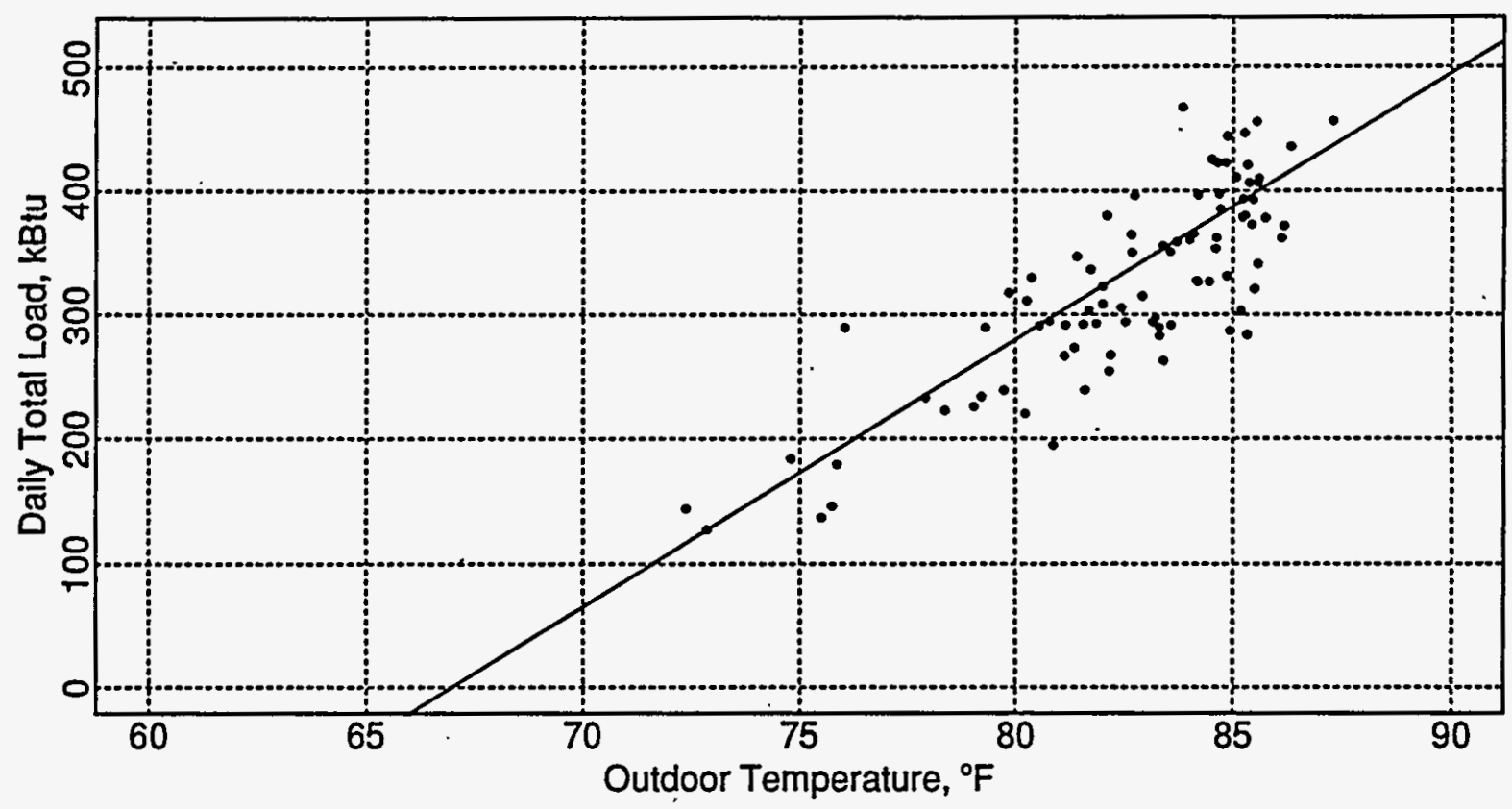

Figure 14. Regression of Daily Total Load Against Outdoor Temperature, House 1, 1994 Cooling Season Test (Triathlon Installed) 


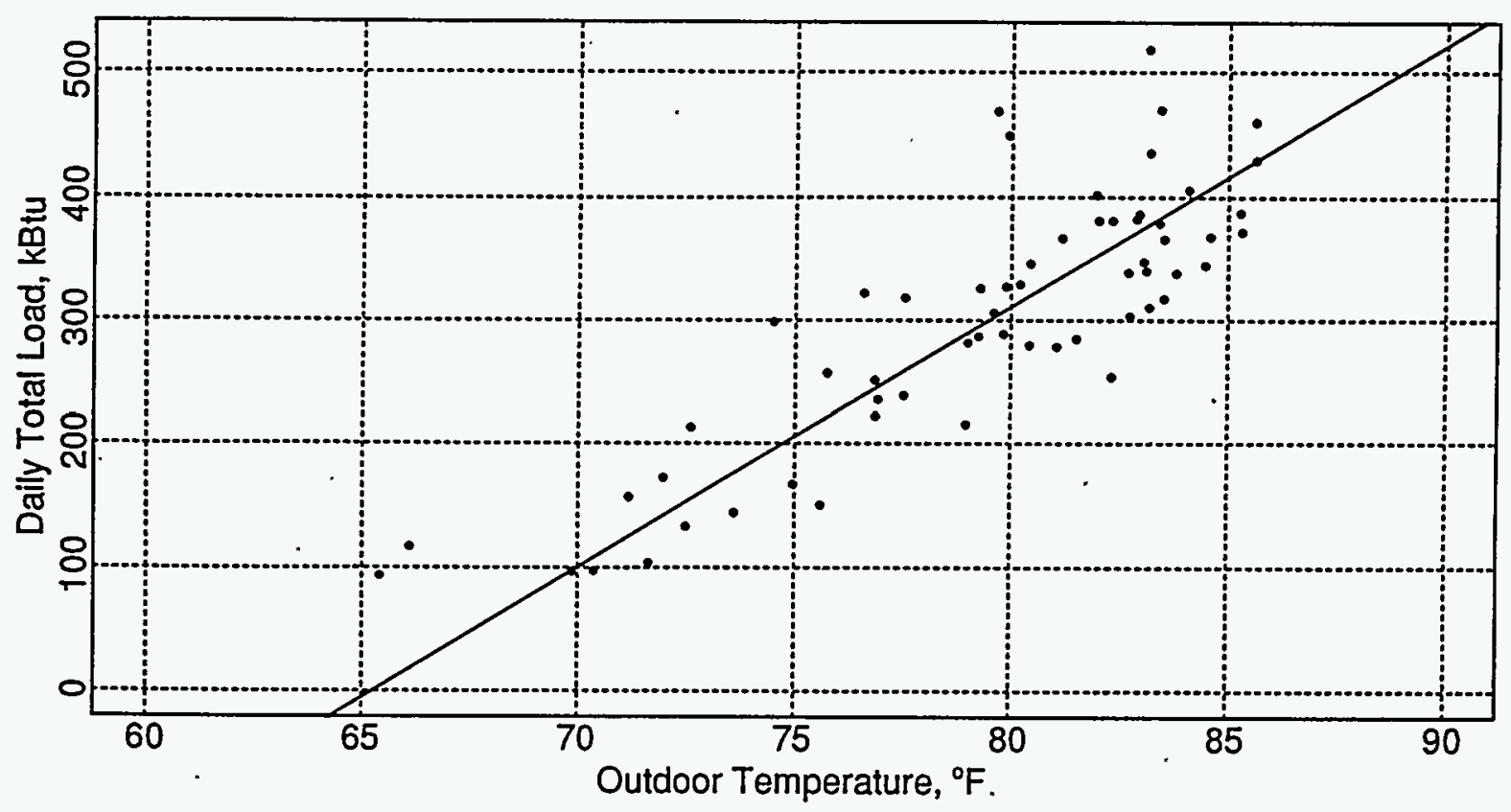

Figure 15. Regression of Daily Total Load Against Outdoor Temperature, House 1, 1993 Cooling Season Test (Baseline)

\section{Normal Weather Year}

The final step in the comparative analysis is to estimate the energy use and corresponding energy savings that would be seen in a normal weather year. A projection to the normal weather year accounts for an unusually hot, cold, or short test period. A normal year is defined as the Test Reference Year (TRY) for San Antonio during the period 1948 to 1975 (Olsen et al. 1984). This TRY year has $2471 \mathrm{CDD}$ relative to a base temperature of $67^{\circ} \mathrm{F}$.

This projection is done by calculating the ratio of the CDD during a normal year in San Antonio (2471 CDD) to those during the 1994 test season (1783 CDD). In these calculations, a base temperature of $67^{\circ} \mathrm{F}$ is used and reflects the outdoor temperature where the house at 842 Chaffee balanced with no load during the 1994 test season. All results from the 1994 test period at 842 Chaffee, including those projected to conditions at 842 Chaffee by the mapping or pre/post techniques, can then be converted to a normal weather year using this factor of 1.386. However, this projection technique does give a slightly conservative estimate of the Triathlon full-season performance. This is because the 1994 season includes the peak and end of the season (not the beginning) and because the Triathlon has higher efficiency at lower loads (and lower speeds) due to its variable-speed capability. 


\section{Computer Simulations}

The field performance of the Triathlon was periodically compared against a computer simulation of its steady-state performance. This simulation served first to establish a baseline performance level of the unit relative to the model. Subsequent performance checks against the computer model were compared to baseline to check for performance deviations throughout the season. Significant deviations from the baseline can be indications of equipment failure. The gasengine heat pump model, owned and developed by GRI, is an evolution of the Mark III heat pump model developed by Oak Ridge National Laboratory for electric heat pump simulation (Fischer and Rice 1986a,b). 



\section{Results}

\section{Unit and Instrumentation Maintenance and Other Events During Testing}

To best present the results of the monitoring, it is useful to start with a brief history of the equipment downtime and maintenance during the testing periods. This provides the rationale behind any subsetting of the data. Throughout the discussion of the results, a distinction is made between commissioned performance and actual full test-season performance. Commissioned performance is determined over a period starting with the commissioning of the unit (including normal maintenance by the base or local dealer) at the beginning of the test period and ending with any event that would cause a significant change in the unit's performance. Commissioned performance differs from full test-season performance only when there is a maintenance event (e.g., a compressor fails and requires a replacement).

The baseline monitoring on the three comparison units started August 22, 1993. All three units performed at their commissioned levels through the baseline cooling-season test period, which ended October 20, 1993. However, Unit 2 had restricted airflow throughout the 1993 and 1994 cooling seasons. The air-conditioner airflow rate at the end of the 1993 season was measured at $577 \mathrm{cfm}$ (compared to 1115 measured for Unit 1). The low-speed fan mode (furnace) for Unit 2 produced slightly lower flow rates of $564 \mathrm{cfm}$. The low flow rates and nearly identical readings for the two fan modes led to the conclusion that there was a problem with the blower or some restriction in the duct system. No changes were made in the 1993 season, but plans were made to inspect the ducts and replace the blower at the beginning of the 1994 season.

An instrumentation failure occurred in the Unit 3 house 22 days into the test. This was the result of a clogged tipping-bucket meter on the condensate line. As a result, no latent capacity measurements on Unit 3 were available until repairs were completed in June 1994. The logger in the Unit 2 house quickly developed problems in its analog boards. This left in question all of the baseline measurements on Unit 2 except for the energy consumption data. It was also determined that the cycling rate of Unit 1 coupled with the logger sampling rates used in 1993 would preclude this unit from a true duty-cycle part-load analysis as shown in Figures 14 and 15. Because of this, Units 1 and 2 were assumed to have the same part-load response as is shown in Figure 14. Logger and tipping-bucket sensor repairs were made at the beginning of the 1994 cooling season.

The 1994 cooling season was defined to start with the removal of Unit 1 and the installation of the Triathlon heat pump June 17, 1994. The test period ran 167 days through the end of November. During this period, the Triathlon unit had $100 \%$ reliability (no downtime).

In June 1994, ice was found on the evaporator coils of Units 2 and 3. It was determined that the icing problem in Unit 3 was the result of a low refrigerant charge. It was thought there might be a developing leak at the refrigerant input tap. Adding refrigerant to proper levels eliminated the icing problem. The problem in Unit 2 was determined to be partly the result of low airflow 
across the evaporator coil. After Unit 1 was removed, the Unit 1 blower was taken and installed into Unit 2 in an attempt to improve airflow. Unit 2 showed only minor improvement in airflow (689 $\mathrm{cfm}$ in cooling mode, 619 in heating mode) over the evaporator coils. The duct system in the attic was inspected for obstructions or damage but none was found. At that time, the increase in airflow from the new fan appeared to eliminate the icing problem in Unit 2.

However, as the testing season progressed, the low airflow in Unit 2, coupled with occupantthermostat settings as low as $70^{\circ} \mathrm{F}$, contributed to two additional periods of coil icing totaling roughly 50 days. The first icing period started approximately 15 days into the cooling season. During the periods of icing, the occupant ran the blower fan continuously to melt the ice when the compressor cycled off. The occupant was encouraged to change to higher thermostat settings, yet clearly the performance of Unit 2 was less than would be expected at normal airflow rates and more conservative thermostat settings.

Unit 3 had a compressor failure 45 days into the 1994 cooling season. The condensing unit was replaced with a scroll-compressor-based unit similar to that used with Units 1 and 2.

Based on this event history, the total cooling-season test periods and commissioned-performance test periods for the four units are shown in Tables 3 and 4. The Triathlon performance analysis is based on the full 1994 cooling season. The pre/post-comparative analysis is based on full 1993 test season data from Unit 1. Mapping-comparative analysis is based on the commissionedperformance test periods for Units 1,2 , and 3.

Table 3. Cooling Season Test Periods

\begin{tabular}{|c|c|c|c|}
\hline Test Type & Dates & $\begin{array}{c}\text { Day Range } \\
0=1 / 1 / 93\end{array}$ & Days \\
\hline Comparison & $6 / 17 / 94-11 / 30 / 94$ & $532-699$ & 167 \\
\hline Baseline & $8 / 22 / 93-10 / 20 / 93$ & $233-293$ & 60 \\
\hline
\end{tabular}

Table 4. Commissioned-Performance Test Periods.

\begin{tabular}{lcccc} 
HVAC System & \multicolumn{1}{c}{ Dates } & & $\begin{array}{c}\text { Day Range } \\
\mathbf{0}=\mathbf{1} \mathbf{1 / 9 3}\end{array}$ & \multirow{2}{*}{ Days } \\
\cline { 2 - 2 } \cline { 5 - 5 } Triathlon & & & $532-699$ & 167 \\
Unit 1 & $6 / 17 / 94-11 / 30 / 94$ & & $233-293$ & 60 \\
Unit 2 & $8 / 22 / 93-10 / 20 / 93$ & & $532-542$ & 10 \\
Unit 3 & $6 / 17 / 94-6 / 26 / 94$ & & $532-577$ & 45
\end{tabular}


Both the baseline and comparison test periods captured peak and late summer conditions. This fully represents the typical range of summer operating conditions. The commissioned-performance test periods for Units 2 and 3 were significantly shorter. However the mapping methodology allows for calibration of the maps from a relatively short amount of monitoring time. The 10 days for Unit 2 is considered acceptable because a relatively large range (as characterized by duty cycle, and outdoor temperature) of cycle events was recorded.

\section{Weather Characteristics}

A distribution of the outdoor operating temperatures during the 1993 and 1994 cooling seasons is illustrated in Figure 16. The traces in the plot are essentially an outline of a histogram of outdoor operating temperatures normalized so that the area under the curve is equal to 1 . The data here represents when the compressor is running (i.e., hours during which there is no call for cooling are not included in the distribution). The mean temperatures, represented with vertical lines, differ by less than $1^{\circ} \mathrm{F}$. The 1994 season had the warmer outdoor operating conditions. Mean outdoor operating temperatures in 1994 for the Unit 2 and 3 houses (not shown in the plot) differ from that for the Triathlon house by less than $1^{\circ} \mathrm{F}$. Statistics on operating conditions are included in each performance summary that follows.

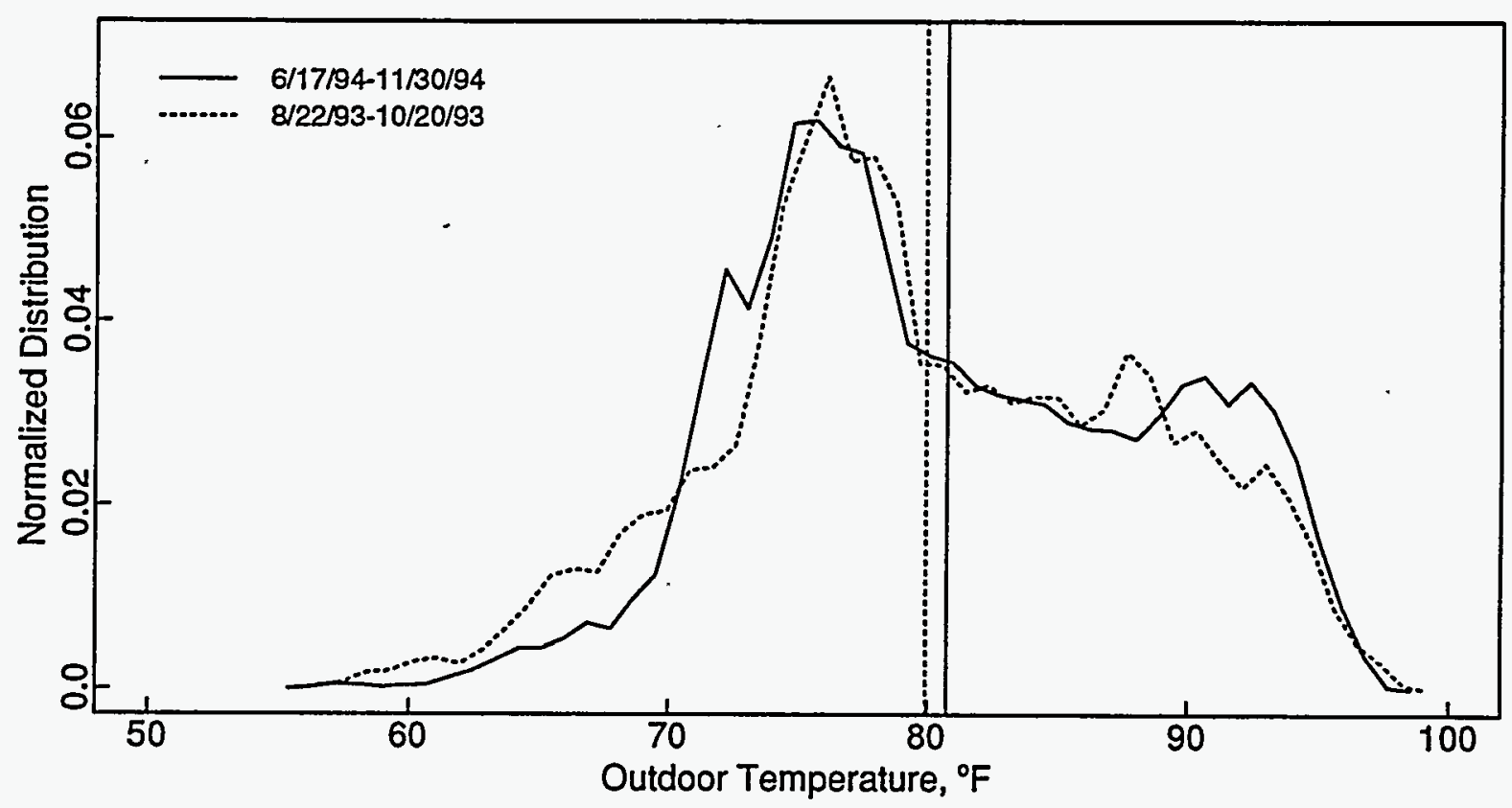

Figure 16. Distribution of Outdoor Operating Temperatures at House 1 During 1993 and 1994 Cooling Seasons 


\section{Triathlon Performance}

The Triathlon GHP demonstrated normal performance levels during the 1994 cooling season. There were no forced outages during the test, giving the unit a $100 \%$ reliability record. Throughout the test, the unit showed normal operating behavior relative to the computer simulation of the Triathlon (see Appendix C). The cooling-season test results demonstrated performance levels slightly above those established in the Phase I Field Test program (York International and Battelle 1993) conducted by the unit's developers. The only maintenance performed during the test period was the replacement of the indoor air filter by the dealer on October 19, 1994. This was done because indoor blower power consumption at minimum speed had risen from $77 \mathrm{~W}$ to nearly $140 \mathrm{~W}$ and indicated that the indoor air filter had become saturated.

The Triathlon GHP energy results are shown in Table 5 for the 1994 cooling season. The GHP had a thermal coefficient of performance (COP) of 1.128 and a cost-equivalent test-period energy efficiency ratio (TP_EER) of $12.23 \mathrm{kBtu} / \mathrm{kWh} .^{(a)}$ An electric air conditioner would require a TP_EER of 12.23 to have the same overall operating costs as the GHP (based on residential fuel prices). Additional details on the performance of the Triathlon, including the daily average summaries, are included in Appendix D.

\section{Comparison Units' Performance}

Unit 1 operated at expected efficiency levels and had the best performance of the three comparison units. Unit 2 had expected poor performance due to low airflow rates at the evaporator, lower than normal thermostat settings, and the resulting coil icing. Tables 6 and 7 summarize the performance of these units. Dashes are shown in cells where there was no data due to instrumentation outages. A particular unit may have more than one column. The first column shows the results for the entire test period. Additional columns may be given to represent performance over a subset of the total test period. For example, in 1993 because of a tipping bucket failure, latent capacity data was not available on Unit 3 after day 255. The two additional columns show the available results before and after the sensor failure. Also in 1993, only electricity usage is shown for Unit 2 because of a logger failure. A second column is shown

(a) TP_EER should never be directly compared with SEER or EER. EER and SEER are based on chamber measurements of capacity and consumption. EER is a direct presentation of chamber performance at rating conditions. SEER is based on chamber measurements along with standard procedures that estimate the dynamic performance of the unit over an entire season of national average conditions. TP_EER is an indicator of actual field efficiency as subject to operating conditions seen in the field test. Generally, field conditions for a TP_EER are more severe than those used in calculating a SEER (e.g., a return temperature of $80^{\circ} \mathrm{F}$ is assumed in SEER calculations). As a result, TP_EER measurements will generally be significantly lower than SEER ratings. 
Table 5. Triathlon GHP 1994 Cooling-Season Test Performance (June 17, 1994, through November 30, 1994)

\begin{tabular}{|c|c|}
\hline Parameter & Value \\
\hline Mean outdoor dry-bulb, ${ }^{\circ} \mathrm{F}$ & 80.7 \\
\hline Mean room dry-bulb, ${ }^{\circ} \mathrm{F}$ & 76.4 \\
\hline Mean return dry-bulb, of & 74.1 \\
\hline Mean return wet-bulb, ${ }^{\circ} \mathrm{F}$ & 62.0 \\
\hline Mean return relative humidity, \% & 50.6 \\
\hline Run time, $h$ & 1729 \\
\hline Sensible Cooling Output, MBtu & 26.3 \\
\hline Latent Cooling Output, MBtu & 8.1 \\
\hline Cooling output, $\mathrm{MBtu}^{(2)}$ & 34.5 \\
\hline Gas consumption, $\mathrm{MBtu}^{(b)}$ & 30.5 \\
\hline Thermal $\mathrm{COP}^{(\mathrm{c})}$ & 1.128 \\
\hline Electricity consumption, $\mathrm{kWh}^{(\mathrm{d})}$ & 623 \\
\hline Cost-equivalent fuel consumption, $\mathrm{kWh}^{(\mathrm{e})}$ & 2817 \\
\hline Cost-equivalent TP_EER, kBtu/kWh ${ }^{(n)}$ & 12.23 \\
\hline Energy cost, $\$^{(8)}$ & 163.6 \\
\hline
\end{tabular}

(a) Total sensible and latent cooling provided during the cooling season (MBtu).

(b) Total natural gas consumed during the cooling season (MBtu). The fuel heating value of $1020 \mathrm{Btu} / \mathrm{ft}^{3}$ provided by City Public Service of San Antonio was assumed throughout the test period.

(c) Cooling output divided by the gas consumption.

(d) Total electricity consumed by the two system fans (electricity used by the starter motor, less than $1 \%$ of the total, is not included).

(e) On a cost basis, the gas consumption of the Triathlon is converted to an equivalent electricity consumption. This effective electricity usage is then added to the actual electricity usage. The resulting total is the cost-equivalent fuel usage by the Triathlon GHP. San Antonio average costs of $\$ 0.4257 / \mathrm{ccf}$ and $\$ 0.05810 / \mathrm{kWh}$ were used to represent the fuel-cost rates from 6/94 through 11/94. These cost are derived from monthly adjusted rates from City Public Service of San Antonio. The monthly rates are weighted by fuel usage of the Triathlon to arrive at the two average-fuel-cost rates above (see Appendix E).

(f) Cooling output divided by the cost-equivalent fuel usage during the test period (kBtu/kWh). (An electric air conditioner operating in substitution for the Triathlon at 842 Chaffee would need an equal TP_EER to have the same overall operating cost as the Triathlon GHP.)

(g) Effective electricity consumption is converted to dollars using $\$ 0.05810 / \mathrm{kWh}$ for the Triathlon GHP. A rate of $\$ 0.06315 / \mathrm{kWh}$ is used for the comparison units. The higher rate for the comparison units reflects the impact of the peak-capacity charge of $\$ 0.015 / \mathrm{kWh}$ for electric usage in excess of $600 \mathrm{kWh} / \mathrm{mo}$, applicable from June through September (see Appendix E). 
Table 6. Comparison Units' Performance in 1993 Test Season

\begin{tabular}{|c|c|c|c|c|c|}
\hline & Unit 1 & Unit 2 & \multicolumn{3}{|c|}{ Unit 3} \\
\hline $\begin{array}{l}\text { Range of days } \\
(233=8 / 22 / 93)\end{array}$ & $233-293 *$ & $233-293$ & $233-293$ & $233-255$ & $255-293$ \\
\hline Total cooling output, MBtu & 18.0 & $\ldots-($ (a) & $\ldots$ & 11.2 & --- \\
\hline Total electricity input, kWh & 1942 & 2366 & 3487 & 1772 & 1715 \\
\hline TP_EER, kBtu/kWh ${ }^{(b)}$ & 9.28 & $\cdots$ & ---- & 6.32 & --- \\
\hline Energy cost, $\$$ & 123 & 149 & 220 & 112 & 108 \\
\hline Duration, days & 60 & 60 & 60 & 22 & 38 \\
\hline Run time, $\mathrm{h}$ & 568 & 750 & 841 & 422 & 419 \\
\hline Sensible capacity, kBtu/h & 24.4 & ---- & 21.1 & 21.3 & 20.9 \\
\hline Latent capacity, kBtu/h & 7.4 & ---- & $---\cdot$ & 5.2 & --- \\
\hline Total capacity, kBtu/h & 31.7 & --- & --- & 26.5 & --- \\
\hline Mean room dry-bulb, ${ }^{\circ} \mathrm{F}$ & 74.9 & ---- & 72.6 & 72.6 & 72.5 \\
\hline Mean return dry-bulb, ${ }^{\circ} \mathrm{F}$ & 74.4 & --- & 71.6 & 71.5 & 71.7 \\
\hline Mean retum wet-bulb, ${ }^{\circ} \mathrm{F}$ & 61.6 & $-\cdots$ & 61.7 & 61.0 & 62.1 \\
\hline Mean return humidity, \% & 48.2 & --- & 57.2 & 55.1 & 58.7 \\
\hline Mean outdoor dry-bulb, ${ }^{\circ} \mathrm{F}$ & 79.3 & $-\cdots$ & 78.4 & 80.9 & 76.8 \\
\hline
\end{tabular}

(a) Dashed line indicates no data because of instrumentation outages.

(b) TP_EER for an electric air conditioner is the ratio of total cooling output (kBtu) to total electricity input $(\mathrm{kWh})$.

for Unit 2 in 1994 to represent 10 days before the first signs of the icing problem appeared. Also in 1994, two additional columns are shown for Unit 3 for before and after the compressor failure. The periods that are used in pre/post and mapping analysis are marked with an asterisk (*) after the range of days.

\section{Comparison Units Projected Performance}

Commissioned performance of the comparison units was projected onto the operating conditions and loads seen by the Triathlon GHP in the house at 842 Chaffee. Both the mapping and the 
Table 7. Comparison Units' Performance in 1994 Test Season

Unit 2

Range of days
$(532=6 / 17 / 94)$

Total cooling output, MBtu

Total electricity input, $\mathrm{kWh}$

TP_EER, kBtu/kWh

Energy cost, \$

Duration, days

Run time, $\mathrm{h}$

Sensible capacity, kBtu/h

Latent capacity, $\mathrm{kBtu} / \mathrm{h}$

Total capacity, $\mathrm{kBtu} / \mathrm{h}$

Mean room dry-bulb, ${ }^{\circ} \mathrm{F}$

Mean return dry-bulb, ${ }^{\circ} \mathrm{F}$

Mean return wet-bulb, ${ }^{\circ} \mathrm{F}$

Mean retum humidity, \%

Mean outdoor dry-bulb, ${ }^{\circ} \mathrm{F}$

532-699 532-542*

54.8

6861

7.99

433

167

2160

19.8

5.6

25.4

72.5

71.1

57.2

42.3

80.8
4.8

621

7.76

39.2

10.4

184

19.5

6.7

26.2

70.0

68.6

55.6

43.6

82.6
Unit 3

$532-699 \quad 532-578^{*} \quad 586-699$

47.3

19.3

24.8

5201

2381

2482

9.10

8.11

9.97

328

150

157

167

46

113

1338

586

664

27.3

26.0

28.2

8.1

35.4

6.9

9.1

37.3

73.5

32.9

71.9

71.9

75.4

69.7

59.9

74.0

58.3

49.7

61.5

50.3

78.9
49.3

83.8
75.4

pre/post CDD correction techniques were used (see the Methodology and Analysis sections). These projections are summarized in Table 8 . These projected energy numbers are the consumptions that would be seen during the 1994 season if these units had been installed in 842 Chaffee in substitution for the Triathlon unit. The TP_EER shown here is the 1994 recorded total test-period load at 842 Chaffee divided by these energy consumption numbers and are an indicator of the projected performance at 842 Chaffee.

These projected TP_EER values can compared with actual commissioned performance TP_EERs of the comparison units (see Tables 6 and 7 in the columns marked with a "*"). Differences seen in such a comparison reflect the differences in the operating conditions of the Triathlon and those of the comparison unit. For example, Unit 2 had a commissioned test period efficiency of 7.76 $\mathrm{kBtu} / \mathrm{kWh}$ while operating under average conditions of $68.6^{\circ} \mathrm{F}$ return dry-bulb and $82.6^{\circ} \mathrm{F}$ outdoor dry-bulb. Its efficiency improved to $8.28 \mathrm{kBtu} / \mathrm{kWh}$ when projected to the milder operating conditions of the Triathlon at 842 Chaffee $\left(74.1^{\circ} \mathrm{F}\right.$ return dry-bulb, $80.7^{\circ} \mathrm{F}$ outdoor dry-bulb). 
Table 8. Commissioned Performance of Comparison Units Projected Onto 1994 Loads and Operating Conditions of Triathlon Unit (842 Chaffee)

\begin{tabular}{lccc} 
Projection Technique & Energy Use, $\mathbf{k W h}$ & TP_EER \\
\cline { 1 - 1 } Unit 1 pre/post & & 4087 & 8.43 \\
Unit 1 coil-map & 3862 & 8.92 \\
Unit 2 coil-map & & 4162 & 8.28 \\
Unit 3 coil-map & & 4185 &
\end{tabular}

\section{Savings}

The 1994 Triathlon cooling season energy consumption (Table 5) and the 1994 projected performance (Table 8) of the comparison units can be extended to normal weather year results using the CDD correction factor of 1.386 (see discussion in Analysis section). Table 9 summarizes these normal year energy consumptions and the corresponding energy cost savings of the Triathlon relative to the comparison units. Cost calculations are based on San Antonio residential fuel prices (see Appendix E). The GHP consumes $\$ 227$ of fuel in a normal summer in the Fort Sam Houston test house. The Triathlon GHP saved from $\$ 111$ to $\$ 139$ over the projected performance of the three comparison units. The best representative of savings relative to a conventional air conditioner is the $\$ 111$ (32.9\%) savings of Unit 1 (10.45 SEER).

\section{Occupant Comfort}

Occupant comfort is difficult to characterize by measurement; many parameters affect human . comfort. However, an attempt is made in Figures 17 and 18 with distribution plots of indoor relative humidity and indoor dry-bulb temperature. These room humidities are based on a measurement of

Table 9. Normal Cooling Season Savings by Triathlon Unit Relative to Comparison Units

\begin{tabular}{|c|c|c|c|c|c|c|}
\hline & $\begin{array}{c}\text { Gas Use, } \\
\text { kcf } \\
\end{array}$ & $\begin{array}{l}\text { Electricity } \\
\text { Use, kWh } \\
\end{array}$ & $\begin{array}{l}\text { Energy } \\
\text { Cost, } \$ \\
\end{array}$ & $\begin{array}{c}\text { Energy Cost } \\
\text { Savings, } \$ \\
\end{array}$ & $\begin{array}{c}\text { Energy } \\
\text { Savings } \\
\end{array}$ & $\begin{array}{l}\text { Cost } \\
\% \\
\end{array}$ \\
\hline Triathlon & 41.5 & 864 & 226.8 & $-\cdots$ & . & - \\
\hline Unit 1 (pre/post) & 0.0 & 5663 & 357.7 & 131 & & 36.6 \\
\hline Unit 1 (mapped) & 0.0 & 5351 & 338.0 & 111 & & 32.9 \\
\hline Unit 2 (mapped) & 0.0 & 5768 & 364.2 & 137 & & 37.7 \\
\hline Unit 3 (mapped) & 0.0 & 5799 & 366.2 & 139 & & 38.1 \\
\hline
\end{tabular}




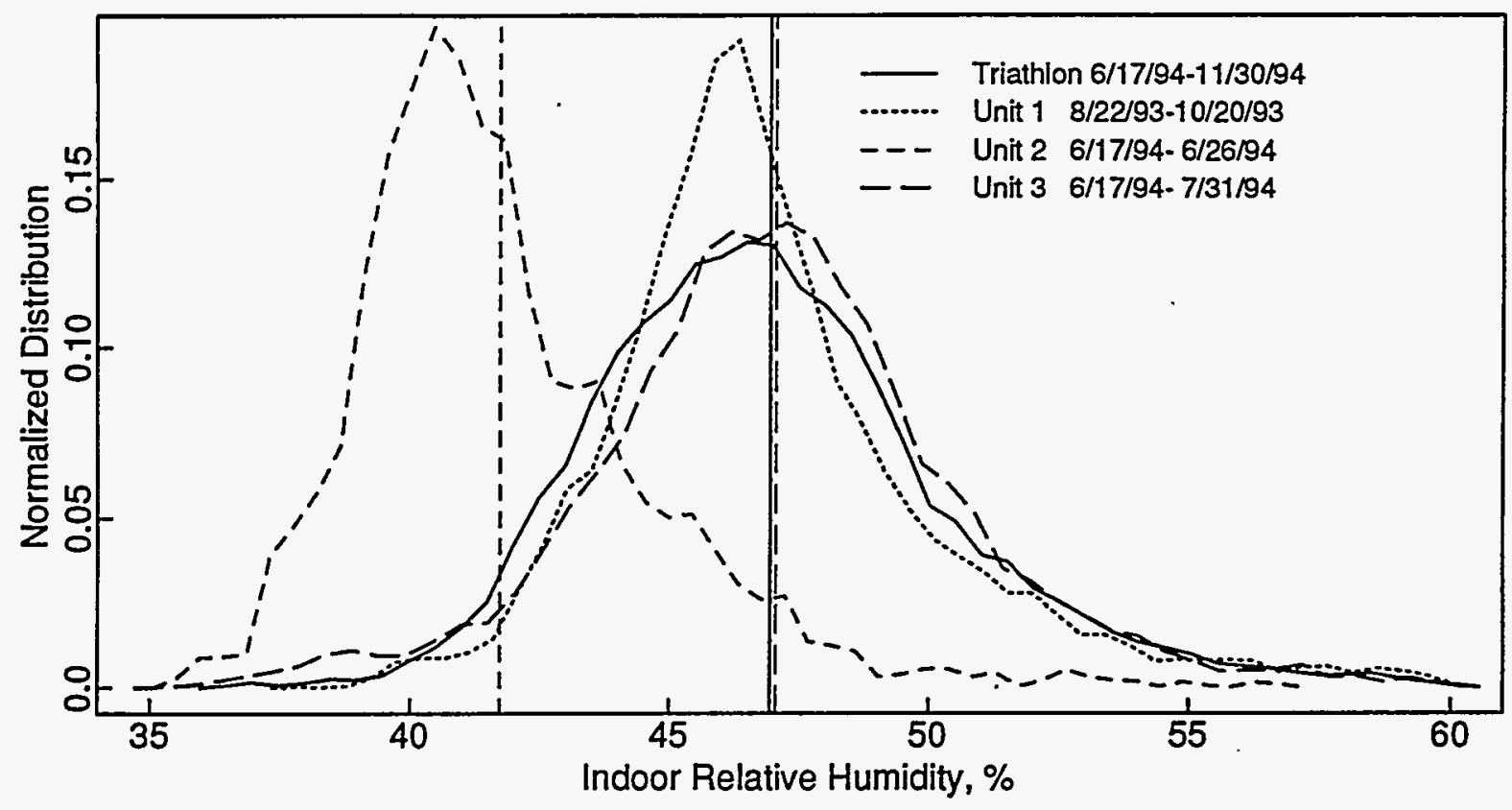

Figure 17. Distribution of Indoor Operating Relative Humidity

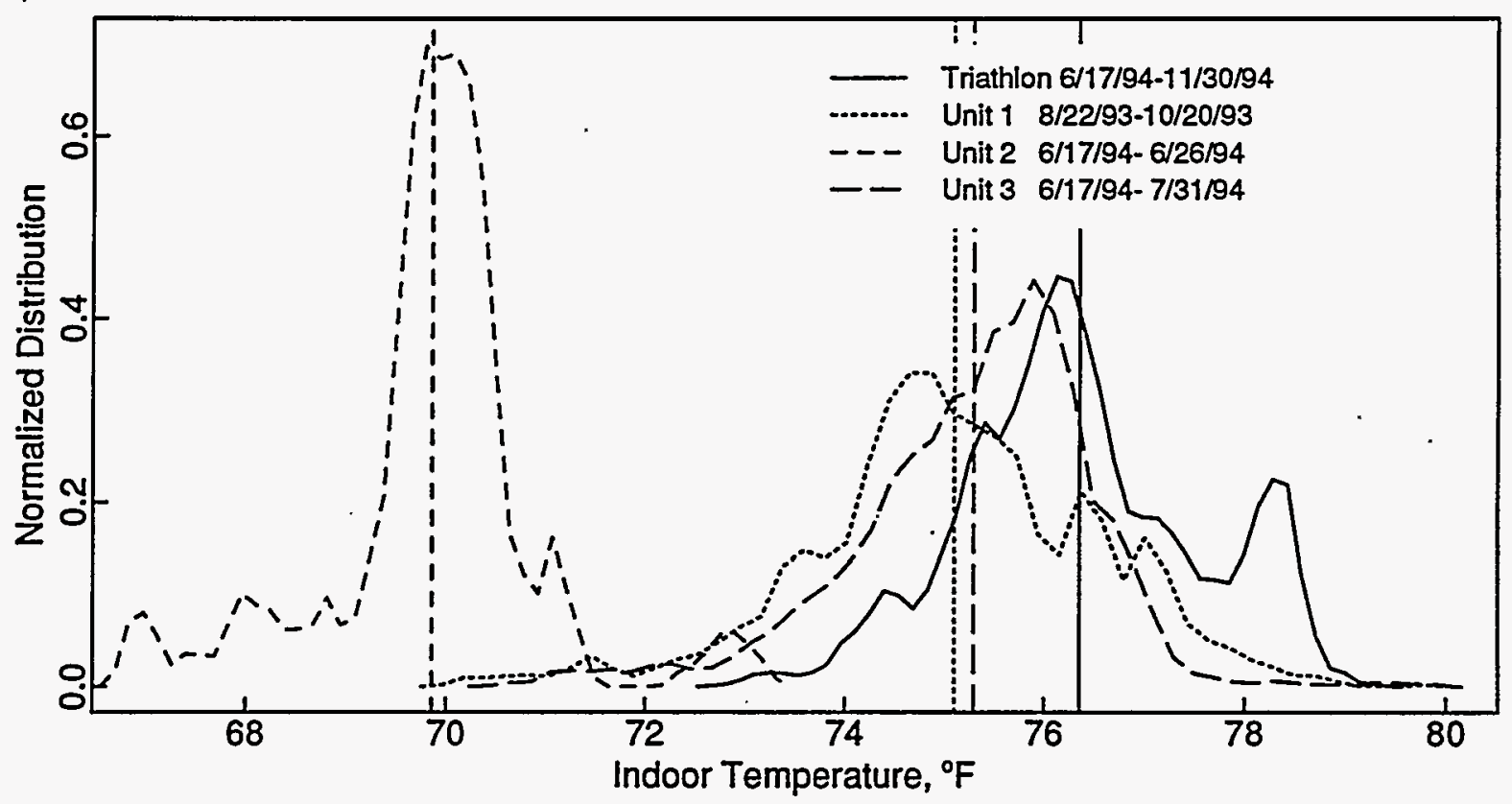

Figure 18. Distribution of Indoor Operating Temperature 
room temperature and retum air humidity while the unit is cooling. These plots are similar to plotting an outline of a histogram except they are normalized so that the area under each curve is equal to 1 . The mean of each distribution is indicated with a vertical line.

Figure 17 shows a nearly identical humidity result of 47\% for Units 1 and 3 and the Triathlon. Unit 2 shows lower humidity levels because of less evaporator-coil airflow and possibly because of the lower thermostat set point. Lower temperatures will increase the run times and the amount of dehumidification but also increase the moisture gains from infiltration. The lower airflow shifts the capacity of the unit from sensible to latent.

Interviews were conducted with the occupants of the house with the Triathlon GHP. The occupants indicated that the unit had provided good comfort. They commented that attempts to get them a thermostat manual had failed and left them unable to use all the features of the thermostat. When they needed to change the temperature, they used the "temporary" set-point adjustment feature on the thermostat. The startup and running sounds from the outdoor section of the Triathion was the greatest concern of the occupants. Although they said these sounds did not disturb them when they were inside the house, they were concerned about disturbing their neighbors. They commented that the nature of the startup sounds reminded them of a lawnmower. They were pleased with the small amount of sound coming from the indoor fan (due to the variable-speed operation). 


\section{Conclusions}

Findings from the summer-cooling test have demonstrated the Triathlon GHP to be a reliable system for Fort Sam Houston. The unit had no downtime, and it operated at performance levels anticipated by the manufacturer. The unit's COP during the summer-cooling test was 1.128 .

The occupants concluded that the GHP provided good comfort with acceptable levels of operating noise. Monitoring of indoor humidity during cooling operation showed nearly identical average humidity levels (and associated comfort) by the Triathlon and comparison air conditioners during the summer test.

The GHP has shown potential to reduce cooling-energy costs over more conventional air conditioners. In a normal San Antonio summer, the GHP uses $41.5 \mathrm{kcf}$ of gas and $864 \mathrm{kWh}$ of electricity. This amount of fuel costs $\$ 227$ (based on San Antonio residential prices) and corresponds to a savings of $\$ 111$ to $\$ 139$ over the three comparison air conditioners in this field test. The savings relative to the best of the comparison units (10.45 SEER) was $\$ 111$ (32.9\%). 



\section{References}

American National Standards Institute. 1994. American National Standard for Performance Testing and Rating of Gas-Fired, AV, and Heat Pumping Appliances, Z21.40.4. New York.

American Society of Heating, Refrigerating and Air-Conditioning Engineers, Inc. 1989. 1989 ASHRAE Handbook - Fundamentals. Atlanta.

Fischer, S. K., and C. K. Rice. 1986a. The Oak Ridge Heat Pump Design Model: Mark III Version Program Documentation. ORNL/TM-10192, Oak Ridge National Laboratory, Oak Ridge, Tennessee.

Fischer, S. K., and C. K. Rice. 1986b. The Oak Ridge Heat Pump Models: I. A Steady-State Computer Design Model for Air-to-Air Heat Pumps. ORNL/CON--90/R1 DE84 001577, Oak Ridge National Laboratory, Oak Ridge, Tennessee.

Gas Research Institute. 1993. "Residential Engine-Driven Gas Heat Pump." Tech Profile 393RPP12000, Chicago.

Harnish, J. T., D. W. Procknow, F. E. Jakob, T. A. Klausing, C. E. French, and G. Nowakowski. 1991. "Residential Gas Heat Pump Design and Development." Paper presented to Cogeneration and

Energy Conservation for the 90's. March 18-19, 1991, Mesa, Arizona.

Olsen, A. R., S. Moreno, J. J. Deringer, and C. R. Watson. 1984. Weather Data for Simplified Energy Calculation, Volume III. Western United States: TRY Data. PNL-5143 Vol. III, Pacific Northwest Laboratory, Richland, Washington.

York International and Battelle Columbus Laboratories. 1993. Field Test of the York Gas Heat Pump. GRI-92/0509, National Technical Information Service, Springfield, Virginia. 
. 
Appendix A

Joint Statement of Work 



\section{JOINT STATEMENT OF WORK \\ TEST BED DEMONSTRATION PROJECT}

FT. SAM HOUSTON

NATURAL GAS HEAT PUMP TEST BED

\subsection{BACKGROUND}

The Federal government is the largest single consumer of energy in the United States. Although energy use is decreasing, there are opportunities for further reduction. Through its Office of Federal Energy Management Program (FEMP), the U.S. Department of Energy (DOE) has been providing technical and administrative support to Federal agency programs directed at reducing energy consumption and cost in Federal buildings and facilities. One such program is the Test Beds Demonstration Program (TBDP), or test bed.

A test bed is a demonstration of a U.S. energy-related technology at a Federal site. Through a partnership with a Federal site, the utility serving the Federal site, a manufacturer of an energy-related technology, Pacific Northwest Laboratory (PNL), and other organizations associated with these interests, new technologies can be evaluated. The partnership of these interests is secured through a Cooperative Research and Development Agreement (CRADA).

The goals of the Test Bed Demonstration Program are:

To deploy a new U.S. technology in the Federal sector.

To improve the energy efficiency of the Federal sector.

To reduce life cycle costs and improve reliability of Federal installations.

To stimulate widespread commercialization of U.S. technology.

To document ways in which Federal facility management can affect change.

To show that govemment and industry can work together toward common goals.

\subsection{OVERALL PURPOSE AND OBJECTIVES}

The purpose of this CRADA is to install, operate, monitor, evaluate and make known the results of the demonstration of a 3-ton natural gas engine driven heat pump (gas heat pump or the technology) to be installed at Ft. Sam Houston, Texas. This JSOW forms part of the Natural Gas Heat Pump Test Bed CRADA C/PNL which has as a major objective, the rapid and widespread application of this new U.S. technology by the Federal sector. 
York and the Gas Research Institute's (GRD) objectives are to further document the capability of their products by installing them in the Federal building environment and having their performance monitored. City Public Service's objectives are to improve their summer and winter load patterns to more effectively use their system capabilities. Ft. Sam Houston's objectives are to reduce energy consumption and cost associated with their operations. The American Gas Cooling Center's (AGCC) objectives are to demonstrate the energy, cost, and environmental benefits of gas cooling technologies. A secondary objective is to take greater advantage of existing collaborations between product development organizations, the Federal sector, utilities, and associated organizations.

\subsection{TECHNICAL OBJECTIVES}

The technical objectives of this collaboration are derived from the requirements within the FEMP and present technology deployment and energy conservation efforts within the heating, ventilating, and air conditioning industry and utility sector. These objectives will be met by work to be done individually and collectively by PNL staff, York, Ft. Sam Houston, City Public Service, GRI and AGCC. The results of this collaboration will include a high-level data reporting, analysis, and management system to support the deployment efforts associated with the technology. The technical objectives are:

Successfully install, commission, operate, maintain, and document the performance of the York 3-ton natural gas engine driven heat pump.

- Determine the life cycle cost savings that can be achieved by using the York 3-ton natural gas engine driven heat pump, based on the documented installed cost and operating and maintenance costs.

Determine if any specific improvements are required in the York 3-ton natural gas engine driven heat pump before it can be successfully deployed in the Federal sector.

Determine the most effective way to facilitate the widespread and rapid deployment of the York 3-ton natural gas engine driven heat pump in the Federal sector and to clearly define any barriers to deployment.

\subsection{INDIVIDUAL RESPONSIBILITIES}

The approach to achieving the objectives stated above involves extensive collaboration between the PNL, York, Ft. Sam Houston, City Public Service, GRI and AGCC. Each party has roles and responsibilities. Through a synergistic effort a significant advancement in deployment of this technology, necessary to support the increased use of this U.S. technology and reduce Federal energy use, will occur. The overall responsibilities are defined here. Detailed responsibilities are defined in subsequent sections of the JSOW.

PNL will have two primary responsibilities in this collaboration. First PNL will provide overall project management and reporting. Second, PNL will oversee monitoring of the existing equipment and the heat pump, analysis of the operating data, and preparation of the results of the evaluation. 
York and GRI will provide the 3-ton natural gas engine driven heat pump, assist with its instrumentation, and support its maintenance during the demonstration project.

City Public Service will provide energy to Ft. Sam Houston, gas metering devices, and, along with GRI, assist with data acquisition and assessment.

Ft. Sam Houston will provide facility access and support all efforts to install, operate, arid monitor the technology demonstration.

AGCC will support outreach efforts to communicate the results of the project within the Federal sector.

\subsection{DESCRIPTION OF THE OVERALL PROJECT}

To demonstrate a new technology, it must be installed, maintained, operated, and monitored. In addition, the results of the installation must be effectively communicated to those in the public and private sectors. The natural gas heat pump test bed covered by this joint statement of work has four distinct areas for activity: planning, execution, documentation, and decommissioning. Within each area numerous tasks are contemplated.

The objective of planning is to ensure that the technology installation at the site can be effectively implemented and that necessary and appropriate data to evaluate the technology will be obtained. This includes tasks related to site preparation, technology procurement and delivery, identification of a methodology to evaluate technology performance, the design of the data acquisition system, and the monitoring and reporting process.

The objective of execution is to obtain the data necessary to serve as a basis for an evaluation of the technology. This includes monitoring baseline information from the existing systems, installing the new technology in a single family residence, operating the building and its systems, monitoring the stream of evaluation data, and recording maintenance activity throughout the length of the project.

The objective of documentation is to record and present the results of the project and make them available. This includes data analysis, preparation of interim and final results, and participation in activities to communicate the results of the project in support of technology deployment.

The objective of decommissioning is to remove the technology, if so desired, and the monitoring equipment. This is a retum of the installation to its original, or some other agreed upon, condition. The effort described herein anticipates that the technology will perform as expected by the manufacturer. If the technology cannot complete the test, decommissioning will supersede all tasks remaining, except for publication of the final report on the project.

A description of each of the tasks to be performed to meet these objectives is provided in Sections 6.0, 7.0, 8.0, and 9.0. The partners having primary and secondary responsibility are specified for each task. The anticipated deliverable for each task is also stated. 
PNL will have the lead responsibility for project management, monthly progress reports, and, with assistance provided by all test bed partners as appropriate (based on who has lead responsibility for the task), all specific reports specified herein.

A task-by-task schedule for the project is provided in Section 10.0 .

\subsection{PLANNING}

The planning effort includes those activities necessary to design the project so that the installation of the gas heat pump can be made at Ft. Sam Houston, necessary operating data can be obtained from the test home as well as several baseline homes, and the formal technology demonstration can be ended. It includes any activity up to the point where full operation and data acquisition begins in addition to the consideration of what to do when the test is completed.

\section{$\underline{6.1 \text { Site Evaluation }}$}

Obtain a description of the candidate single family homes fronting essentially on the 700 and 800 blocks of Patch and Chaffee Roads, their existing energy systems and as-built construction, and available information about past operation, maintenance, and control of the energy systems that will be replaced or modified. This must include necessary schematics, energy consumption and billing information, maintenance records, and photographs, as well as other information necessary to portray the building as it currently exists. This information must emphasize and detail those parts of the building and energy systems that will be changed pursuant to the project and which will impact the validity of any tests associated with the technology.

Primary responsibility: Ft. Sam Houston.

Secondary responsibility: PNL.

Deliverable: A report detailing the "before" condition of the homes and their energy systems that focuses on those aspects of the building and energy systems to which the new technology will apply and reduce energy use and cost.

\subsection{Integration of Monitoring Instrumentation}

The gas heat pump will first be shipped to Battelle Memorial Institute who, under contract to York and GRI, will integrate performance monitoring sensors into the gas heat pump unit. This includes the installation of various temperature, pressure, and flow sensors in the heat pump. A bench-top test of the heat-pump and instrumentation package will be conducted to insure the proper operation of the data acquisition system before shipment to Ft. Sam Houston for installation.

Primary responsibility: York and GRI.

Secondary responsibility: PNL. 
Deliverable: A report documenting the location of sensors in the heat pump, any heat-pump modifications needed to accommodate the instrumentation, and the results of the bench-top check-out; also, the necessary data logging instrumentation, software, and manuals to support the collection and processing of data from the sensors monitoring the gas engine driven heatpump.

\subsection{Equipment Specification and Delivery}

Based on the description of the existing building and energy systems installation and operating history, provide the necessary drawings, operations and maintenance manuals, specifications, and instructions for installation and commissioning of the 3-ton natural gas engine driven heat pump instrumented under Task 6.2. This will include those items that must be modified on site to accommodate the technology, as well as equipment and accessories that must be delivered. Deliver to the site the 3-ton natural gas engine driven heat pump and any necessary accessories (such as tools, fixtures, and consumables) required to install and commission the technology. Although Federal facility staff are not to be responsible for any service and maintenance they must be provided training to understand the operation and maintenance of the technology. Also provide a baseline operating specification and a statement of technology goals in terms of fuel consumption, reduction, availability and reliability, service and maintenance.

Primary responsibility: GRI and York.

Secondary responsibility: Ft. Sam Houston.

Deliverables: The gas heat pump, drawings, operations and maintenance manuals, specifications, and instructions that will ensure the proper installation and commissioning of the technology; and any accessories necessary to facilitate technology installation and commissioning.

\subsection{Technology Monitoring Design and Delivery}

Design a monitoring approach for the project based on the description of the homes, the gas heat pump, the installation instructions, the report on the "before" condition of the building, and information that will be needed to evaluate the technology. This will include defining what is to be measured and logged, the method of measurement, the increment at which measurement should be taken, the method of data acquisition and reporting, and the necessary report formats, forms, and $\log$ sheets to be used. In addition, provide the equipment needed for baseline monitoring and the corresponding installation, operation, and maintenance instructions. Also develop and define the quality assurance program for the acquisition of the performance and the operations and maintenance data.

Primary responsibility: PNL.

Secondary responsibility: York, GRI, and City Public Service.

Deliverable: A detailed plan for technology monitoring; aiso, the necessary instrumentation to support the collection of baseline data from the existing HVAC systems. 


\subsection{Technology and Monitoring Installation}

Install the technology and the data acquisition equipment based on the instructions and plan prepared pursuant to Sections 6.3 and 6.4 above. Also conduct testing and field verification work to further establish both the "before" conditions for the test and baseline upon which to technology will be evaluated. Subsequent to installation, commission the technology and the data acquisition equipment and conduct a test to verify that it will properly function; that all necessary data are being obtained and can be secured according to the technology monitoring plan.

Primary responsibility for technology side: York and GRI.

Secondary responsibility for technology side: Ft. Sam Houston.

Primary responsibility for monitoring side: PNL.

Secondary responsibility for monitoring side: City Public Service.

Deliverable: A report documenting the installation process, documenting that the installation is functioning properly, and that it is being properly monitored.

\subsection{Technology Decommissioning}

To provide for the completion of the test and possible removal or continuation of the operation, a plan for responsibilities under technology and removal scenarios must be prepared. This plan must also include a contingency plan to address the early forced removal of the technology due to failure of the technology or catastrophic events which could adversely impact the specific site or Ft. Sam Houston.

Primary responsibility: PNL.

Secondary responsibility: Ft. Sam Houston.

Deliverable: A plan for unscheduled and scheduled decommissioning of the technology.

\subsection{EXECUTION}

The execution effort includes those activities necessary to operate, maintain, monitor, and document the performance of the gas heat pump throughout the project and to ensure that information on the progress and results associated with the project is made available to those associated with the project.

\subsection{Performance Monitoring and Data Acquisition}

Monitor the operation of the gas heat pump and other baseline homes as well as other building and system functions pursuant to Section 6.4. This includes acquisition of all data (at specified intervals) 
that are defined as critical to technology performance monitoring, and conduct of data validation tests to ensure that accurate data are being obtained. Carry out calibration of any automated data acquisition equipment throughout the test, as required. Implement all quality assurance program tasks associated with performance and operations and maintenance data acquisition.

Primary responsibility: PNL.

Secondary responsibility: City Public Service.

Deliverable: Monthly reports on the status of the test and data acquisition effort.

\subsection{Operation and Maintenance}

Operate and maintain the gas heat pump as defined by the operations and maintenance manual and training provided by the manufacturer, commensurate with the building use, the intended purpose of the gas heat pump, and other requirements of the managers of the facility. Data must be logged with sufficient accuracy to permit detailed cost and reliability analyses to be carried out. This includes maintaining a log of all O\&M activities, parts and materials usage and cost, labor cost, and downtime associated with maintenance of the technology.

Primary responsibility: York.

Secondary responsibility: Ft. Sam Houston.

Deliverable: Monthly reports on technology maintenance activities and expenses.

\subsection{Data Analysis}

Analyze the performance and operation and maintenance data to determine the performance, energy use, operating costs, and life cycle cost, associated with the gas heat pump and other baseline homes, as well as the reliability, safety, and serviceability aspects of the installation.

Primary responsibility: PNL.

Secondary responsibility: City Public Service.

Deliverable: A preliminary report midway through the test period on the results of the data analysis and a final report containing the results of the data analysis for the entire test period.

\subsection{Energy Supply}

The energy required to operate the gas heat pump must be provided. If the gas heat pump is expected to operate during facility-wide energy supply interruptions, the necessary connection to any stand-by power source or back-up fuel source must be made, maintained, and routinely tested. 
Primary responsibility: City Public Service.

Secondary responsibility: Ft. Sam Houston.

Deliverable: Continuous energy supply (including the interconnection to the stand-by power source if required) to the building and its systems so that the technology can perform its intended function.

\subsection{DOCUMENTATION}

Documentation includes those efforts necessary to record the project activities, evaluate the project, determine the level of success of the project, and present the results of the project.

\subsection{Preparation of Test Bed Report}

The data acquired pursuant to Section 7.1 and 7.2 and the analysis conducted on the data pursuant to Section 7.3 will make it possible to report on the results of the gas heat pump installation. Prepare a report detailing if and to what degree the 3-ton natural gas engine driven heat pump will benefit the Federal sector. In preparing this report the information obtained in Section 6.1 to describe the "before" condition of the building and the data acquired pursuant to the test of the baseline homes and new technology must be used. This must include performance, energy use, operating costs, maintenance costs, reliability, quality of service, and other factors considered important for evaluation.

Primary responsibility: PNL.

Secondary responsibility: City Public Service, GRI, York, and Ft. Sam Houston.

Deliverable: A detailed report that contains the results of the data acquisition and analysis effort, the expected benefits of the gas heat pump in the Federal sector, a description of any necessary improvements required in the gas heat pump before its widespread deployment in the Federal sector, and a description of any factors limiting deployment.

\subsection{Development of Project Presentation and Media}

Commensurate with the success of the project, develop necessary materials to communicate the results of the project and identify those in the Federal sector, policy makers, utilities, and others involved in impacting technology use in the Federal sector. In addition, identify the most effective media for making these materials and the results of the project available. This could include a press release, video, printed matter, conference, or workshop.

Primary responsibility: PNL.

Secondary responsibility: AGCC, York, and GRI. 
Deliverable: A communication package on the results of the project targeted to different key audiences.

\section{$\underline{8.3 \text { Implementation of Presentation }}$}

Implement the most beneficial presentation through the most effective media based on the efforts of Section 8.2. The purpose of this presentation will be to communicate the results of the project to those in the Federal sector who could specify increased use of the gas heat pump in the Federal sector and who would support the test bed concept. In addition communication must also focus on those in the private sector who would advocate the use of the gas heat pump and the test bed concept.

Primary responsibility: AGCC and GRI.

Secondary responsibility: York, City Public Service, Ft. Sam Houston, and PNL.

Deliverable: A copy of the presentation and a report on its implementation, distribution, and reception.

\subsection{DECOMMISSIONING}

The decommissioning effort includes those activities necessary to remove the technology (if it is determined that it is to be removed) as well as the monitoring equipment.

\subsection{Technology Removal}

If it is determined that the technology is to be removed pursuant to the plan developed under Section 6.6 , or due to a failure in the technology, the building is to be returned to its previous condition or to some other condition agreed upon in advance by the Ft. Sam Houston, York, and GRI. The equipment that was installed to monitor the technology installation and any accessory equipment associated with the monitoring installation must also be removed.

Primary responsibility for equipment: York and GRI.

Secondary responsibility for equipment: Ft. Sam Houston.

Primary responsibility for monitoring: PNL.

Secondary responsibility for monitoring: City Public Service.

Deliverable: A report on the disposition of the technology and the monitoring equipment, and the return of the installation to the Federal site in an acceptable manner. 


\subsection{PROJECT SCHEDULE AND RESPONSIBILITIES}

The following schedule shows each of the tasks in Sections 6.0 through 9.0 and the starting point, ending point, and duration of each task. Timelines are shown for years 1993 through 1995.

6.0 Planning

6.1 Site Evaluation

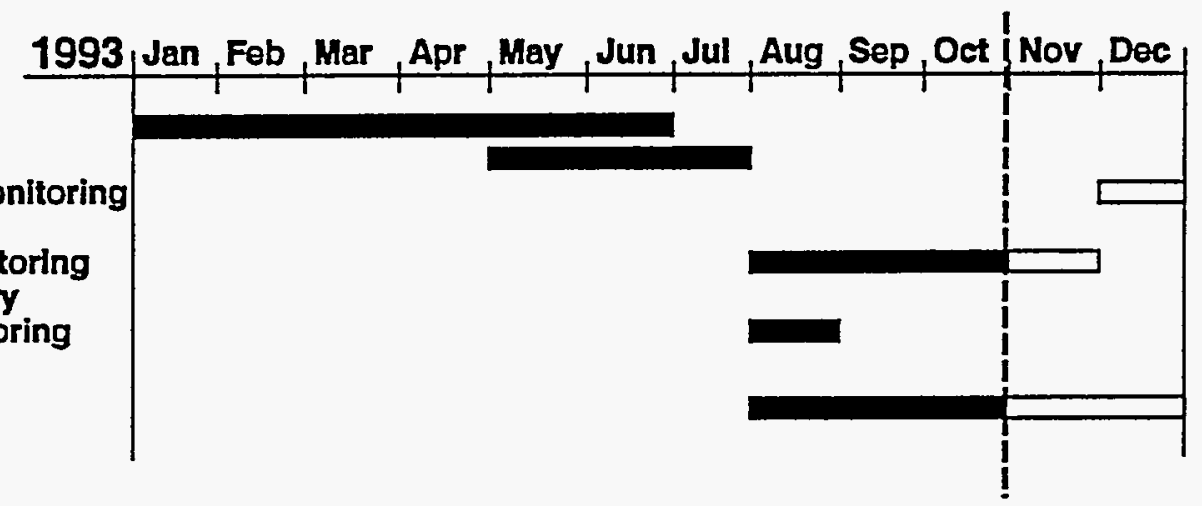

bep030701201

Integration of Monitoring

Instrumentation

6.4 Heat Pump Monltoring

Design \& Delivery

6.5 Tech. and Monitoring Installation

7.0 Execution

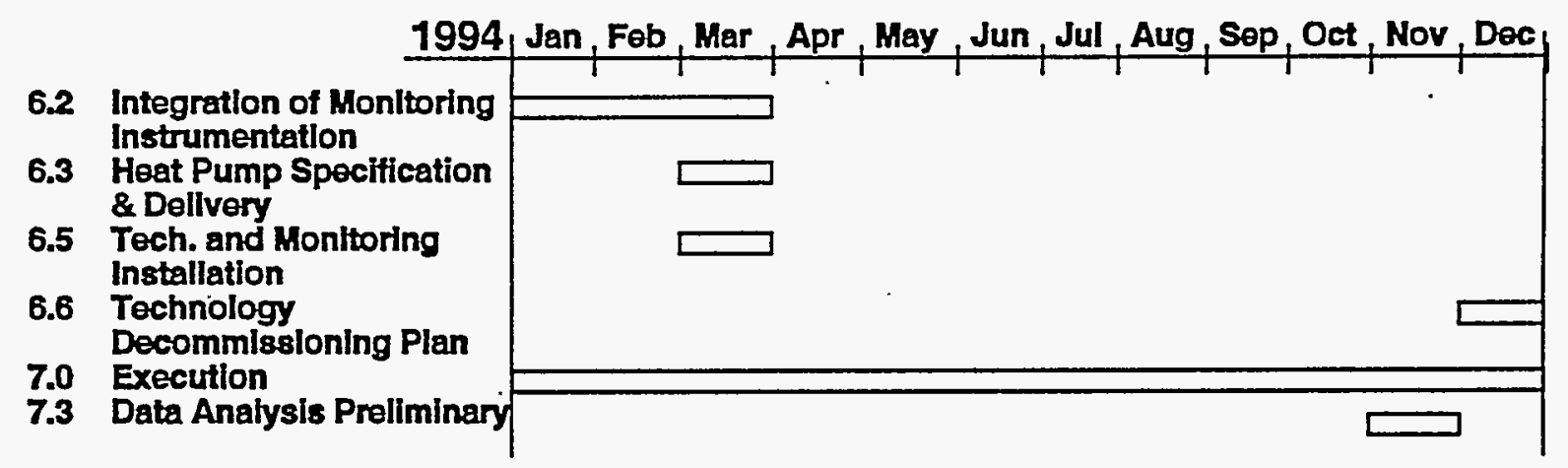

bepostrot2or

7.0 Execution

8.0 Documentation

8.1 Preparation of Test Bed Report

8.2 Development of TBDP Presentation \& Medla

8.3 Implementation of Presentation

9.0 Technology Removal

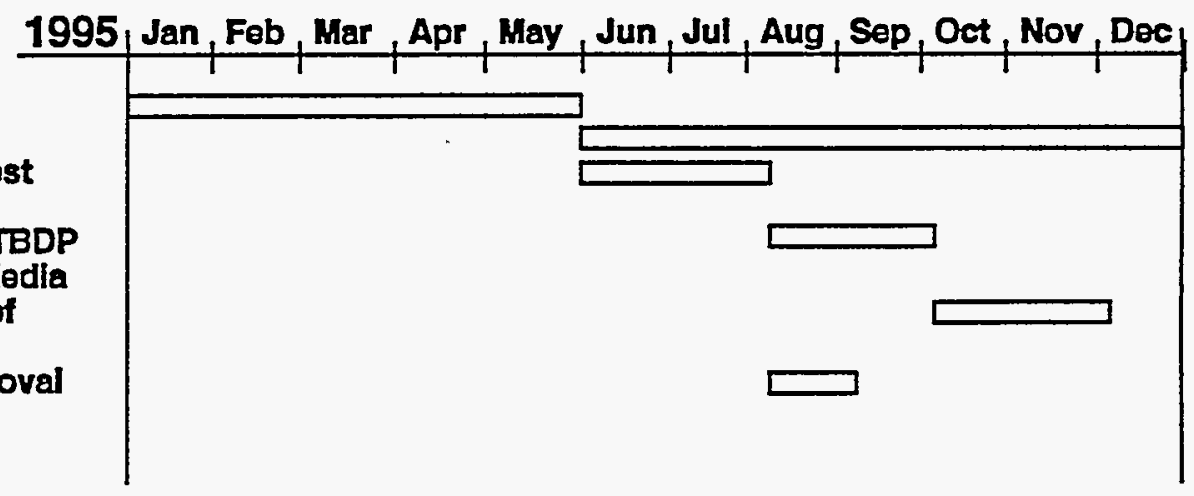

buposoro120e 


\section{Appendix B}

\section{Instrumentation Details for Gas Heat Pump Monitoring}





\section{Appendix B}

\section{Instrumentation Details for Gas Heat Pump Monitoring}

This appendix contains documentation on the data acquisition system (DAS) used in monitoring the Triathlon GHP. This documentation was provided to PNL by Battelle Columbus Laboratory in Ohio. As a subcontractor to the Gas Research Institute, Battelle had the role of installing the monitoring instrumentation on the GHP and collecting the data from this DAS. The following are pages from original documents produced by Battelle-Columbus. 


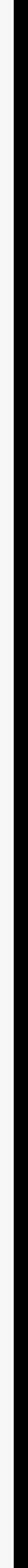




\title{
ATTACHMENT 1
}

\author{
Triathlon CRADA Unit DAS: \\ Installation, Calibration, and Data Format
}

\section{DAS Installation}

The York Triathlon unit was instrumented using instrumentation provided from the York 10unit field test. Several minor modifications were made to accommodate changes in the hardware and system configuration. Complete documentation on the configuration and wiring of the DAS is attached.

\section{Checkout}

The DAS instrumentation was fully checked out by operating the unit in the laboratory. All sensor inputs and wiring were confirmed to be operational. The DAS cable design permits the instrumentation to be easily reconnected after shipping to the test site.

\section{Calibrations}

All preliminary calibrations to individual sensors and to instrumentation subsystems were performed at Battelle. All calibrations performed at Battelle's instrument lab are against NIST traceable standards. These calibrations include:

- Gas meter calibration in Battelle's Instrument Lab

- Suction and Discharge pressure transducer calibration in Battelle's Instrument Lab

- Barometric pressure transducer calibration in Battelle's Instrument Lab

- Calibration of the Metrabyte A/D board

- Calibration of the engine speed signal

- Initial calibration of the RTD current supply boards

- Trial calibration of the indirect indoor airflow measurement methods

Remaining calibrations performed upon installation at the test site include:

- Final calibration of the RTD current supply boards

- Calibration of the thermocouple cold junction compensation

- System capacity calibration of the airflow measurement using the electric resistance heat injection method developed during the original 10-unit field test 


\section{Data Reporting}

Data collected during the York Triathlon field test will be analyzed and reported in several different manners. Daily graphs of GHP operation are performed with CGHP, a custom graphic and data display utility which has proven to be a useful tool in quickly visualizing single-day operation of the GHP. It also has been very useful in diagnosing operational problems with the GHP. A sample CGHP graph from the York 10-unit field test is shown in . Figure 1. The CGHP utility has been provided to Jim Miller and PNL.

Performance data are reduced in several steps and loaded into a database. This data base is then queried to generate a periodic performance report. The periodic performance report will be issued on a monthly basis along with the monthly report. A sample periodic performance report is shown in Figure 2. 


\section{OUTDOOR UN}

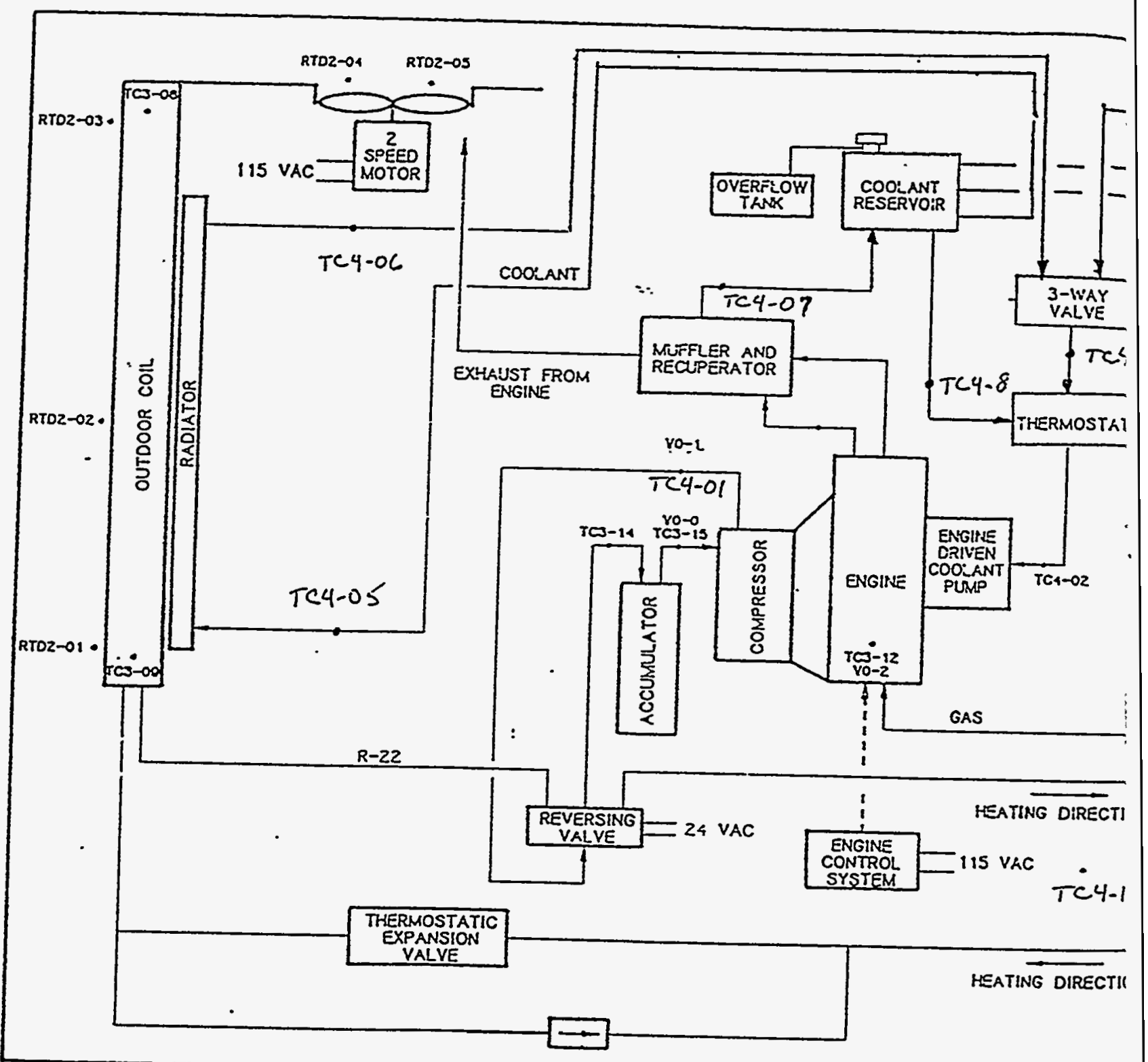

\section{York Triathlon Cra Showing DA}




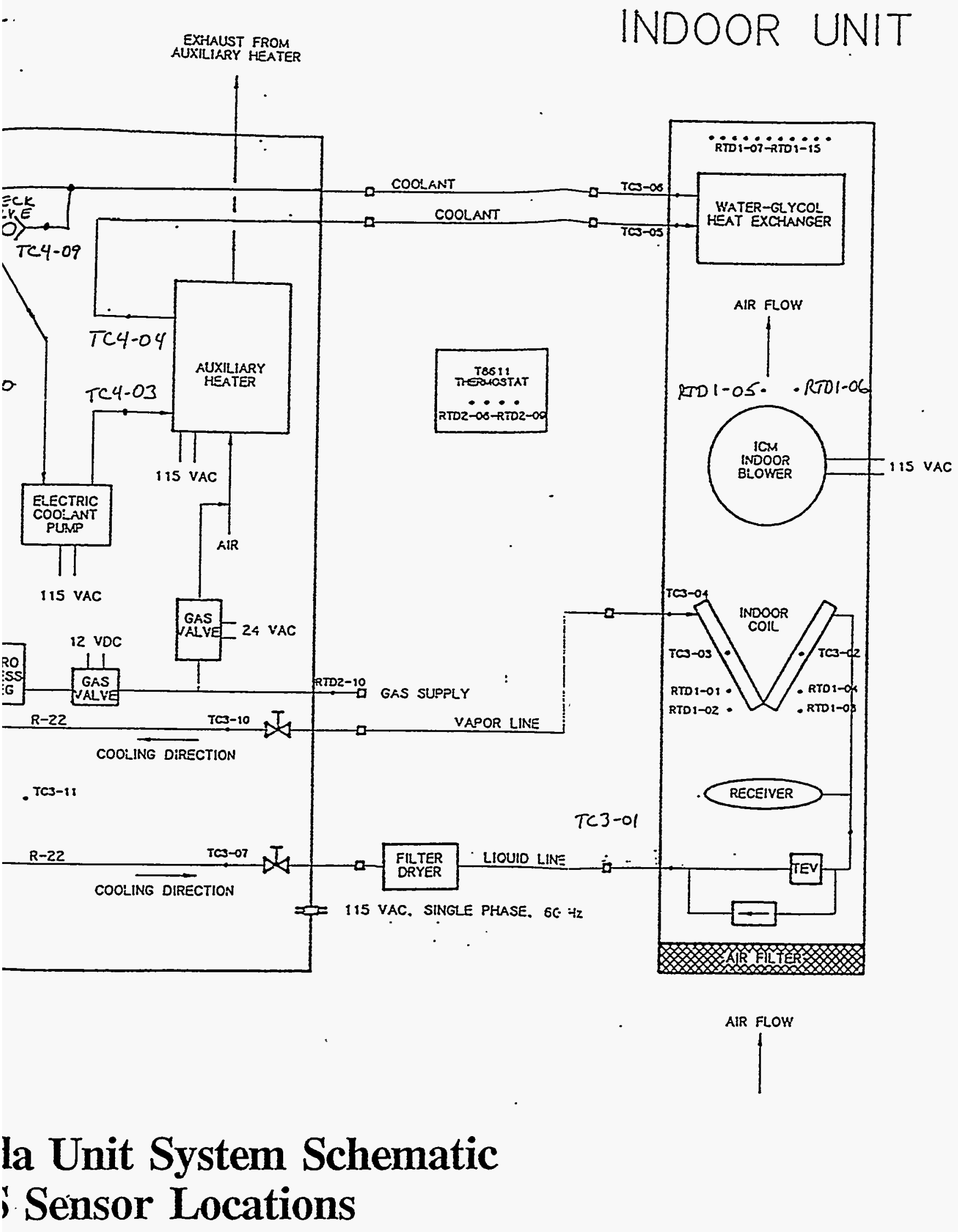




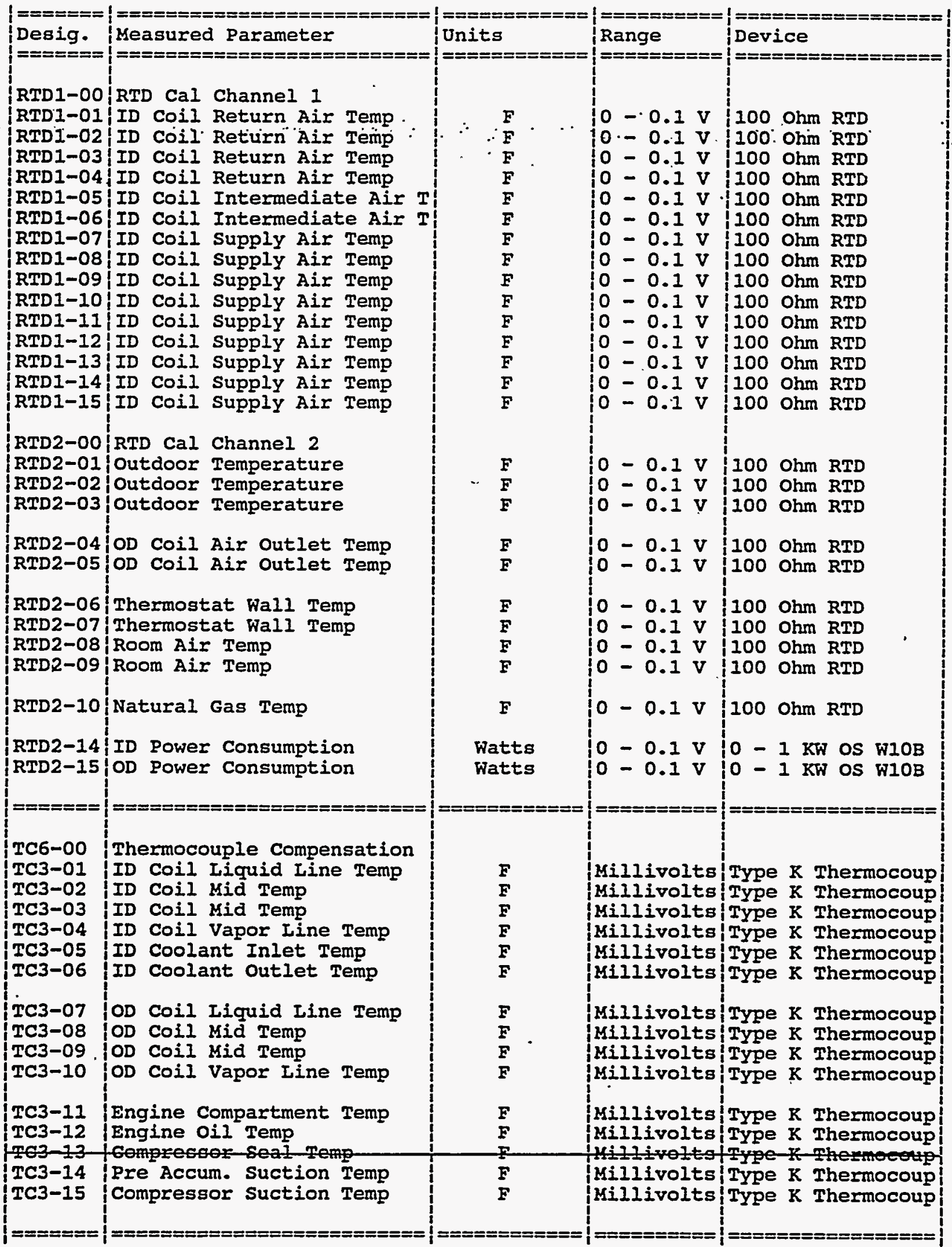





\begin{tabular}{|c|c|c|c|c|}
\hline & $=-1=$ & & & \\
\hline $\begin{array}{l}\text { TC7-00 } \\
\text { TC4-01 }\end{array}$ & $\begin{array}{l}\text { Thermocouple Compensation } \\
\text { Compressor Dischg Temp }\end{array}$ & $\mathbf{F}$ & Millivolts & | Type $\mathrm{K}$ Thermoco \\
\hline $\begin{array}{l}T C 4-02 \\
T C 4-03 \\
T C 4-04 \\
T C 4-05 \\
T C 4-06 \\
T C 4-07 \\
T C 4-08\end{array}$ & $\begin{array}{l}\text { Coolant Temp into Engine } \\
\text { Coolant Temp into Aux Heat } \\
\text { Coolant Temp out of Aux He } \\
\text { Coolant Temp into Radiator } \\
\text { Coolant Temp out of Radiat } \\
\text { Coolant Temp out of Engine } \\
\text { Coolant Temp Warm-up Loop }\end{array}$ & $\begin{array}{l}F \\
F \\
F \\
F \\
F \\
F \\
F\end{array}$ & $\begin{array}{l}t s \\
t s \\
t s \\
t s \\
t s \\
t s \\
t s\end{array}$ & $\begin{array}{l}\text { Type K Th } \\
\text { Type K Th } \\
\text { Type K Th } \\
\text { Type K Th } \\
\text { Type K Th } \\
\text { Type K Th } \\
\text { Type K Th }\end{array}$ \\
\hline $\begin{array}{l}\text { TC4-09 } \\
\text { TC4-10 }\end{array}$ & $\begin{array}{l}\text { Coolant Temp \& Check Valve } \\
\text { Coolant Temp Rtn to Tstat }\end{array}$ & $\mathbf{F}$ & & $\begin{array}{l}\text { Type } \mathrm{K} \text { Therm } \\
\text { Type } \mathrm{K} \text { Therm }\end{array}$ \\
\hline$======$ & $\begin{array}{l}\text { Encl Temp in Control Tray } \\
==============-==-=======\end{array}$ & 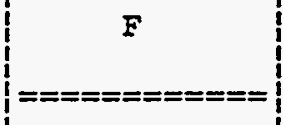 & Millivolts & $\begin{array}{l}\text { Type K Thermocou } \\
=============\end{array}$ \\
\hline $\begin{array}{l}\text { vo-00 } \\
\text { vo-01 } \\
\text { vo-02 } \\
\text { vo-03 } \\
\text { vo-04 }\end{array}$ & $\begin{array}{l}\text { Compressor Suction Press } \\
\text { Compressor Dischg Press } \\
\text { Oil Lubricant Press } \\
\text { Barometric Press } \\
\text { Commanded Engine Speed }\end{array}$ & $\begin{array}{l}\text { Psis } \\
\text { Psis } \\
\text { Psis } \\
\text { Psia } \\
\text { RPM }\end{array}$ & $\left\{\begin{array}{l}1-6 \text { VDC } \\
1-6 \text { VDC } \\
1-6 \text { VDC } \\
1-6 \text { VDC } \\
1-2 \text { VDC }\end{array}\right.$ & $\begin{array}{l}\text { Data Inst. SA500 } \\
\text { Data Inst. SA500 } \\
\text { Data Inst. SA100 } \\
\text { Data. Inst. XT15 } \\
\text { From w7505 }\end{array}$ \\
\hline $\begin{array}{l}\text { vo-05 } \\
\text { vo-06 } \\
\text { vo-07 } \\
\text { vo-08 } \\
\text { vo-09 } \\
\text { vo-10 }\end{array}$ & $\begin{array}{l}\text { Indoor Relative Humidity } \\
\text { ID Relative Humidity Temp } \\
\text { Outdoor Relative Humidity } \\
\text { OD Relative Humidity Temp } \\
\text { Indoor Airflow }\end{array}$ & $\begin{array}{l}q \\
F \\
q \\
\text { F } \\
\text { CFH }\end{array}$ & $\left\{\begin{array}{l}0-5 \text { VDC } \\
0-5 \text { VDC } \\
0-5 \text { VDC } \\
0-5 \text { VDC } \\
0-5 \text { VDC }\end{array}\right.$ & $\begin{array}{l}\text { Valasia RH Meter } \\
\text { Valasia RH Meter } \\
\text { Valasia RH Meter } \\
\text { Valasia RH Meter } \\
\text { FMT Air Flow }\end{array}$ \\
\hline $\begin{array}{l}V O-11 \\
V O-12 \\
V O-13 \\
V O-14 \\
V O-15\end{array}$ & $\begin{array}{l}\text { Actual Engine speed } \\
\text { Reversing Valve state } \\
\text { Coolant Valve State } \\
\text { Auxiliary Heater Gas Valve }\end{array}$ & $\begin{array}{l}\text { RPM } \\
\text { Heat/Cool } \\
\text { On-Off } \\
\text { On-Off }\end{array}$ & $\left\{\begin{array}{l}0-5 \text { VDC } \\
0-5 \text { VDC } \\
0-5 \text { VDC } \\
0-5 \text { VDC }\end{array}\right.$ & $\begin{array}{l}\text { From Microtach } \\
\text { From } 24 \text { VAC Sig } \\
\text { From } 24 \text { VAC Sig } \\
\text { From } 24 \text { VAC Sig }\end{array}$ \\
\hline$:=====1$ & 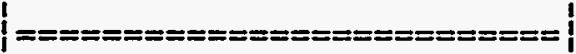 & $===========1$ & $=========$ & \\
\hline $\begin{array}{l}D B O-0 \\
D B O-1 \\
D B O-2 \\
D B O-3 \\
D B O-4 \\
===== \\
=====\end{array}$ & $\begin{array}{l}\text { Natural Gas Consumption } \\
\text { Indoor Blower Wheel Speed } \\
\text { Iatent Capacity } \\
\text { ID Elect Consump. } \\
\text { OD Elect Consump. } \\
======================= \\
=========================\end{array}$ & $\begin{array}{c}\mathrm{CFH} \\
\mathrm{RPH} \\
\mathrm{Btu} / \mathrm{Hr} \\
\mathrm{W}-\mathrm{Hr} \\
\mathrm{W}-\mathrm{Hr} \\
=========== \\
===========\end{array}$ & $\begin{array}{l}\text { Pulse } 0-5 \\
\text { Pulse } 0-5 \\
\text { Pulse, clo } \\
\text { Pulse, clo } \\
\text { Pulse, clo } \\
=========\end{array}$ & $\begin{array}{l}\text { Rockwell as modif } \\
\text { BAE Hall Sensor } \\
\text { Belfort Model } 30 \\
\text { Ohio Semitronics } \\
\text { Ohio Semitronics } \\
============\end{array}$ \\
\hline
\end{tabular}




\section{York Gas Heat Pump Field Test Data Acquisition System (DAS)}

The data acquisition system (DAS) at each of the York GHP field test sites was designed, built, and maintained by Battelle and developed specifically to meet the needs of this test program. Many of the components and the history of the software date back to prior field testing of residential gas heat pumps. The current DAS was adapted and developed for use with an early GHP field experiment ${ }^{(2,3)}$ and then further expanded to meet the requirements of the ten-unit York GHP field test. The DAS logged and displayed data on a continuous basis. Remote access to the DAS could be made via a modem allowing current or logged heat pump operations to be reviewed. The DAS proved to be highly effective at providing reliable and accurate performance data as well as detailed information on the heat pump for characterization and troubleshooting of problems.

\section{Components}

The main components of the DAS were the DAS enclosure, the sensors, and the IBM PC-XT. The sensors and the computer were linked to the DAS with shielded cables to reduce electromagnetic interference. The DAS enclosure regulated the sensor power, conditioned the sensor outputs, and then linked these outputs to the computer.

\section{Quálity Assurance}

Battelle's Instrument Laboratory (BIL) verified the proper operation of sensors critical to heat pump performance monitoring; in addition, BIL calibrated all critical instruments traceable to the National Bureau of Standards (NBS). Throughout testing, instrumentation was continuously monitored by Battelle staff for drift and inaccuracies. In addition to the component-level calibration performed by . $\mathrm{BI}$, Battelle field service engineers and technicians conducted system-level calibration and verification at the specific field sites.

\section{DAS Hardware}

\section{Sensors}

The DAS sensors monitored conditions of the indoor and outdoor units as well as ambient conditions at the site. A listing of the sensors and their designations is shown in Table I-3. Figure I-5 shows a schematic of the field test GHP and sensor locations. 
Resistance Temperature Devices (RTDs) and Thermocouples (TCs)

Temperatures were monitored at 48 locations by use of $100 \mathrm{ohm}$ resistance temperature devices (RTDs) and type K duplex wired thermocouples (TCs). Grids of RTDs were used to measure the temperature rise or drop across the indoor unit. Multipoint measurements significantly improved the measurement accuracy and averaged where the air temperature was nonuniform. This method also allowed redundancy should a sensor fail. Individual measurements were automatically excluded from the grid average if they fell outside of an acceptable range. Four measurement points were used for the return air temperature and nine for the supply. Two RTDs were used between the refrigeration and coolant heat exchanger to determine the relative contribution of these coils.

The air outlet temperature of the heat pump outdoor coil was measured by a grid of three RTDs mounted on each coil face of the outdoor coil. The air outlet temperature of the outdoor coil was measured by two RTDs mounted on the coil face of the heat pump by the outdoor fan exhaust. These measurements indicated the air temperature as seen by the heat pump and might have exhibited recirculation effects as a result of hot soak and solar effects due to the heat pump's location. Attempts were made to minimize these effects; however, this measurement might not represent the actual outdoor temperatures when the outdoor fan is off.

The indoor coil supply air temperature (supplied to the house) was measured at the exit of the indoor unit by a grid of nine RTDs. Intermediate temperatures were measured within the indoor unit by two RTDs located between the indoor fan and the indoor coil. The indoor return (return from the house) was measured by four RTDs located at the entrance of the indoor unit underneath the indoor coil.

The room temperature and thermostat temperature were measured by four RTDs located within the thermostat at the site: Natural gas temperature was measured by one RTD. The natural gas temperature and pressure were used to determine the density of the natural gas supplied to the heat pump.

The critical components and systems of the GHP (e.g., coolant loop, engine, refrigerant circuit, etc.) were heavily instrumented with thermocouples, primarily for diagnostic purposes.

\section{Barometric and System Pressures}

Data Instrument type SA R0-200, SA R0-500, and SA R0-100 sensors were used to monitor the compressor suction, the compressor discharge, and the engine oil lubricant pressure respectively. The aforementioned pressure readings were oversampled to average out fluctuations due to compressor pulsations. Barometric pressure at the site was monitored by use of a Data Instruments XT15 sensor to correct for airflow measurements and to determine the natural gas line pressure. No pressure sensor failures were experienced with over $1 \times 10^{9}$ cycles per sensor per site. 


\section{Humidity and Temperature Transmitter}

Two Vaisala series HMD 30YB Humidity and Temperature Transmitters were employed to monitor temperature and humidity within the plenum on the indoor unit and the ambient conditions in the vicinity of the outdoor unit. The maximum humidity uncertainty for the Vaisala sensor was \pm 3 percent $\mathrm{RH}$ within the 90 to 100 percent $\mathrm{RH}$ range and \pm 2 percent $\mathrm{RH}$ in the 0 to 9.0 percent $\mathrm{RH}$ range. The output uncertainty for temperature on the Vaisala sensor was $\pm 0.2 \mathrm{C}$. The outdoor humidity sensor was protected with a solar and weather shield. The indoor humidity sensor, located in the plenum, measured relative humidity with respect to the return air temperature to the indoor unit. The retum air temperature at most sites was less than the temperature in the living space, and since the water content was relatively constant, the relative humidity in the living space was less than the humidity of the retum air at the indoor unit.

Humidity measurements greater than the living space conditions were frequently measured when the indoor blower was shut off after the GHP had been in the cooling mode. These higher humidity measurements were due to the evaporation of condensate from the indoor coil and the condensate tray.

\section{Electronic Airflow Measurement System . . and the Indirect Airflow Measurement Method}

Initially only an Ebtron Model 400 hot wire aiflow sensor was used for measuring airflow inside the return air duct. As testing progressed a noticeable drift over time became apparent at both high and low flow conditions; hence a second method of monitoring aifflow was developed. The second method, referred to as the indirect method, used a detailed blower map to determine airflow from the blower wheel speed and power consumption. A detailed description of the development and application of this method is described in Reference 4.

\section{Engine RPM}

The DAS measured the actual engine speed by monitoring the engine control system (ECS-3). The ECS-3 output a pulse width modulation (PWM) signal which was converted to a 0 to 5 VDC signal corresponding to the engine speed. This signal was calibrated on-site with a digital tachometer. A polynomial was generated for voltage versus engine rpm and was incorporated into the DAS program which displayed and recorded engine speed in rpm.

\section{Natural Gas Meter}

The natural gas consumption of the heat pump was monitored by use of a Battelle modified Rockwell gas meter. The Battelle modification consisted of replacing the Rockwell gas meter top plate with a plate housing a Hall-effect sensor and substituting a linkage with a magnet for the existing coupling link. The Hall-effect sensor provided a pulse output for each $1 / 8$ cubic foot of gas consumed. The digital signal was read by the Counter Debounce board and was summed by the software for display and logging. 


\section{Tipping Bucket}

Latent capacity of the heat pump was recorded by use of a modified Belfort Model 302B Rain Gauge Assembly. The unit metered the condensate draining from the indoor coil. A reed switch was used to produce a pulse output for each tip of the instrument. The unit capacity was calibrated at Battelle's Instrument Lab and each tip of the bucket was incremented as a unit of latent heat. Measurement of latent capacity using a positive displacement device such as the tipping bucket insured accuracy and long-term stability of the measurement. There was, however, a finite amount of time lag between formation of condensate and actual measurement. This time delay could vary from 15 minutes to over an hour under worst-case conditions. For this reason, the instantaneous cooling capacity could be slightly inaccurate; however, the long-term ( $>1$ hour) averages were representative.

\section{Electronic Watt Watt-Hour Transducer}

Indoor and outdoor electric power consumptions were monitored by use of Ohio Semitronic Series W10B Watt Watt-Hour Transducers. Pulse outputs were generated by these devices for recording the cumulative energy use. An analog signal output from the meter was also used for instantaneous power measurement.

\section{DAS Enclosure}

Internal to the DAS enclosure were control boards which acted as an interface for the computer and the sensors. The boards also regulated the sensors' output power and filtered the input signals from the sensors. The DAS housed five general purpose MetraByte EXP-16 multiplexer boards, a custom Counter Debounce board, a custom engine sensor interface board, and an OPTO 22 Input Module. The DAS enclosure also provided 15 VDC and 24 VDC regulated power for the boards and sensors. The DAS enclosure was prewired and used a number of plug-in type connectors, which significantly improves ease of installation, removal, and calibration.

\section{MetraByte EXP-16 Boards}

The DAS enclosure contained five EXP-16 boards which multiplex the analog inputs to the single 16-channel analog to digital (A/D) board. The V0 board was one of the MetraByte EXP-16 boards which served as a high level analog input board. Sixteen signals such as the engine rpm, valve states, pressure readings, and airflow were relayed from the sensors to the computer via this board. Two of the MetraByte EXP-16 boards were used for signal conditioning the RTDs. A custom current supply board was used to regulate the current supplies for the RTDs. The last two MetraByte EXP-16 boards (TC3 and TC4) were used for inputs from the thermocouples.

\section{Debounce Board (DBO)}

The Debounce Board (DBO) debounced noisy pulse inputs from switch closure type devices. The board has five channels which were dedicated to counting signals from the gas meter, the indoor 
blower, the tipping bucket, the indoor electric watt-hour meter, and the outdoor electric watt-hour meter. Digital signals from the sensors were conditioned for the counter/timer input.

\section{OPTO 22 Input Module (OPTO 22)}

The OPTO 22 Input Module (OPTO 22) served as an optically coupled interface module. Valve status was monitored as a 24 VAC signal from the GHP control system. The OPTO 22 converted the 0 to 24 VDC signal to a 0 to 5 VDC signal which could be read by the V0 board.

\section{Engine Sensor Interface Board (RB)}

The RB board powered the engine hour meter, the barometric pressure transducer, and the OPTO 22 board. The RB board also conditioned the pulse width modulation (PWM) output from the ECS-3 and produced a 0 to 5 VDC analog output for engine rpm.

\section{IBM PC-XT and the Gas Heat Puimp DAS Monitoring Program}

The DAS made use of an IBM PC-XT equipped with a modem, a MetraByte CTM-05 multifunction counter/timer, and a MetraByte DAS-8 analog to digital input board. The monitoring software for the heat pump DAS was written in MicroSoft Quick Basic and was custom developed for this field testing program. The program continuously sampled all analog inputs from the DAS up to 20 times a second. The samples were used to update the display every 5 seconds. Samples that were displayed are shown in Figures I-6 through I-9. The data were logged to disk approximately every 10 to 15 minutes depending on the mode of the system. During standby modes the interval was increased to 30 minutes to minimize the size of the data files. At any point should the GHP change modes the program averaged the data taken during the elapsed period and recorded it.

A Practical Peripherals 2400 Baud modem was installed in the computer at each of the sites. This allowed authorized personnel to remotely access the site information for troubleshooting and data retrieval. Access was linked via the commercial communications software, Carbon Copy. During a link session the local computer could display the current screen at the site. Display screens could be changed at the site through the remote link. The communication link served as a means to upload or download files to or from the site. SAIC also used the communication link for daily retrieval of the GHP performance data.

\section{Operating Mode}

To determine the operating mode of the heat pump, the DAS monitors the status of the system. The mode depends upon the status of the engine, indoor blower, coolant valve, reversing valve, auxiliary heater, and the W7505 Controller advisory signal. Solenoid valves are used to control the flow of coolant and refrigerant within the heat pump. Voltage at the solenoids controlling these valves is used 
to determine valve control system status. Table I-4 lists the conditions used to determine the GHP modes in the DAS program. Table I -4 also shows the predominant operating modes of the GHP. 
GEHP Data Acquisition PC screen 1

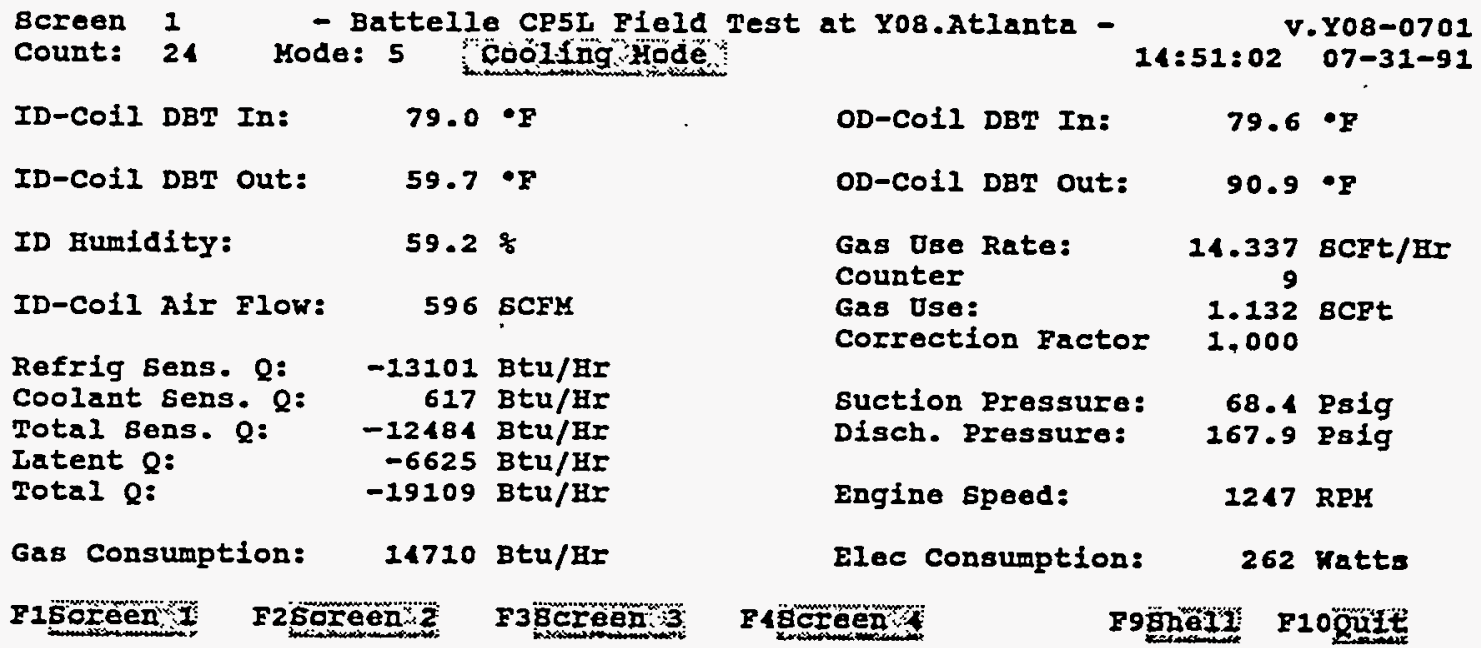

FIGURE 1-6. GHP DATA ACQUISITION PC SCREEN 1

GEHP Data Acquisition PC Bcreen 4

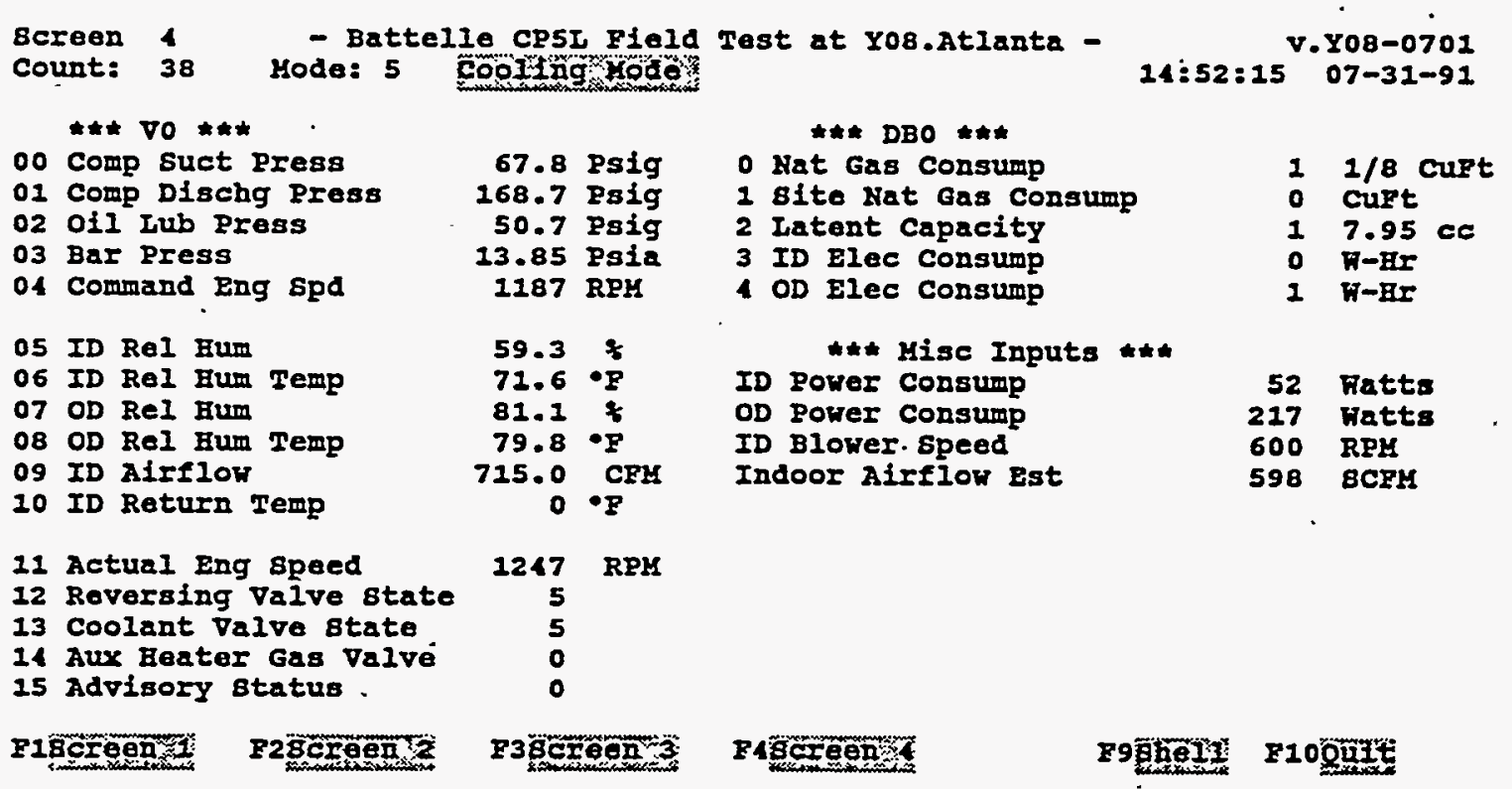

FIGURE I-7. GHP DATA ACQUISITION PC SCREEN 2 
GEHP Data Acquisition PC Bcreen 2

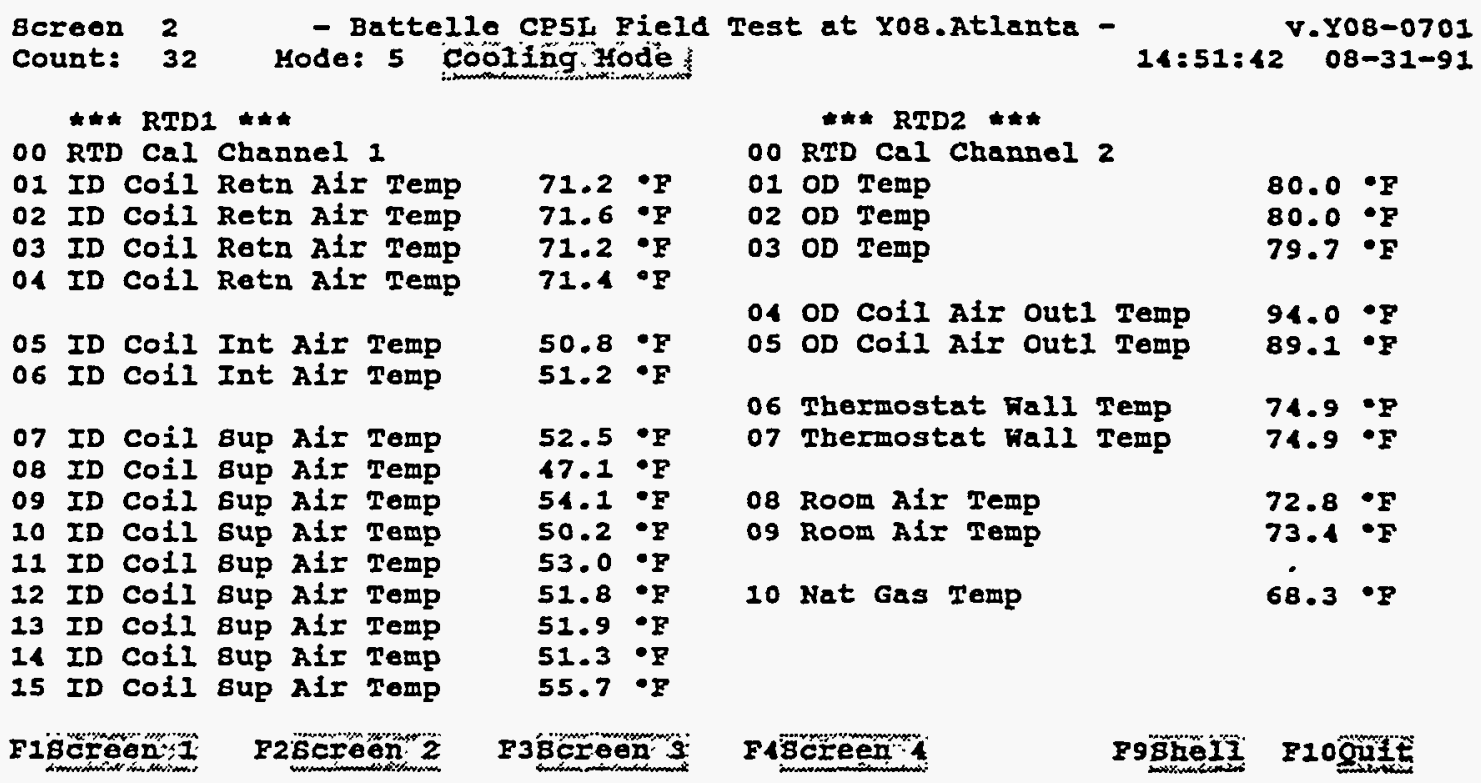

FIGURE I-8. GHP DATA ACQUISITION PC SCREEN 3

GEHP Data Acquisition PC Bcreen 3

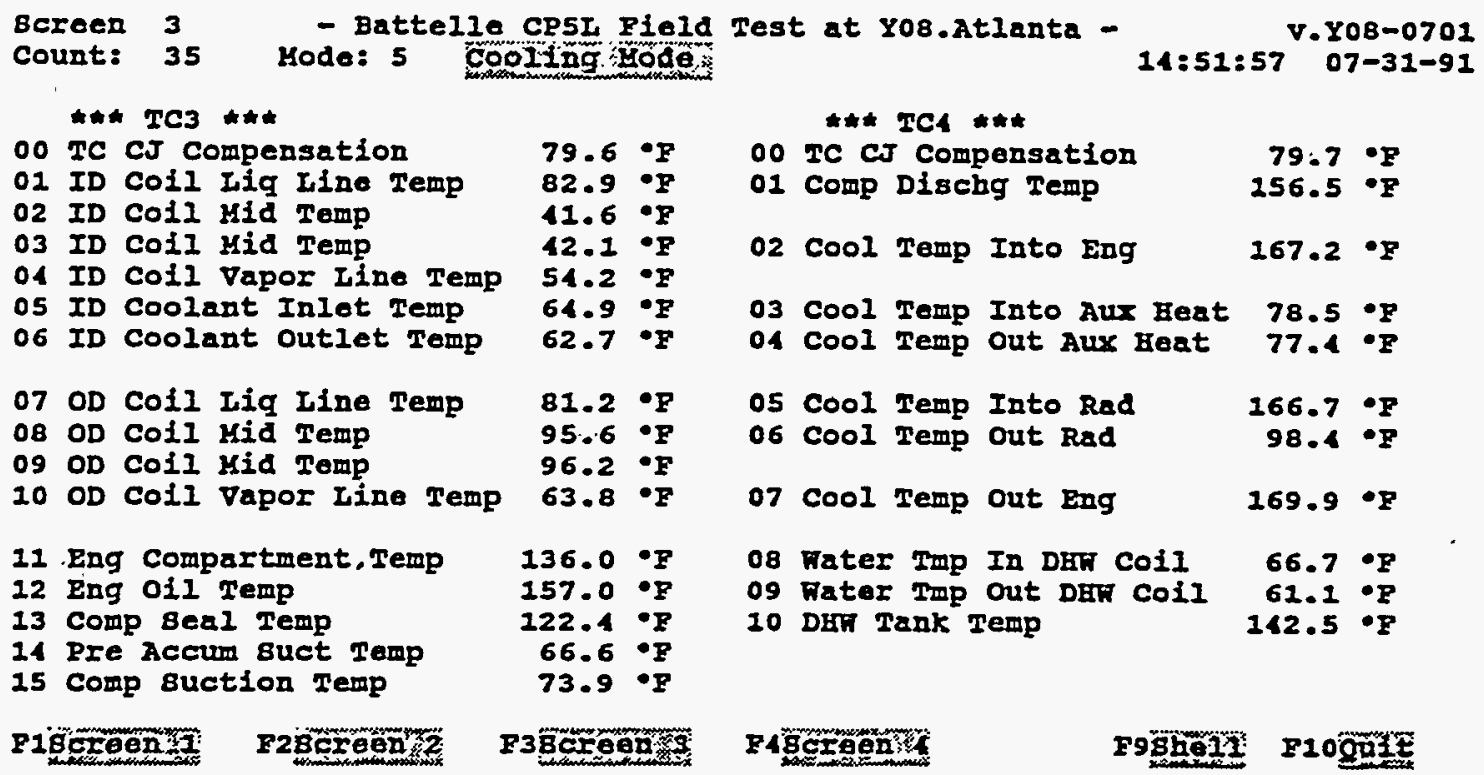

FIGURE I-9. GHP DATA ACQUISITION PC SCREEN 4 
TABLE I-4. GHP MODES AND SYSTEM STATES

\begin{tabular}{|c|c|c|c|c|c|c|c|}
\hline MOOE & DISPLAY & $\begin{array}{l}\text { ADVIS } \\
\text { STATE } \\
\end{array}$ & $\begin{array}{c}\text { REV } \\
\text { VALVE }\end{array}$ & $\begin{array}{l}\text { AUXX } \\
\text { HTR } \\
\end{array}$ & $\begin{array}{l}\text { ENG } \\
\text { STAT } \\
\end{array}$ & $\begin{array}{l}\text { BLUR } \\
\text { STATE } \\
\end{array}$ & $\begin{array}{l}\text { COOL } \\
\text { VALVE }\end{array}$ \\
\hline $\begin{array}{l}0 \\
0 \\
0 \\
1 \\
2 \\
3 \\
4 \\
4 \\
5 \\
6 \\
7 \\
8\end{array}$ & $\begin{array}{c}\text { Standby } \\
\text { Standby (Fan On, Cool) } \\
\text { Standby (Fan On, Heat) } \\
\text { Heating (Eng Only) } \\
\text { Heating (Eng \& Aux Htr) } \\
\text { Heating (Aux Htr Only) } \\
\text { ID Fan Overrun (Heat) } \\
\text { ID Fan Overrun (Cool) } \\
\text { Cool ing Hode } \\
\text { Defrost (Eng Only) } \\
\text { Defrost (Eng \& Aux Htr) } \\
\text { Engine Down - Advisory }\end{array}$ & $\begin{array}{l}\text { off } \\
\text { off } \\
\text { off } \\
\text { off } \\
\text { off } \\
\text { off } \\
\text { off } \\
\text { off } \\
\text { off } \\
\text { off } \\
\text { off } \\
\text { on }\end{array}$ & $\begin{array}{l}\text { on } \\
\text { on } \\
\text { off } \\
\text { off } \\
\text { off } \\
\text { off } \\
\text { off } \\
\text { on } \\
\text { on } \\
\text { on } \\
\text { on } \\
\text { on/off }\end{array}$ & $\begin{array}{l}\text { on/off } \\
\text { on/off } \\
\text { off } \\
\text { off } \\
\text { on } \\
\text { on } \\
\text { off } \\
\text { on/off } \\
\text { on/off } \\
\text { off } \\
\text { on } \\
\text { on/off }\end{array}$ & $\begin{array}{l}\text { off } \\
\text { off } \\
\text { off } \\
\text { on } \\
\text { on } \\
\text { off } \\
\text { off } \\
\text { off } \\
\text { on } \\
\text { on } \\
\text { on } \\
\text { off }\end{array}$ & $\begin{array}{l}\text { on/off } \\
\text { on } \\
\text { on } \\
\text { on/off } \\
\text { on/off } \\
\text { on/off } \\
\text { on } \\
\text { on } \\
\text { on/off } \\
\text { on/off } \\
\text { on/off } \\
\text { on/off }\end{array}$ & $\begin{array}{l}\text { on/off } \\
\text { on/off } \\
\text { on/off } \\
\text { on/off } \\
\text { on/off } \\
\text { on/off } \\
\text { on/off } \\
\text { on/off } \\
\text { on } \\
\text { on/off } \\
\text { on/off } \\
\text { on/off }\end{array}$ \\
\hline
\end{tabular}




\section{Appendix C}

Performance Check by Computer Simulation 


\section{Appendix C}

\section{Performance Check by Computer Simulation}

The documentation in this appendix was provided to PNL by Battelle-Columbus. Battelle served as a subcontractor to the Gas Research Institute and had the role of installing the monitoring instrumentation on the GHP and collecting the data from that system. The following are pages from original documents produced by Battelle.

\section{Attachment 2. Performance Check of the San Antonio Triathion GHP}

$\begin{array}{lll}\text { Measured } & \text { Model Est. } & \text { Difference } \\ \text { Performance } & \text { Performance } & \end{array}$

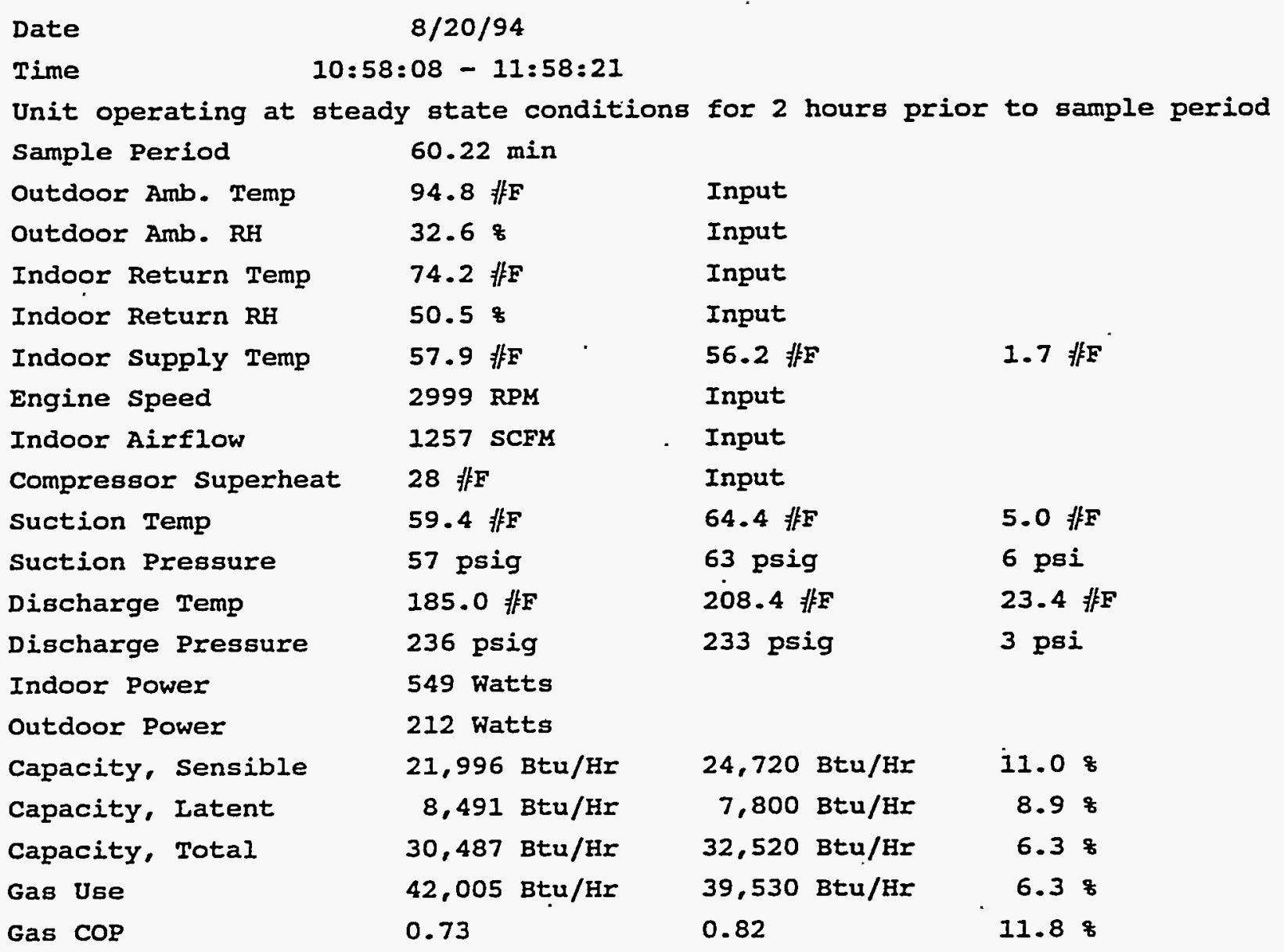


Attachment 2. Performance Check of the San Antonio Triathlon GHP (Continued)

$\begin{array}{lll}\text { Measured } & \text { Model Est. } & \text { Difference } \\ \text { Performance } & \text { Performance } & \end{array}$

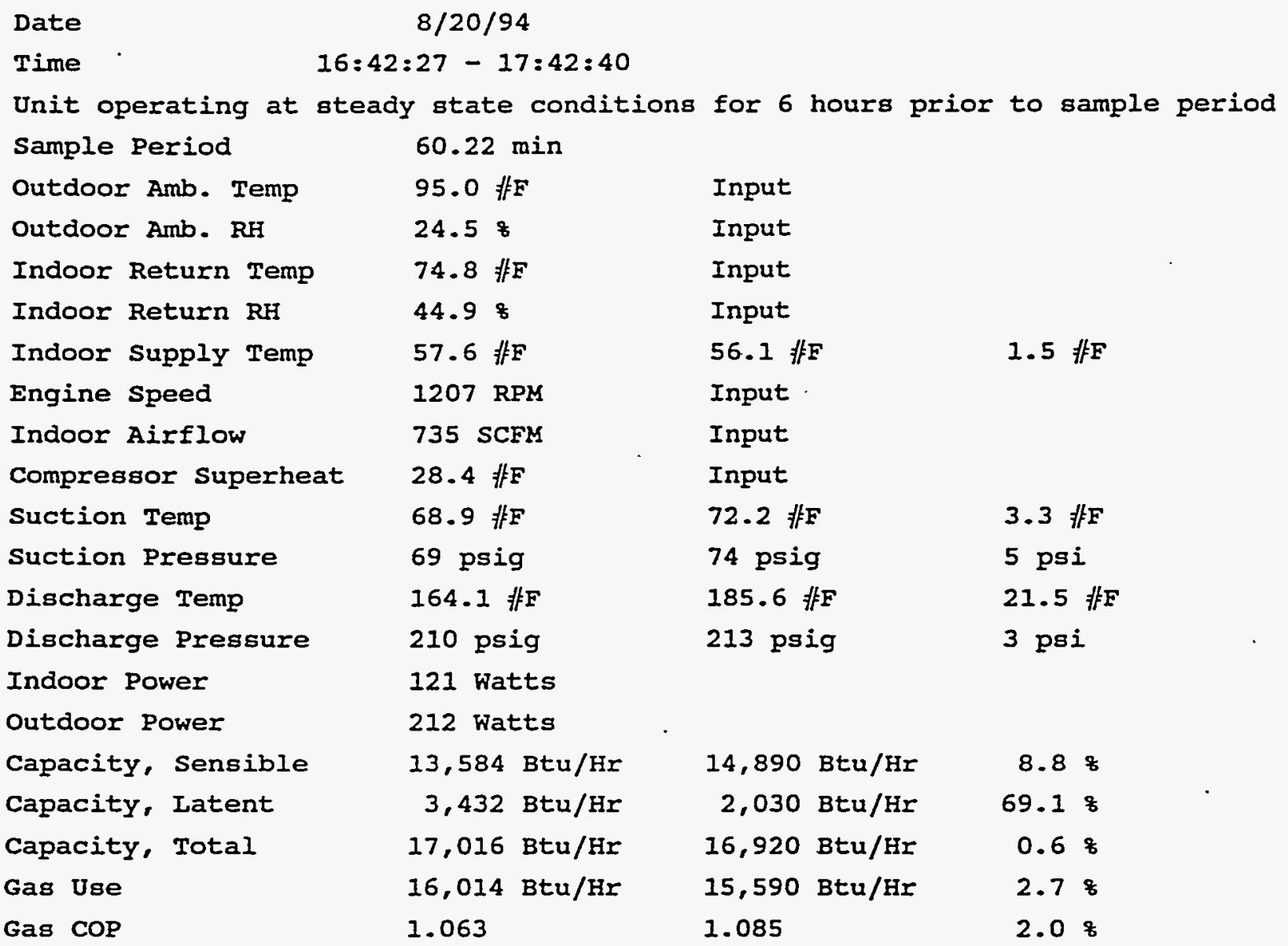




\section{Appendix D}

\section{Additional Field Data on Triathlon}





\section{Appendix D}

\section{Additional Field Data on Triathlon}

This appendix contains field data provided by Battelle-Columbus. Battelle served as a subcontractor to the Gas Research Institute and had the role of installing the monitoring instrumentation on the GHP and collecting the data from that system. The following are pages from original documents produced by Battelle.

D.1 
Revised Periodic Performance Report

for San Antonio Triathlon Test Site

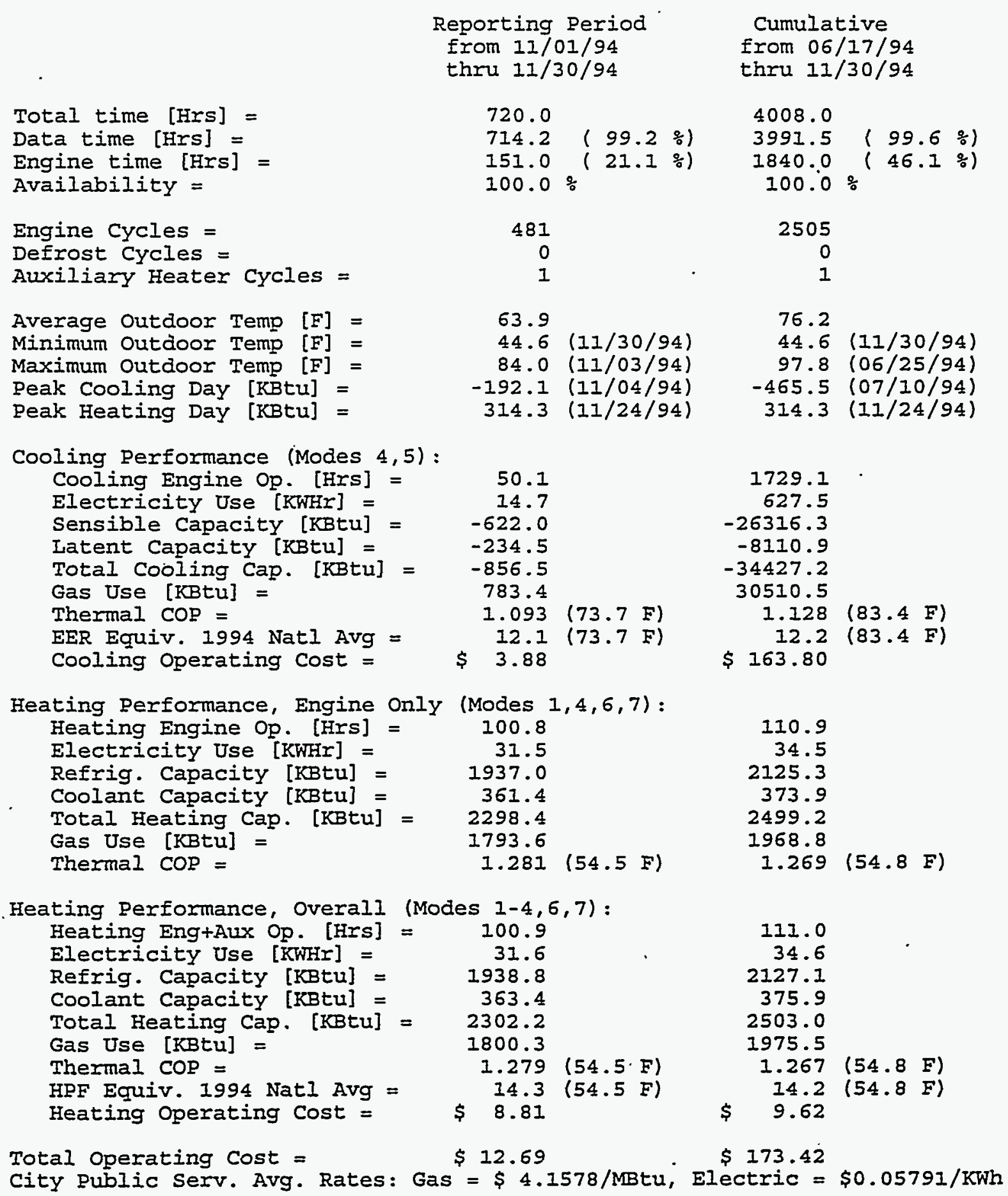




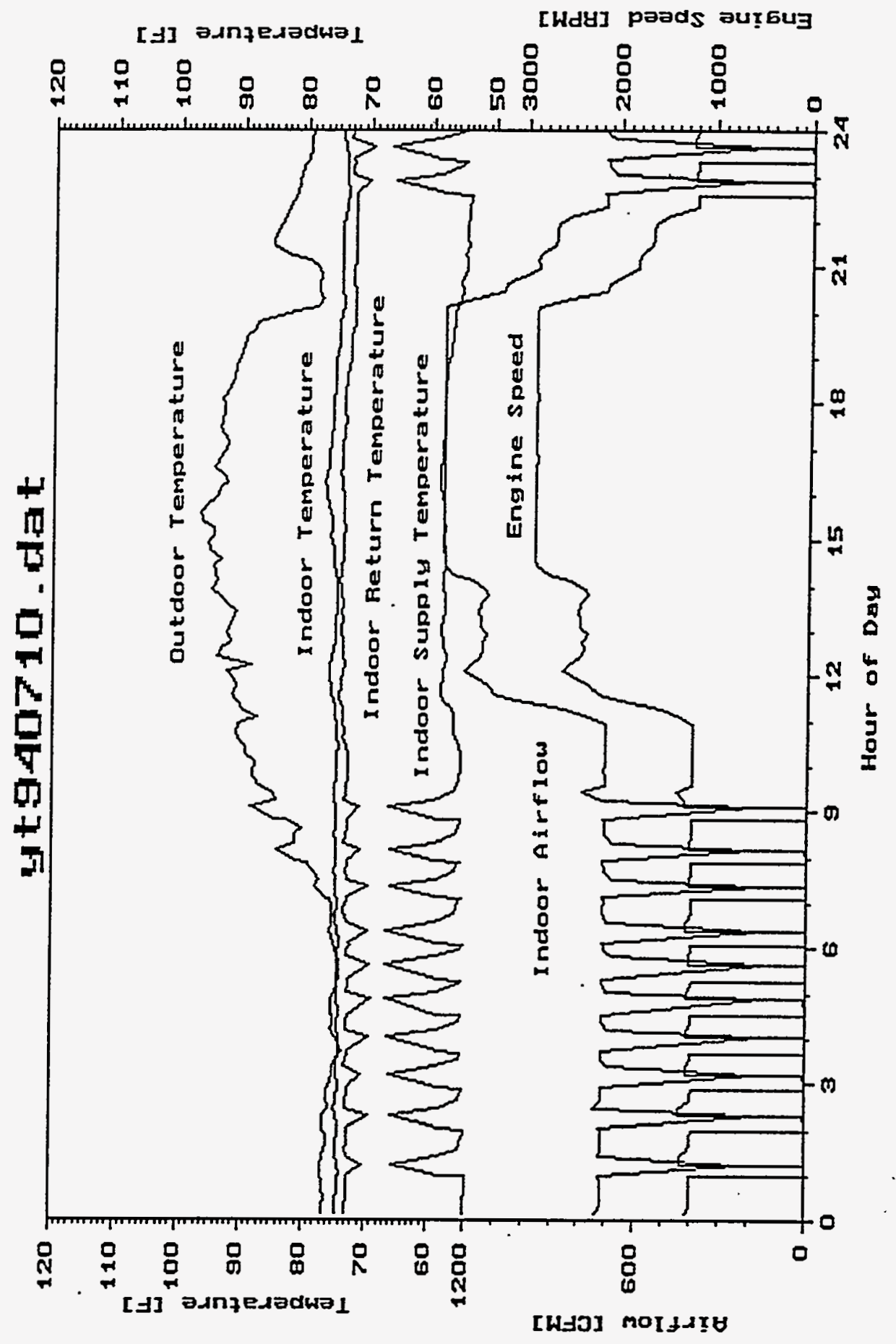

D. 3 


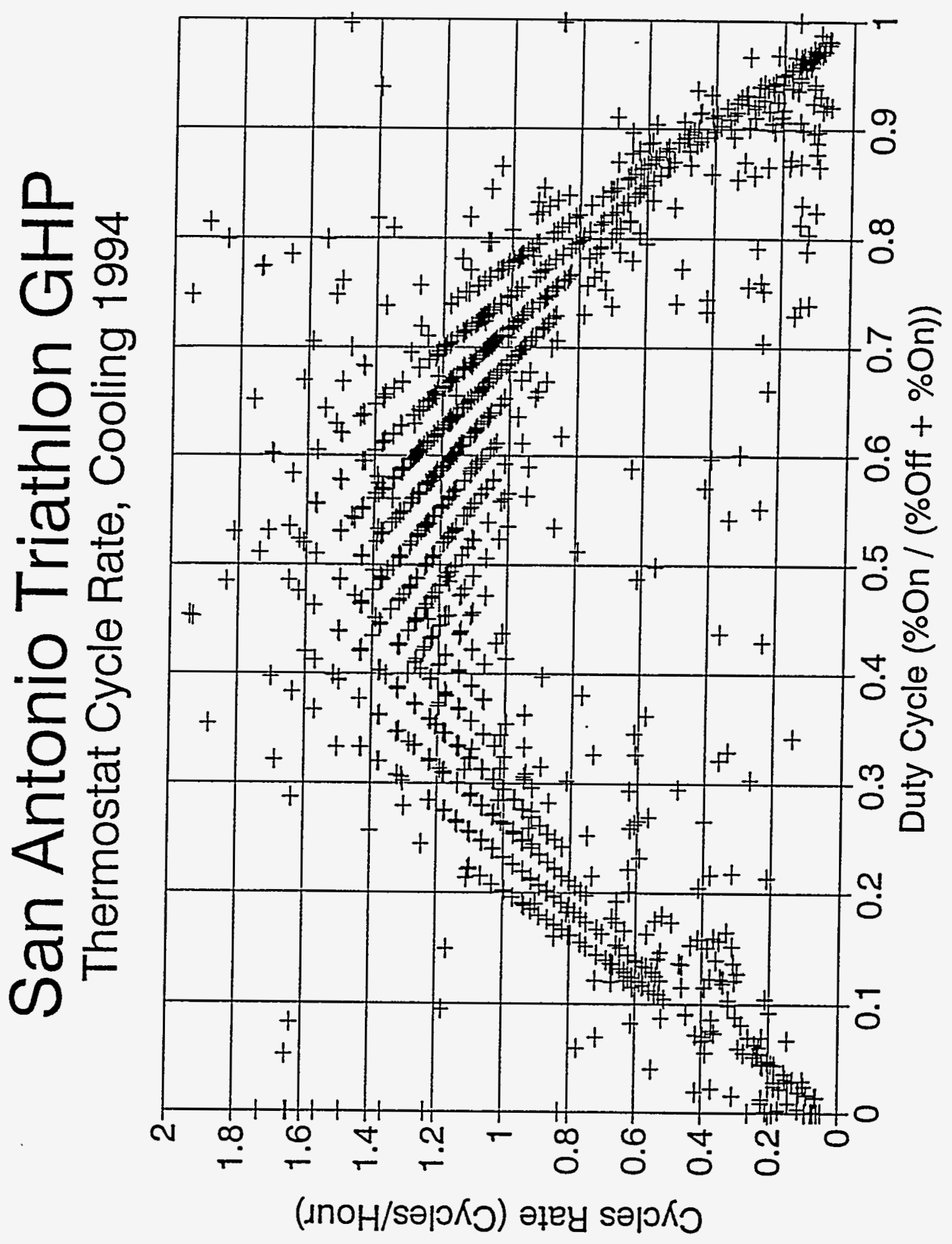



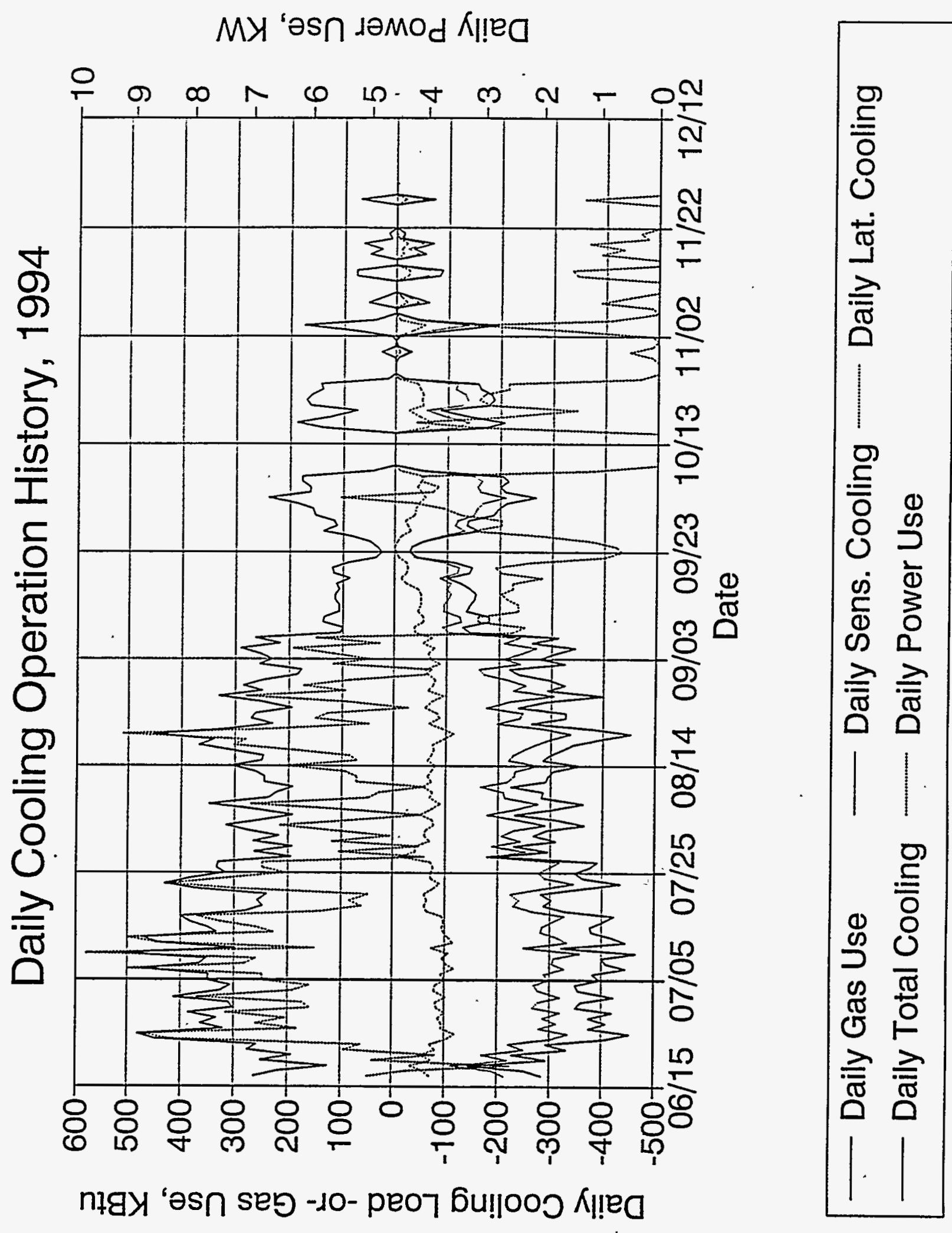


\section{San Antonio Triathlon GHP}

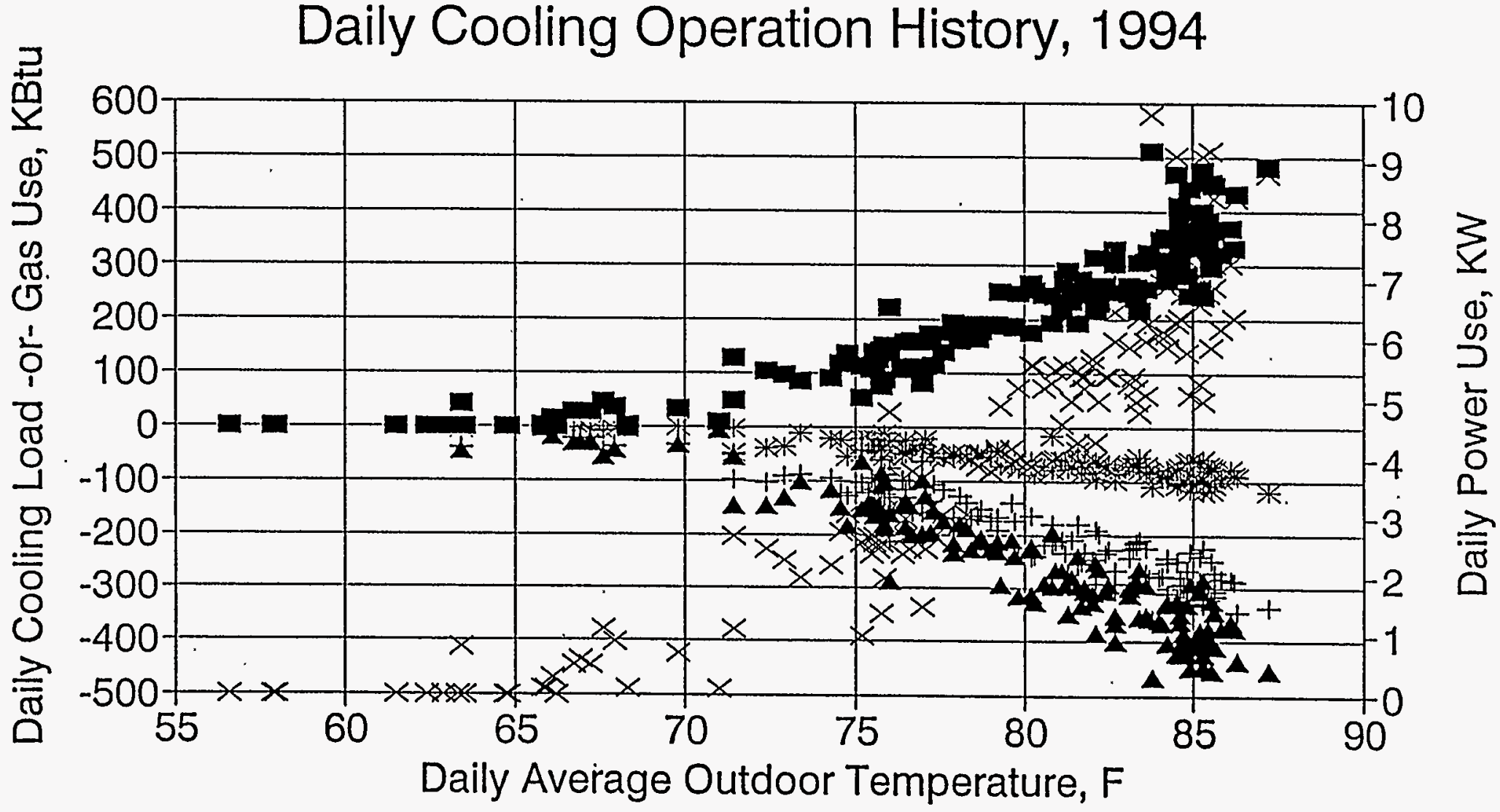

- Daily Gas Use

+ Daily Sens. Cooling * Daily Lat. Cooling

$\Delta$ Daily Total Cooling $\times$ Daily Power Use 
Daily Avg. Eng. Spd., RPM / ID Air, CFM

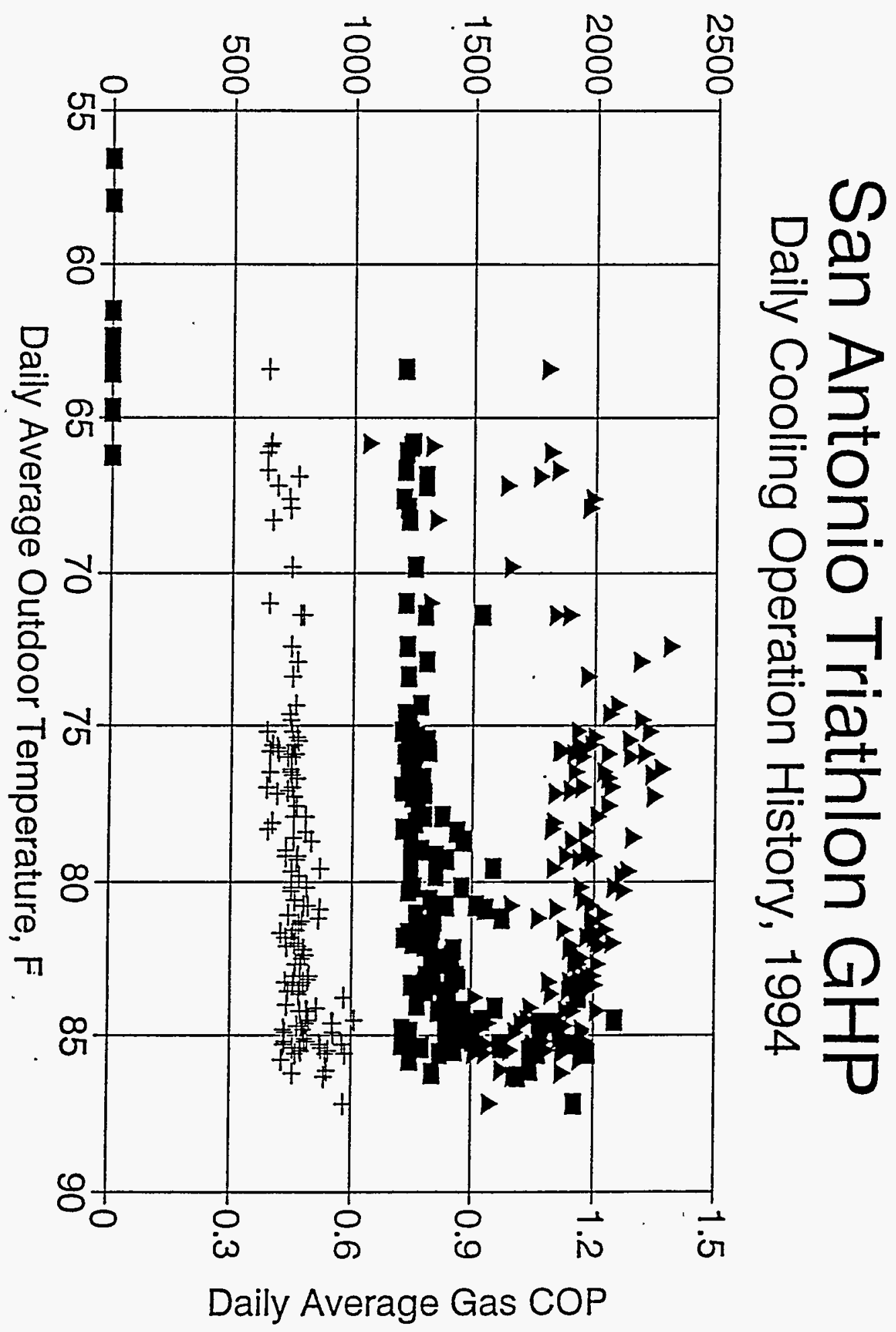




\section{San Antonio Triathlon GHP}

Daily Cooling Operation History, 1994

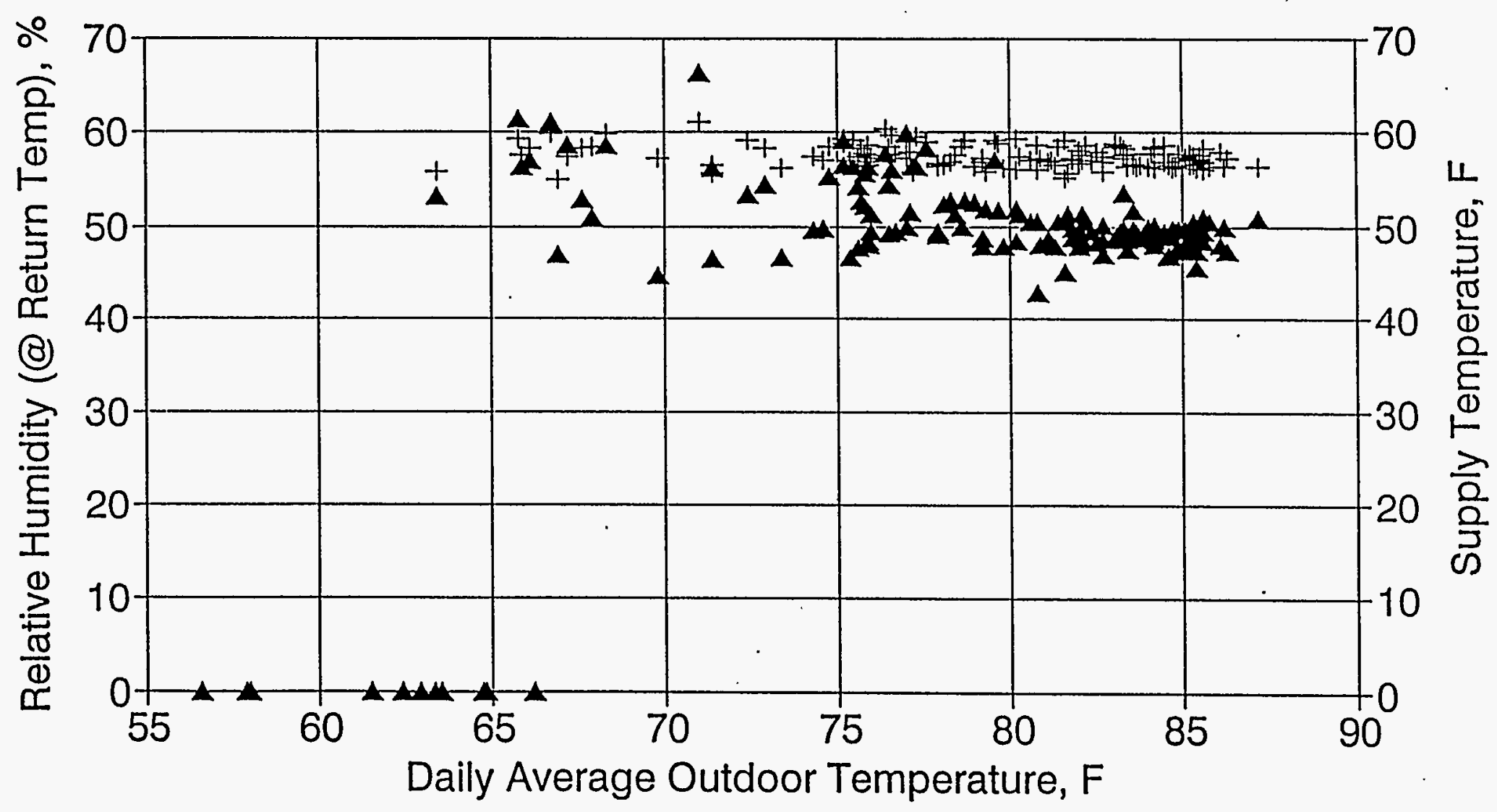

- Indoor Rel. Hum. + Supply Temperature 
Daily sumnary file - San Antonio Crada site

Site Date Total Total Total Total Min Avg Max

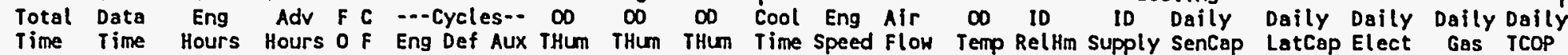
YY HM/DD/YY [HrS] [Hrs] [Hrs] [Hrs]

$[F][F][F]$ [Hrs] [RPH] [SCFM] [F] [X] [F] [KBtu] [KBtu] [KUHr] [KBtu]

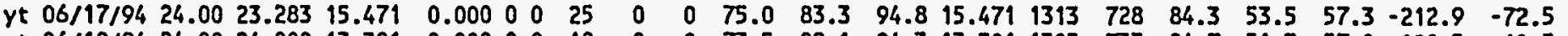

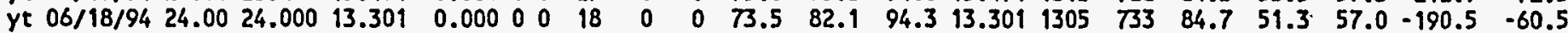

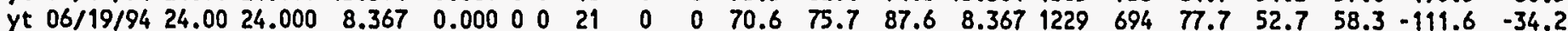

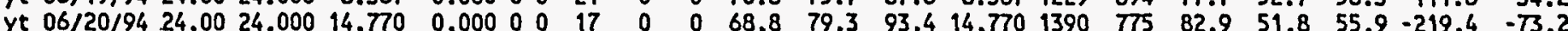

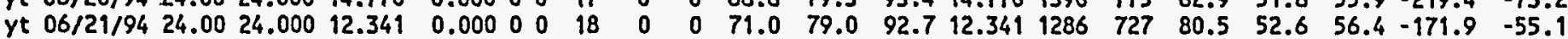

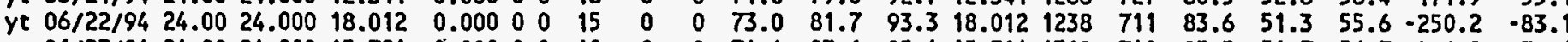

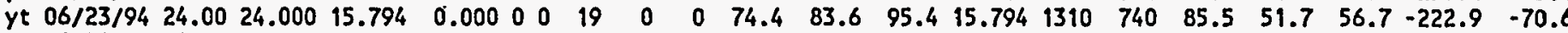

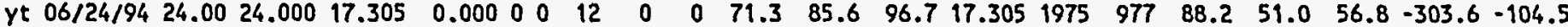

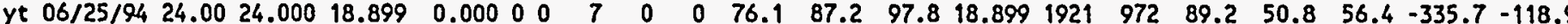
yt $06 / 26 / 9424.0024 .00020 .067 \quad 0.00000 \quad 10$ yt 0612719424.0024 .01

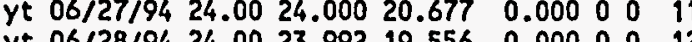

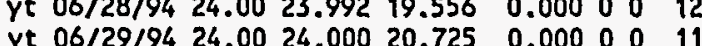

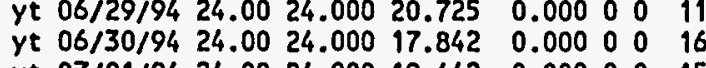
yt $07 / 01 / 94 \quad 24.00 \quad 24.00019 .442 \quad 0.00000015$ yt $07 / 02 / 9424.00 \quad 24.000 \quad 18.167 \quad 0.000 \quad 0 \quad 0 \quad 8$ yt $07 / 03 / 94 \quad 24.0024 .000 \quad 18.195 \quad 0.000000015$ yt $07 / 04 / 9424.0024 .00017 .673 \quad 0.00000014$ $y t \quad 07 / 05 / 9424.00 \quad 24.00019 .498 \quad 0.00000$ yt $07106 / 9424.0024 .00019 .6510 .00000911$ yt 0710719424.00 yt yt $07 / 08 / 9424.0024 .00019 .743 \quad 0.00000011$ $\begin{array}{rrrrrrrrr}\text { yt } & 07 / 09 / 94 & 24.00 & 24.000 & 19.235 & 0.000 & 0 & 0 & 8 \\ \text { yt } 07 / 10 / 94 & 24.00 & 24.000 & 20.261 & 0.000 & 0 & 0 & 12\end{array}$ $\begin{array}{lllllllll}\text { yt } 07 / 10 / 94 & 24.00 & 24.000 & 20.261 & 0.000 & 0 & 0 & 12 \\ \text { yt } 07 / 11 / 94 & 24.00 & 24.000 & 16.245 & 0.000 & 0 & 0 & 18\end{array}$ $\begin{array}{lllllllll}\text { yt } & 07 / 11 / 94 & 24.00 & 24.000 & 16.245 & 0.000 & 0 & 0 & 18 \\ \text { yt } & 07 / 12 / 94 & 24.00 & 24.000 & 19.210 & 0.000 & 0 & 0 & 12\end{array}$ yt $07 / 13 / 94 \quad 24.0024 .000 \quad 17.172 \quad 0.000000$ yt $07 / 14 / 94 \quad 24.0023 .596 \quad 18.489 \quad 0.000 \quad 0 \quad 0 \quad 11$ yt $07 / 15 / 94 \quad 24.00 \quad 24.000 \quad 18.166 \quad 0.000 \quad 0 \quad 0 \quad 13$ yt $07 / 16 / 94 \quad 24.0024 .000 \quad 18.379 \quad 0.000000011$ yt $07 / 17 / 9424.0024 .00019 .3540 .00000012$ yt $07 / 18 / 94 \quad 24.00 \quad 24.000 \quad 18.343 \quad 0.000000016$ yt $07 / 19 / 9424.0024 .00015 .706 \quad 0.00000021$ yt $07 / 20 / 94 \quad 24.0024 .00016 .414 \quad 0.00000016$

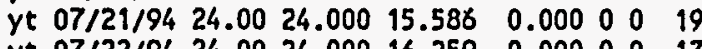
yt $07 / 22 / 94 \quad 24.0024 .00016 .259 \quad 0.00000017$ yt $07 / 23 / 94 \quad 24.0024 .00019 .636 \quad 0.000 \quad 0 \quad 0 \quad 14$ yt $07 / 24 / 94 \quad 24.00 \quad 24.00016 .099 \quad 0.000 \quad 0 \quad 0011$ yt $07 / 25 / 94 \quad 24.0024 .000 \quad 16.708 \quad 0.000 \quad 0 \quad 0 \quad 11$ yt $07 / 26 / 9424.0023 .757 \quad 18.798 \quad 0.00000014$ yt $07 / 27 / 9424.0024 .00020 .298 \quad 0.000 \quad 00012$ $\begin{array}{llllllll}\text { yt } 07 / 28 / 94 & 24.00 & 24.000 & 10.262 & 0.000 & 0 & 0 & 19\end{array}$

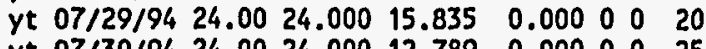

$\begin{array}{lllllllllllll}0 & 76.6 & 85.8 & 94.8 & 20.067 & 1249 & 718 & 87.3 & 50.5 & 56.4 & -281.5 & -93.8\end{array}$

$\begin{array}{llllllllllll}0 & 74.5 & 85.6 & 96.5 & 20.677 & 1370 & 771 & 87.5 & 49.4 & 56.1 & -313.1 & -94.3\end{array}$

$\begin{array}{llllllllllll}0 & 73.4 & 86.2 & 97.2 & 19.556 & 1337 & 757 & 88.2 & 50.0 & 56.3 & -287.7 & -87.0\end{array}$

$\begin{array}{llllllllllllll}0 & 73.7 & 84.8 & 96.3 & 20.725 & 1461 & 803 & 86.7 & 49.6 & 56.3 & -320.2 & -100.6\end{array}$

$\begin{array}{lllllllllllll}0 & 72.5 & 82.7 & 93.9 & 17.842 & 1367 & 772 & 85.1 & 50.1 & 56.8 & -266.8 & -84.3\end{array}$

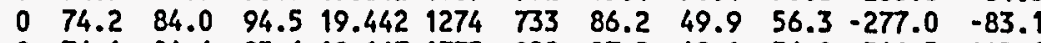

$\begin{array}{llllllllllll}0 & 76.1 & 84.6 & 93.6 & 18.167 & 1775 & 929 & 87.2 & 49.0 & 56.8 & -319.5 & -103.1\end{array}$

$\begin{array}{lllllllllllll}0 & 74.0 & 83.7 & 94.1 & 18.195 & 1403 & 787 & 86.0 & 49.4 & 56.4 & -278.1 & -78.6\end{array}$

$\begin{array}{lllllllllllll}0 & 74.7 & 83.6 & 94.1 & 17.673 & 1386 & 783 & 86.0 & 49.7 & 56.6 & -269.3 & -82.4\end{array}$

$\begin{array}{lllllllllllll}0 & 76.4 & 84.7 & 96.2 & 19.498 & 1419 & 795 & 85.8 & 49.8 & 56.5 & -297.8 & -99.2\end{array}$

$\begin{array}{llllllllllll}0 & 77.0 & 84.7 & 95.1 & 19.651 & 1394 & 778 & 85.1 & 49.8 & 56.5 & -290.8 & -99.2\end{array}$

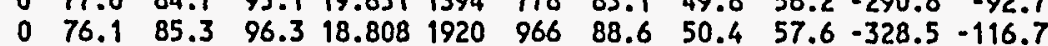

$\begin{array}{lllllllllllll}0 & 76.5 & 85.1 & 95.1 & 19.743 & 1454 & 810 & 87.3 & 49.7 & 57.4 & -306.0 & -101.9\end{array}$

$\begin{array}{lllllllllllll}0 & 76.6 & 84.2 & 95.1 & 19.235 & 1469 & 819 & 84.4 & 48.5 & 56.2 & -306.9 & -94.3\end{array}$

$\begin{array}{lllllllllllll}0 & 74.1 & 83.8 & 93.5 & 20.261 & 1941 & 970 & 85.4 & 48.8 & 56.5 & -357.3 & -108.2\end{array}$

$\begin{array}{llllllllllll}0 & 74.0 & 85.5 & 95.6 & 16.245 & 1432 & 800 & 86.9 & 49.5 & 57.2 & -248.9 & -73.6\end{array}$

$\begin{array}{llllllllllll}0 & 74.8 & 84.9 & 96.7 & 19.210 & 1782 & 925 & 86.7 & 49.8 & 57.1 & -332.3 & -113.6\end{array}$

$\begin{array}{llllllllllll}0 & 75.5 & 84.5 & 94.9 & 17.172 & 2085 & 1016 & 86.0 & 49.4 & 56.8 & -314.8 & -106.0\end{array}$

$\begin{array}{llllllllllll}0 & 77.3 & 85.2 & 94.5 & 18.489 & 1422 & 807 & 86.9 & 49.9 & 56.5 & -284.0 & -96.0\end{array}$

$\begin{array}{lllllllllllll}0 & 77.1 & 85.2 & 94.8 & 18.166 & 1503 & 820 & 85.7 & 49.8 & 57.0 & -284.7 & -94.0\end{array}$

$\begin{array}{lllllllllllll}0 & 76.5 & 85.4 & 95.6 & 18.379 & 1622 & 877 & 87.8 & 49.4 & 57.0 & -305.7 & -98.1\end{array}$

$\begin{array}{llllllllllll}0 & 74.9 & 85.3 & 95.9 & 19.354 & 1619 & 871 & 86.7 & 48.3 & 56.6 & -327.5 & -95.0\end{array}$

$\begin{array}{llllllllllll}0 & 72.8 & 84.8 & 94.5 & 18.343 & 1211 & 722 & 86.7 & 47.3 & 56.3 & -264.9 & -63.9\end{array}$

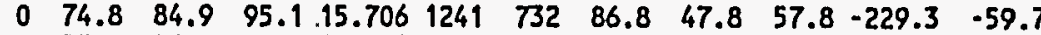

$\begin{array}{lllllllllllll}0 & 75.8 & 85.2 & 95.2 & 16.414 & 1230 & 729 & 87.5 & 47.5 & 57.2 & -239.4 & -63.5\end{array}$

$\begin{array}{lllllllllllll}0 & 75.7 & 85.3 & 95.6 & 15.586 & 1212 & 721 & 87.5 & 47.5 & 57.6 & -224.5 & -58.0\end{array}$

$\begin{array}{lllllllllllll}0 & 74.6 & 86.1 & 96.6 & 16.259 & 1740 & 905 & 88.7 & 48.0 & 57.9 & -284.5 & -76.9\end{array}$

$\begin{array}{llllllllllll}0 & 74.9 & 86.3 & 97.0 & 19.636 & 1692 & 890 & 87.5 & 47.4 & 57.2 & -345.1 & -89.9\end{array}$

$\begin{array}{llllllllllll}0 & 72.6 & 84.6 & 96.9 & 16.099 & 1822 & 919 & 85.8 & 46.8 & 56.5 & -291.5 & -71.2\end{array}$

$\begin{array}{llllllllllll}0 & 72.3 & 84.6 & 97.0 & 16.708 & 1492 & 818 & 86.1 & 46.9 & 56.8 & -276.7 & -72.0\end{array}$

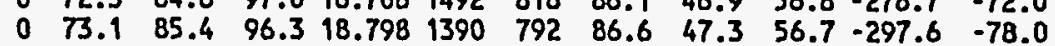

$\begin{array}{llllllllllll}0 & 78.0 & 85.4 & 95.6 & 20.298 & 1295 & 762 & 86.5 & 45.6 & 56.2 & -319.0 & -70.8\end{array}$

$\begin{array}{llllllllllll}0 & 70.8 & 80.8 & 92.5 & 10.262 & 1517 & 820 & 82.7 & 42.8 & 56.0 & -179.2 & -14.5\end{array}$

$\begin{array}{llllllllllll}0 & 70.2 & 81.6 & 93.6 & 15.835 & 1339 & 771 & 83.4 & 45.0 & 55.2 & -253.4 & -41.6\end{array}$

$\begin{array}{llllllllllll}0 . & 69.7 & 79.2 & 88.8 & 12.789 & 1245 & 732 & 80.3 & 47.8 & 56.8 & -188.9 & -41.2\end{array}$

$\begin{array}{llllllllllllll}0 & 73.7 & 80.2 & 89.4 & 15.121 & 1453 & 817 & 81.5 & 48.3 & 56.0 & -242.5 & -68.8\end{array}$
$5.0 \quad 261.4-1.092$ $4.3 \quad 218.2-1.150$ $2.5 \quad 124.1-1.175$ $4.9250 .8-1.967$ $3.8 \quad 191.6-1.185$ $5.4 \quad 275.9-1.208$ $5.1257 .3-1.141$ $8.4 \quad 448.0-0.911$ $8.8 \quad 480.0 \quad-0.947$ $6.2320 .2-1.172$ $6.9362 .0-1.126$ $6.4 \quad 333.1-1.125$ $7.4 \quad 385.7-1.091$ $6.0 \quad 303.6-1.157$ $6.1310 .7-1.159$ $7.9 \quad 412.5-1.024$ $6.3 \quad 324.4-1.100$ $6.0 \quad 308.3-1.141$ $6.8 \quad 350.1-1.134$ $6.8 \quad 348.6-1.100$ $9.1 \quad 474.3 \quad-0.939$ $7.1365 .2-1.117$ $6.9353 .4-1.135$ $9.8 \quad 511.0-0.911$ $5.9296 .6-1.087$ $8.6 \quad 442.0-1.009$ $9.1 \quad 469.7=0.896$ $6.6 \quad 331.9-1.145$ $6.9349 .9-1.083$ $7.5383 .4-1.053$ $7.9399 .7-1.057$ $5.8 \quad 280.2-1.173$ $5.1246 .2-1.174$ $5.3256 .9-1.180$ $5.0 \quad 240.7-9.173$ $\begin{array}{llll}7.3 & 369.4 & -0.978\end{array}$ $8.4 \quad 431.6-1.008$ $7.4 \quad 383.7-0.945$ $6.4318 .1-1.096$ $6.8 \quad 331.3-1.134$ $6.8330 .1-1.181$ $4.0 \quad 194.2 \quad-0.998$ $5.5 \quad 261.0-1.131$ $\begin{array}{lll}4.1 & 191.4 & -1.202 \\ 5.6 & 265.6 & -1.172\end{array}$ yt $07 / 31 / 94 \quad 24.00 \quad 24.000 \quad 15.121 \quad 0.00000015$ 
yt $08 / 01 / 94 \quad 24.00 \quad 23.802 \quad 14.121 \quad 0.00000020$

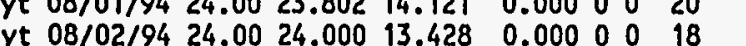

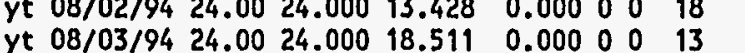
yt $08 / 04 / 94 \quad 24.0024 .000 \quad 15.346 \quad 0.000 \quad 0 \quad 0 \quad 12$ yt $08 / 05 / 9424.0024 .00012 .207 \quad 0.000 \quad 0 \quad 0 \quad 14$ $y t 08 / 06 / 9424.0024 .00016 .142 \quad 0.0000016$ $\begin{array}{llllllll}\text { yt } 08 / 07 / 94 & 24.00 & 24.000 & 16.765 & 0.000 & 0 & 0 & 14\end{array}$ yt $08 / 08 / 94 \quad 24.0024 .00014 .541 \quad 0.000 \quad 0 \quad 0020$ yt $08 / 09 / 9424.0024 .00015 .045 \quad 0.000 \quad 00025$ yt $08 / 10 / 9424.0024 .000 \quad 10.848 \quad 0.00000015$ yt $08 / 11 / 94 \quad 24.0024 .000 \quad 14.937 \quad 0.000 \quad 0 \quad 0 \quad 17$ yt $08 / 12 / 9424.0024 .000 \quad 16.191 \quad 0.000 \quad 00018$ yt $08 / 13 / 9424.0024 .00014 .829 \quad 0.00000017$ yt $08 / 14 / 9424.0024 .00018 .067 \quad 0.000000014$

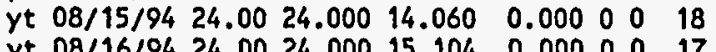
yt 0811718424.0024 .00015 .5220 .00000 17

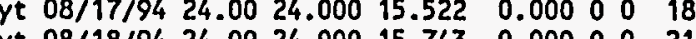
yt $08 / 18 / 9424.0024 .00015 .7430 .00000021$ yt $08 / 19 / 9424.0024 .00019 .242 \quad 0.000000016$ yt $08 / 20 / 9424.0024 .00020 .040 \quad 0.00000010$ yt $08 / 21 / 9424.0024 .00019 .067 \quad 0.0000009$ yt $08 / 22 / 94 \quad 24.0024 .00012 .974 \quad 0.00000020$ yt $08 / 23 / 94 \quad 24.0024 .000 \quad 16.112 \quad 0.00000014$ yt $08 / 24 / 94 \quad 24.0024 .00016 .611 \quad 0.00000018$ yt $08 / 25 / 9424.0023 .94712 .246 \quad 0.00000022$

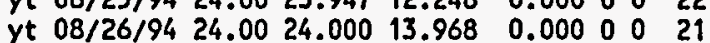
$\begin{array}{lllllllll}y t & 08 / 27 / 94 & 24.00 & 24.000 & 20.188 & 0.000 & 0 & 0 & 12\end{array}$ yt $08 / 28 / 94 \quad 24.0024 .00014 .791 \quad 0.000000015$ yt $08 / 29 / 94 \quad 24.00 \quad 24.000 \quad 15.752 \quad 0.000000016$ yt $08 / 30 / 9424.0024 .00014 .307 \quad 0.0000000$ yt $08 / 31 / 9424.0024 .00012 .259 \quad 0.000 \quad 0 \quad 0 \quad 21$ yt $09 / 01 / 9424.0024 .00011 .379 \quad 0.000 \quad 0 \quad 0 \quad 26$ yt $09 / 02 / 9424.0024 .00016 .870 \quad 0.000 \quad 0 \quad 0 \quad 20$ yt $09103 / 9424.0024 .00013 .906 \quad 0.00000 \quad 18$ yt $09104 / 9424.0024 .00016 .206 \quad 0.00000014$ yt $09 / 04 / 9424.0024 .00016 .206 \quad 0.000000$ 14

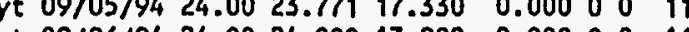
yt $09 / 06 / 9424.0024 .00013 .982 \quad 0.00000016$ yt $09 / 07 / 9424.0023 .46814 .802 \quad 0.00000020$ yt $09 / 08 / 94 \quad 24.0024 .000 \quad 7.285 \quad 0.000 \quad 0 \quad 0 \quad 22$ yt $09 / 09 / 94 \quad 24.0024 .000 \quad 6.382 \quad 0.000 \quad 0 \quad 0 \quad 15$ yt $09 / 10 / 9424.0024 .000 \quad 9.286 \quad 0.00000022$ yt $09 / 11 / 94 \quad 24.0024 .000 \quad 9.264 \quad 0.00000021$ yt $09 / 12 / 9424.0024 .000 \quad 6.790 \quad 0.00000016$

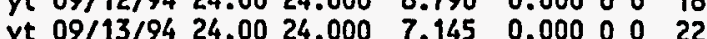
yt $09 / 14 / 9424.0024 .000 \quad 7.609 \quad 0.0000020$ yt $09 / 15 / 9424.0024 .000 \quad 7.768 \quad 0.00000018$ $\begin{array}{lllllllllllll}0 & 71.3 & 81.1 & 92.8 & 14.121 & 1268 & 742 & 81.7 & 48.7 & 56.9 & -208.0 & -59.2\end{array}$ $\begin{array}{llllllllllll}0 & 71.0 & 81.2 & 91.5 & 13.428 & 1623 & 864 & 82.8 & 48.1 & 57.1 & -231.2 & -60.9\end{array}$ $\begin{array}{lllllllllllll}0 & 72.3 & 82.7 & 92.4 & 18.511 & 1374 & 790 & 85.0 & 46.9 & 55.9 & -291.2 & -75.6\end{array}$ $\begin{array}{llllllllllll}0 & 72.3 & 79.8 & 91.9 & 15.346 & 1351 & 782 & 78.6 & 47.9 & 56.2 & -238.7 & -74.7\end{array}$ $\begin{array}{lllllllllll}71.9 & 77.9 & 90.9 & 12.207 & 1297 & 760 & 80.9 & 49.1 & 56.4 & -180.1 & -52.9\end{array}$ $\begin{array}{llllllllllll}70.6 & 81.8 & 92.9 & 16.142 & 1276 & 755 & 85.2 & 49.8 & 57.3 & -233.6 & -72.7\end{array}$ $\begin{array}{lllllllllllll}74.6 & 84.9 & 94.8 & 16.765 & 1599 & 862 & 86.8 & 49.2 & 57.7 & -274.2 & -89.9\end{array}$ $\begin{array}{lllllllllllll}76.7 & 83.3 & 93.3 & 14.541 & 1304 & 762 & 83.8 & 49.7 & 58.2 & -213.3 & -70.0\end{array}$ $\begin{array}{lllllllllll}70.5 & 76.0 & 81.7 & 15.045 & 1239 & 737 & 75.9 & 59.3 & 56.9 & -210.9 & -75.4\end{array}$ $\begin{array}{llllllllllll}71.1 & 78.4 & 89.0 & 10.848 & 1437 & 810 & 81.1 & 51.4 & 57.6 & -168.2 & -57.3\end{array}$ $\begin{array}{llllllllllll}0 & 70.9 & 80.6 & 89.8 & 14.937 & 1322 & 766 & 83.7 & 50.4 & 57.0 & -218.5 & -70.9\end{array}$ $\begin{array}{llllllllllll}0 & 72.7 & 81.8 & 90.4 & 16.191 & 1217 & 729 & 84.3 & 48.7 & 57.0 & -230.1 & -64.8\end{array}$ $\begin{array}{llllllllllll}0 & 74.1 & 82.4 & 91.0 & 14.829 & 1416 & 807 & 83.3 & 49.5 & 57.1 & -233.7 & -71.3\end{array}$

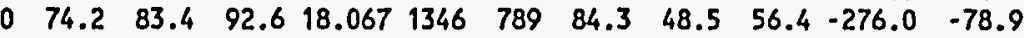
$\begin{array}{lllllllllllll}0 & 75.1 & 83.3 & 94.8 & 14.060 & 1418 & 805 & 83.4 & 48.7 & 57.5 & -221.2 & -64.0\end{array}$ $\begin{array}{lllllllllllll}0 & 73.4 & 83.1 & 94.6 & 15.104 & 1312 & 768 & 84.9 & 48.9 & 58.5 & -226.7 & -71.0\end{array}$ $\begin{array}{llllllllllll}0 & 73.6 & 84.5 & 94.7 & 15.522 & 1541 & 829 & 87.0 & 48.9 & 58.6 & -246.6 & -76.8\end{array}$ $\begin{array}{llllllllllll}0 & 75.5 & 85.6 & 95.3 & 15.743 & 1772 & 895 & 88.0 & 48.4 & 58.3 & -269.4 & -74.7\end{array}$ $\begin{array}{lllllllllll}77.1 & 85.2 & 94.9 & 19.242 & 1402 & 812 & 86.4 & 48.9 & 57.7 & -298.5 & -93.7\end{array}$ $\begin{array}{lllllllllll}75.6 & 85.5 & 96.0 & 20.040 & 1740 & 906 & 87.7 & 48.6 & 57.5 & -337.6 & -114.8\end{array}$

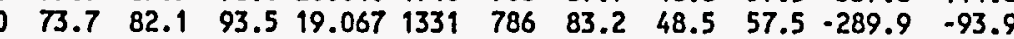
$\begin{array}{llllllllllll}0 & 73.0 & 82.2 & 92.4 & 12.974 & 1422 & 801 & 83.6 & 50.5 & 58.6 & -196.6 & -66.9\end{array}$ $\begin{array}{lllllllllllll}0 & 76.6 & 84.2 & 94.8 & 16.112 & 1361 & 791 & 85.0 & 50.1 & 58.5 & -241.3 & -86.7\end{array}$ $\begin{array}{llllllllllll}0 & 75.7 & 82.0 & 95.8 & 16.611 & 1299 & 769 & 82.9 & 49.6 & 58.1 & -244.1 & -82.7\end{array}$

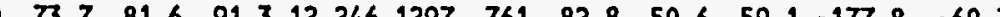

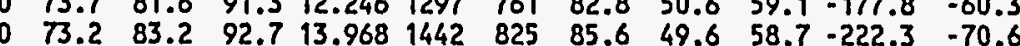
$\begin{array}{llllllllllll}0 & 74.3 & 82.7 & 93.4 & 20.188 & 1330 & 788 & 83.9 & 48.6 & 57.4 & -304.6 & -95.6\end{array}$ $\begin{array}{llllllllllll}0 & 72.5 & 82.5 & 92.6 & 14.791 & 1351 & 795 & 85.3 & 48.2 & 57.9 & -227.6 & -65.5\end{array}$ $\begin{array}{llllllllllll}0 & 75.7 & 84.2 & 94.0 & 15.752 & 1430 & 817 & 85.7 & 48.0 & 58.3 & -251.0 & -75.4\end{array}$ $\begin{array}{lllllllllllll}0 & 74.7 & 80.8 & 88.6 & 14.307 & 1393 & 809 & 81.2 & 50.5 & 58.6 & -216.9 & -78.2\end{array}$ $\begin{array}{llllllllllll}0 & 75.6 & 79.7 & 86.9 & 12.259 & 1242 & 751 & 79.5 & 51.6 & 58.8 & -173.2 & -64.6\end{array}$ $\begin{array}{llllllllllll}0 & 74.1 & 80.2 & 90.0 & 11.379 & 1259 & 751 & 80.6 & 51.9 & 59.4 & -161.6 & -59.6\end{array}$ $\begin{array}{llllllllllll}0 & 72.8 & 80.3 & 90.7 & 16.870 & 1237 & 753 & 81.8 & 51.3 & 57.4 & -239.0 & -86.1\end{array}$ $\begin{array}{llllllllllll}0 & 71.5 & 81.4 & 91.5 & 13.906 & 1333 & 785 & 83.8 & 50.4 & 58.4 & -209.5 & -68.5\end{array}$

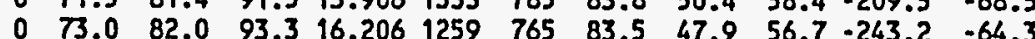
$\begin{array}{lllllllllllll}0 & 70.7 & 81.3 & 92.7 & 17.330 & 1343 & .798 & 84.0 & 47.9 & 56.6 & -270.9 & -75.6\end{array}$ $\begin{array}{lllllllllllll}0 & 73.6 & 83.4 & 93.6 & 13.982 & 1250 & 759 & 84.8 & 47.5 & 57.8 & -209.4 & -53.0\end{array}$ $\begin{array}{llllllllllll}0 & 68.6 & 83.1 & 94.0 & 14.802 & 1434 & 828 & 84.9 & 48.6 & 58.8 & -240.4 & -71.3\end{array}$ $\begin{array}{llllllllllll}0 & 70.7 & 72.4 & 75.5 & 7.285 & 1227 & 745 & 72.1 & 53.4 & 59.2 & -103.8 & -39.7\end{array}$ $\begin{array}{lllllllllllll}0 & 69.0 & 72.9 & 79.4 & 6.382 & 1306 & 771 & 73.0 & 54.5 & 58.2 & -91.8 & -37.3\end{array}$ $\begin{array}{llllllllllllll}0 & 68.0 & 74.8 & 84.6 & 9.286 & 1237 & 746 & 76.7 & 55.4 & 58.5 & -126.9 & -54.0\end{array}$ $\begin{array}{llllllllllll}0 & 71.0 & 75.9 & 84.9 & 9.264 & 1237 & 750 & 77 . & 56.4 & 58.7 & -126.5 & -54.9\end{array}$ $\begin{array}{llllllllllll}0 & 71.8 & 75.5 & 82.8 & 6.790 & 1309 & 778 & 76.2 & 56.3 & 59.1 & -94.0 & -43.8\end{array}$ $\begin{array}{llllllllllll}0 & 72.6 & 76.4 & 87.2 & 7.145 & 1233 & 747 & 76.5 & 57.7 & 60.3 & -95.1 & -48.8\end{array}$ $\begin{array}{llllllllllll}0 & 71.8 & 75.2 & 85.1 & 7.609 & 1245 & 756 & 75.2 & 56.6 & 59.3 & -103.1 & -48.6\end{array}$ $\begin{array}{lllllllllllll}0 & 71.4 & 77.3 & 86.4 & 7.768 & 1253 & 763 & 78.3 & 56.4 & 59.5 & -105.9 & -49.5\end{array}$
$4.6 \quad 217.6-1.228$ $5.6 \quad 274.2-1.065$ $6.5 \quad 314.2 \cdot 1.167$ $5.2 \quad 246.7-1.270$ $4.1 \quad 192.1-1.213$ $5.4258 .6-1.184$ $7.4258 .6 \cdot 1.184$ $7.0347 .2-9.049$ $4.0238 .1-1.190$ $4.8 \quad 221.0-1.295$ $4.0 \quad 191.1-1.180$ $5.2 \quad 245.8-1.178$ $5.2244 .9-1.204$ $5.4263 .0-1.160$ $6.4305 .4-1.162$ $5.2248 .2-1.145$ $5.2249 .2-1.145$ $6.3247 .8-1.201$ $6.3 \quad 310.3-1.042$ $\begin{array}{llll}7.3 & 367.5 & -0.936\end{array}$ $7.1 \quad 340.9-1.150$ $9.2 \quad 453.3 \quad-0.998$ $6.7 \quad 314.5-1.220$ $5.0230 .4-1.144$ $5.9271 .0-1.210$ $5.7261 .7-1.249$ $4.7261 .7-1.249$ $5.4251 .2-1.166$ $7.1330 .8-1.210$ $5.4 \quad 249.9-1.173$ $6.1283 .6-1.151$ $5.3 \quad 246.3-1.198$ $4.0 \quad 184.8-1.286$ $3.9 \quad 176.4-1.254$ $5.6 \quad 255.4-1.273$ $5.6 \quad 255.4-1.273$ 5.0232. $5.6253 .9-1.219$ $6.3 \quad 289.0-1.199$ $4.8 \quad 218.0-1.203$ $5.9 \quad 263.2-1.184$ $2.5 \quad 103.2-1.390$ $2.3 \quad 98.3-1.314$ $3.1 \quad 137.2-1319$ $3.1 \quad 135.3-1.326$ $2.4 \quad 106.8-1.291$ $2.4 \quad 105.3-1.367$ $2.6 \quad 113.2-1.339$ $2.7 \quad 115.1-1.35$ 
Daily sumary file - San Antonio Crada site, cont'd

Total Totsl Total

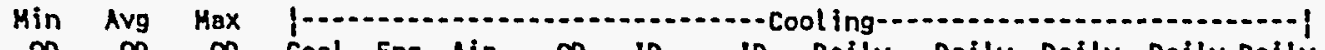

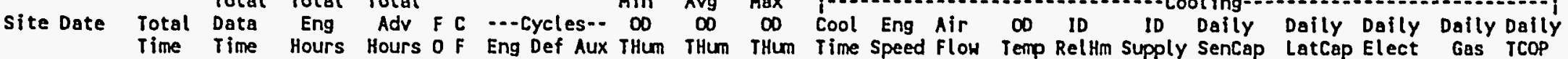

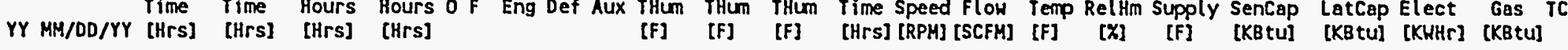

yt $09 / 16 / 9424.0024 .000 \quad 7.354 \quad 0.00000021$ $\begin{array}{lllllllll}\text { yt } 09 / 17 / 94 & 24.00 & 24.000 & 7.562 & 0.000 & 0 & 0 & 24\end{array}$ yt $09 / 18 / 94 \quad 24.0024 .000 \quad 5.872 \quad 0.000000015$ yt $09 / 19 / 9424.0024 .000 \quad 7.880 \quad 0.00000017$ yt $09 / 20 / 94 \quad 24.0023 .724 \quad 8.249 \quad 0.000000022$ yt $09 / 21 / 9424.0024 .000 \quad 6.042 \quad 0.000000017$ yt $09 / 22 / 94 \quad 24.0024 .000 \quad 2.452 \quad 0.00000011$ yt $09 / 23 / 94 \quad 24.0024 .000 \quad 1.723 \quad 0.000 \quad 0 \quad 0 \quad 5$ yt $09 / 24 / 9424.0024 .000 \quad 2.121 \quad 0.00000$ yt $09 / 25 / 9424.0024 .000 \quad 3.179 \quad 0.00000$ yt $09 / 26 / 9424.0024 .000 \quad 5.783 \quad 0.000000013$ yt $09 / 27 / 94 \quad 24.0024 .000 \quad 8.935 \quad 0.00000019$ yt $09 / 28 / 94 \quad 24.0024 .000 \quad 7.686 \quad 0.000000$ yt $09 / 29 / 9424.0024 .000 \quad 7.547 \quad 0.000 \quad 0 \quad 0 \quad 16$ yt $09 / 30 / 94 \quad 24.0024 .000 \quad 9.913 \quad 0.000000016$ $\begin{array}{llllllllll}y t & 10 / 01 / 94 & 24.00 & 24.000 & 10.693 & 0.000 & 0 & 0 & 20\end{array}$ yt $10 / 02 / 94 \quad 24.0024 .00011 .015 \quad 0.000 \quad 0 \quad 0 \quad 18$ yt $10 / 03 / 94 \quad 24.0024 .00012 .454 \quad 0.000 \quad 0 \quad 0 \quad 14$ $\begin{array}{lllllllll}\text { yt } 10 / 04 / 94 & 24.00 & 24.000 & 10.986 & 0.000 & 0 & 0 & 23\end{array}$ $\begin{array}{llllllllll}y t & 10 / 05 / 94 & 24.00 & 24.000 & 10.423 & 0.000 & 0 & 0 & 23\end{array}$ yt 10/06/94 $24.00 \quad 23.999 \quad 10.591 \quad 0.000 \quad 0 \quad 0 \quad 13$ yt $10 / 07 / 94 \quad 24.0022 .661 \quad 9.889 \quad 0.00000022$ yt $10 / 08 / 94 \quad 24.00 \quad 24.000 \quad 3.130 \quad 0.000 \quad 0 \quad 0 \quad 12$

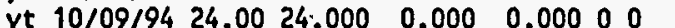
yt $10 / 10 / 9424.0023 .750 \quad 0.000 \quad 0.00000$ $\begin{array}{lllllll}\text { yt } 10 / 11 / 94 & 24.00 & 24.000 & 0.000 & 0.000 & 0 & 0 \\ \text { yt } 10 / 12 / 94 & 24.00 & 24.000 & 0.000 & 0.000 & 0 & 0\end{array}$ $\begin{array}{llllllll}\text { yt } & 10 / 12 / 94 & 24.00 & 24.000 & 0.000 & 0.000 & 0 & 0 \\ \text { yt } & 10 / 13 / 94 & 24.00 & 24.000 & 0.000 & 0.000 & 0 & 0\end{array}$ $\begin{array}{lllllll}\text { yt } 10 / 14 / 94 & 24.0024 .000 & 0.000 & 0.000 & 0 & 0\end{array}$ $\begin{array}{llllllll}\text { yt } 10 / 16 / 94 & 24.00 & 23.565 & 8.799 & 0.000 & 0 & 0 & 12\end{array}$

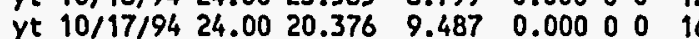
yt $10 / 18 / 9424.0023 .813 \quad 6.848 \quad 0.000 \quad 00013$ $\begin{array}{llllllll}\text { yt } 10 / 18 / 94 & 24.00 & 23.813 & 6.848 & 0.000 & 0 & 0 & 13 \\ \text { yt } 10 / 19 / 94 & 24.00 & 24.000 & 4.935 & 0.000 & 0 & 0 & 11\end{array}$ $\begin{array}{llllllll}\text { yt } 10 / 19 / 94 & 24.00 & 24.000 & 4.935 & 0.000 & 0 & 0 & 11 \\ \text { yt } 10 / 20 / 94 & 24.00 & 24.000 & 10.205 & 0.000 & 0 & 0 & 10\end{array}$ $\begin{array}{llllllll}\text { yt } 10 / 20 / 94 & 24.00 & 24.000 & 10.205 & 0.000 & 0 & 0 & 10 \\ \text { yt } 10 / 21 / 94 & 24.00 & 23.316 & 11.435 & 0.000 & 0 & 0 & 23\end{array}$

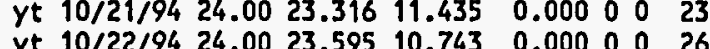
$\begin{array}{lllllllll}y t & 10 / 22 / 94 & 24.00 & 23.595 & 10.743 & 0.000 & 0 & 0 & 26 \\ y t & 10 / 23 / 94 & 24.00 & 23.651 & 9.157 & 0.000 & 0 & 0 & 18\end{array}$ $\begin{array}{lllllllll}y t & 10 / 24 / 94 & 24.00 & 23.391 & 8.808 & 0.000 & 0 & 0 & 15\end{array}$ yt $10 / 25 / 9424.0024 .000 \quad 1.151 \quad 0.00000$ yt $10 / 26 / 9424.0024 .000 \quad 0.790 \quad 0.00000$

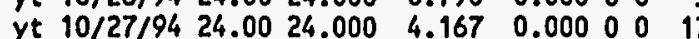
yt $10 / 28 / 9424.0024 .000 \quad 4.048 \quad 0.00000017$ yt $10 / 29 / 9424.0024 .0001 .336 \quad 0.00000$ $\begin{array}{llllllll}y t & 10 / 30 / 94 & 24.00 & 24.000 & 1.780 & 0.000 & 0 & 0 \\ y t & 10 / 31 / 94 & 24.00 & 23.891 & 0.262 & 0.000 & 0 & 0\end{array}$

$\begin{array}{llllllllllll}0 & 71.8 & 76.6 & 86.7 & 7.354 & 1239 & 752 & 76.3 & 56.0 & 59.7 & -100.4 & -44.3\end{array}$ $\begin{array}{llllllllllll}71.4 & 77.1 & 86.3 & 7.562 & 1210 & 736 & 79.1 & 51.5 & 57.9 & -106.7 & -20.6\end{array}$

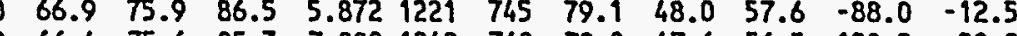
$\begin{array}{lllllllllllll}66.4 & 75.6 & 85.3 & 7.880 & 1249 & 760 & 78.0 & 47.6 & 56.5 & -120.2 & -20.8\end{array}$ $\begin{array}{llllllllllll}0 & 63.0 & 74.6 & 84.7 & 8.249 & 1216 & 744 & 76.4 & 49.7 & 57.9 & -121.4 & -25.3\end{array}$ $\begin{array}{lllllllllllll}0 & 63.6 & 74.3 & 84.1 & 6.042 & 1282 & 766 & 74.4 & 49.6 & 57.4 & -93.3 & -20.9\end{array}$

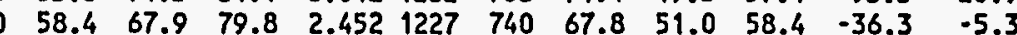
$\begin{array}{lllllllllll}54.1 & 66.9 & 78.2 & 1.723 & 1302 & 772 & 71.1 & 46.9 & 55.0 & -27.1 & -1.7\end{array}$ $\begin{array}{llllllllllll}0 & 59.3 & 69.8 & 80.0 & 2.121 & 1256 & 748 & 75.3 & 44.7 & 57.3 & -32.6 & 0.0\end{array}$ $\begin{array}{lllllllllllll}0 & 58.7 & 71.4 & 85.2 & 3.179 & 1298 & 785 & 73.4 & 46.4 & 55.7 & -50.8 & -3.4\end{array}$ $\begin{array}{llllllllllll}0 & 60.3 & 73.4 & 85.7 & 5.783 & 1230 & 754 & 77.5 & 46.6 & 56.2 & -88.2 & -12.2\end{array}$ $\begin{array}{llllllllllll}0 & 63.2 & 76.0 & 90.0 & 8.935 & 1254 & 755 & 80.7 & 49.5 & 57.3 & -131.1 & -28.5\end{array}$ $\begin{array}{llllllllllll}0 & 65.7 & 76.5 & 88.1 & 7.688 & 1235 & 748 & 78.7 & 49.2 & 58.5 & -113.4 & -23.8\end{array}$ $57.1-119.6-19.9$ $\begin{array}{lllllllllll}67.8 & 75.9 & 86.0 & 9.913 & 1260 & 768 & 78.6 & 48.4 & 56.5 & -150.7 & -36.5\end{array}$ $\begin{array}{llllllllllll}66.3 & 77.0 & 86.9 & 10.693 & 1218 & 755 & 79.0 & 49.9 & 57.2 & -156.5 & -40.1\end{array}$ $\begin{array}{llllllllllll}68.2 & 79.2 & 89.6 & 11.015 & 1349 & 781 & 81.9 & 48.8 & 57.3 & -167.3 & -43.9\end{array}$ $\begin{array}{llllllllllll}70.4 & 80.9 & 91.7 & 12.454 & 1551 & 870 & 82.9 & 48.1 & 57.3 & -210.7 & -56.5\end{array}$ $\begin{array}{llllllllllll}71.9 & 78.6 & 88.0 & 10.986 & 1242 & 759 & 79.4 & 50.0 & 58.5 & -161.9 & -49.0\end{array}$ $\begin{array}{lllllllllll}66.8 & 76.7 & 86.2 & 10.423 & 1295 & 774 & 77.9 & 49.5 & 57.8 & -157.3 & -42.5\end{array}$ $\begin{array}{lllllllllll}68.2 & 77.9 & 88.7 & 10.591 & 1376 & 812 & 80.1 & 49.4 & 56.7 & -164.6 & -49.2\end{array}$ $\begin{array}{llllllllllll}66.2 & 78.7 & 86.7 & 9.889 & 1458 & 832 & 80.1 & 52.8 & 59.1 & -149.7 & -54.2\end{array}$ $\begin{array}{lllllllllll}62.0 & 67.6 & 77.0 & 3.130 & 1208 & 737 & 69.3 & 52.9 & 58.2 & -44.0 & -9.4\end{array}$ $\begin{array}{lllllllllll}58.8 & 64.8 & 71.7 & 0.000 & 0 & 0 & 0.0 & 0.0 & 0.0 & 0.0 & 0.0\end{array}$ $\begin{array}{lllllllllll}53.7 & 63.5 & 73.0 & 0.000 & 0 & 0 & 0.0 & 0.0 & 0.0 & 0.0 & 0.0\end{array}$

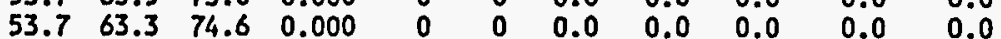
$\begin{array}{lllllllllll}50.1 & 63.3 & 75.2 & 0.000 & 0 & 0 & 0.0 & 0.0 & 0.0 & 0.0 & 0.0\end{array}$ $\begin{array}{lllllllllll}54.0 & 64.7 & 74.8 & 0.000 & 0 & 0 & 0.0 & 0.0 & 0.0 & 0.0 & 0.0\end{array}$

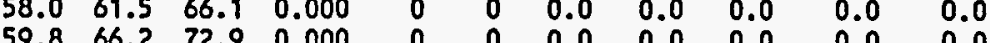
$\begin{array}{lllllllllll}73.3 & 77.6 & 84.8 & 8.799 & 1275 & 770 & 80.5 & 58.3 & 58.9 & -113.7 & -58.3\end{array}$ $\begin{array}{llllllllllll}72.9 & 79.6 & 87.2 & 9.487 & 1588 & 873 & 80.7 & 57.1 & 59.1 & -139.3 & -68.1\end{array}$ $\begin{array}{llllllllllll}68.0 & 71.4 & 74.9 & 6.848 & 1537 & 796 & 71.3 & 56.2 & 56.6 & -96.3 & -47.8\end{array}$ $\begin{array}{lllllllllll}69.6 & 75.8 & 84.7 & 4.935 & 1245 & 663 & 79.2 & 55.6 & 57.7 & -59.3 & -24.8\end{array}$ $\begin{array}{llllllllllll}73.2 & 78.1 & 86.5 & 10.205 & 1260 & 674 & 81.3 & 52.3 & 56.6 & -126.1 & -51.6\end{array}$ $\begin{array}{llllllllllll}0 & 73.8 & 78.3 & 86.3 & 11.435 & 1214 & 653 & 80.7 & 52.8 & 56.8 & -137.6 & -49.8\end{array}$ $\begin{array}{llllllllllll}0 & 72.1 & 76.5 & 83.1 & 10.743 & 1231 & 659 & 77.1 & 54.5 & 57.6 & -130.9 & -52.2\end{array}$ $\begin{array}{lllllllllllll}0 & 70.9 & 75.6 & 83.6 & 9.157 & 1268 & 676 & 76.6 & 54.2 & 57.4 & -115.7 & -46.7\end{array}$ $\begin{array}{llllllllllll}0 & 70.4 & 75.8 & 83.9 & 8.808 & 1317 & 697 & 78.1 & 52.2 & 56.3 & -116.6 & -41.3\end{array}$ $\begin{array}{llllllllllll}0 & 56.4 & 66.1 & 73.0 & 1.151 & 1216 & 645 & 66.7 & 57.0 & 58.2 & -13.7 & -4.1\end{array}$

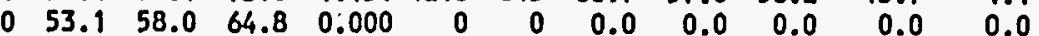

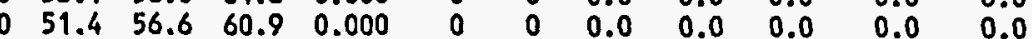
$\begin{array}{llllllllllll}0 & 55.3 & 62.4 & 71.0 & 0.000 & 0 & 0 & 0.0 & 0.0 & 0.0 & 0.0 & 0.0\end{array}$

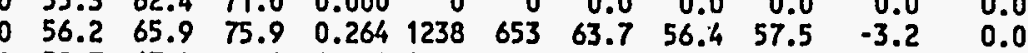
$\begin{array}{lllllllllllll}0 & 59.7 & 67.2 & 77.1 & 1.780 & 1301 & 684 & 73.5 & 58.7 & 57.4 & -21.5 & -6.6\end{array}$

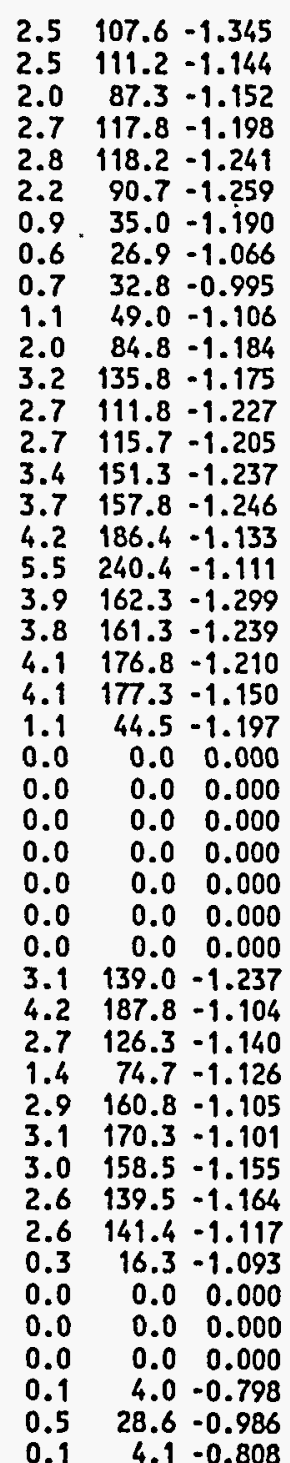

$\begin{array}{lll}2.5 & 107.6 & -1.345 \\ 2.5 & 111.2 & -1.144\end{array}$ $2.0 \quad 87.3-1.152$ $2.7 \quad 117.8-1.198$ $2.8 \quad 118.2-1.241$ $90.7-1.259$ $0.6 \cdot 26.9-1.066$ $0.7 \quad 32.8-0.995$ $49.0-1.106$ $111.8-1.227$ $115.7-1.205$ $7157.8-1.246$ $\begin{array}{lll}.2 & 186.4 & -1.133\end{array}$ $92162.3-1.299$ $1.3-1.239$ $177.3-1.150$ $1444.5-1.197$ $\begin{array}{lll}0.0 & 0.0 & 0.000\end{array}$ $\begin{array}{lll}0.0 & 0.0 & 0.000 \\ 0 & 0.0 & 0.000\end{array}$ $\begin{array}{lll}.0 & 0.0 & 0.000\end{array}$ $\begin{array}{lll}0.0 & 0.0 & 0.000\end{array}$ $\begin{array}{lll}139.0 & -1.237\end{array}$ $\begin{array}{lll}187.8 & -9.104\end{array}$ $\begin{array}{lll}.7 & 126.3-1.140\end{array}$ $.9 \quad 160.8-1.105$ 3.6 939.5 $141.4-1.117$ $0.3 \quad 16.3-1.093$ $\begin{array}{lll}0.0 & 0.0 & 0.000\end{array}$ $\begin{array}{lll}0.1 & 4.0 & -0.798\end{array}$ $0.1 \quad 4.1 \quad-0.808$ 
Daily sumary file - San Antonio Crada site, cont'd

Min Avg Max

Cool Eng Air Do ID ID Daily Dally Daily Daily Daily

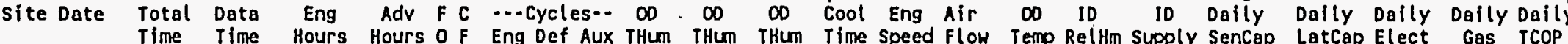
YY MM/DD/YY [Hrs] [Hrs] [Hrs] [Hrs]

[F] [F] [F] [Hrs] [RPM] [SCFM] [F] [X] [F] [KBtU] [KBtU] [KHHr] [KBtU]

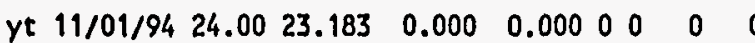
yt $11 / 02 / 94 \quad 24.0024 .000 \quad 0.496 \quad 0.0000002$ yt $111 / 03 / 9424.0022 .664 \quad 5.629 \quad 0.000000017$ yt $11 / 04 / 9424.0021 .448 \quad 10.973 \quad 0.00000022$ yt $11 / 06 / 9424.0024 .000 \quad 0.000 \quad 0.00000$

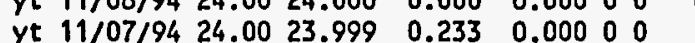

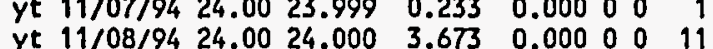

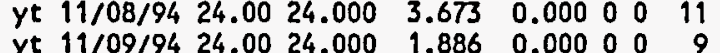
$\begin{array}{rrrrrrrrr}y t & 11 / 09 / 94 & 24.00 & 24.000 & 1.886 & 0.000 & 0 & 0 & 9 \\ y t & 11 / 10 / 94 & 24.00 & 24.000 & 5.589 & 0.000 & 0 & 0 & 16\end{array}$ $\begin{array}{lllllllll}y t & 11 / 10 / 94 & 24.00 & 24.000 & 5.589 & 0.000 & 0 & 0 & 16\end{array}$

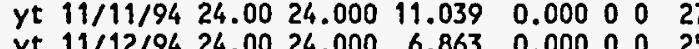

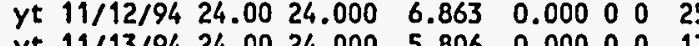
$\begin{array}{llllllll}\text { yt } 11 / 13 / 94 & 24.00 & 24.000 & 5.806 & 0.000 & 0 & 0 & 17 \\ \text { yt } 11 / 14 / 94 & 24.00 & 24.000 & 5.363 & 0.000 & 0 & 0 & 20\end{array}$ yt $11 / 1519424.0024 .000 \quad 0.03120 .000000$ yt $11 / 16 / 9424.0024 .000 \quad 5.9590 .00000023$ $\begin{array}{llllllll}\text { yt } & 11 / 17194 & 24.00 & 24.000 & 7.055 & 0.000 & 0 & 0\end{array}$

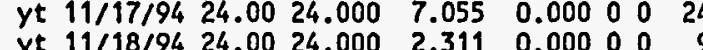

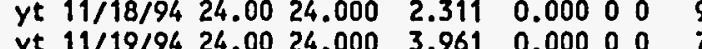
$\begin{array}{lllllll}\text { yt } 11 / 19 / 94 & 24.00 & 24.000 & 3.961 & 0.000 & 0 & 0 \\ \text { yt } 11 / 20 / 94 & 24.00 & 24.000 & 0.747 & 0.000 & 0 & 0\end{array}$

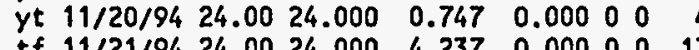
tf $11 / 21 / 9424.0024 .000 \quad 4.237 \quad 0.00000017$ yt $11 / 22 / 9424.0023 .282 \quad 2.507 \quad 0.000000012$ yt $11 / 23 / 94 \quad 24.0024 .000 \quad 7.905 \quad 0.000000025$ yt $11 / 24 / 94 \quad 24.0024 .00014 .134 \quad 0.00000033$ yt $11 / 25 / 9424.0024 .000 \quad 6.861 \quad 0.00000022$ ye $11 / 2619424.0024 .0002 .0870 .000000$ yt $11 / 26 / 9424.0024 .0002 .087 \quad 0.0000010$ yt $11 / 27 / 94,24.0024 .000 \quad 4.8180 .000000019$

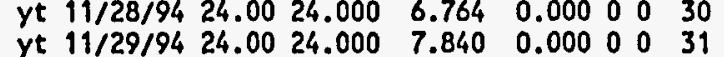
$\begin{array}{lllllllll}\text { yt } 11 / 30 / 94 & 24.00 & 24.000 & 13.196 & 0.000 & 0 & 0 & 36\end{array}$

$\begin{array}{rrrrrrrrrrrr}0 & 47.1 & 57.9 & 68.0 & 0.000 & 0 & 0 & 0.0 & 0.0 & 0.0 & 0.0 & 0.0 \\ 0 & 57.3 & 71.0 & 82.0 & 0.496 & 1220 & 653 & 75.3 & 66.3 & 61.1 & -4.9 & -1.2 \\ 0 & 73.2 & 77.0 & 84.0 & 5.629 & 1206 & 648 & 78.4 & 59.8 & 59.2 & -64.0 & -32.7 \\ 0 & 74.7 & 77.2 & 82.0 & 10.973 & 1301 & 693 & 77.3 & 56.4 & 55.9 & -137.1 & -55.0 \\ 0 & 54.6 & 63.4 & 75.9 & 3.004 & 1212 & 647 & 68.2 & 53.2 & 55.8 & -38.4 & -7.4 \\ 0 & 54.6 & 62.9 & 73.6 & 0.000 & 0 & 0 & 0.0 & 0.0 & 0.0 & 0.0 & 0.0 \\ 0 & 54.1 & 65.8 & 75.3 & 0.233 & 1244 & 662 & 71.5 & 61.4 & 59.4 & -2.4 & 0.0 \\ 0 & 70.2 & 75.2 & 82.4 & 3.673 & 1208 & 651 & 77.3 & 59.1 & 58.8 & -42.6 & -20.1 \\ 0 & 53.7 & 66.7 & 80.4 & 1.886 & 1213 & 643 & 69.7 & 61.1 & 59.9 & -21.0 & -9.2 \\ 0 & 46.6 & 52.8 & .62 .2 & 0.000 & 0 & 0 & 0.0 & 0.0 & 0.0 & 0.0 & 0.0 \\ 0 & 45.5 & 54.2 & 62.1 & 0.000 & 0 & 0 & 0.0 & 0.0 & 0.0 & 0.0 & 0.0 \\ 0 & 57.3 & 63.1 & 68.6 & 0.000 & 0 & 0 & 0.0 & 0.0 & 0.0 & 0.0 & 0.0 \\ 0 & 66.3 & 72.1 & 79.0 & 4.401 & 1393 & 735 & 74.0 & 56.4 & 55.7 & -58.8 & -22.6 \\ 0 & 63.2 & 71.7 & 78.8 & 5.363 & 1205 & 648 & 72.0 & 58.4 & 56.6 & -62.7 & -25.0 \\ 0 & 56.3 & 58.1 & 62.6 & 0.000 & 0 & 0 & 0.0 & 0.0 & 0.0 & 0.0 & 0.0 \\ 1 & 54.6 & 58.6 & 62.5 & 0.000 & 0 & 0 & 0.0 & 0.0 & 0.0 & 0.0 & 0.0 \\ 0 & 58.9 & 65.1 & 73.9 & 2.625 & 1630 & 824 & 64.7 & 50.7 & 51.9 & -42.4 & -12.0 \\ 0 & 63.6 & 67.9 & 71.3 & 1.996 & 1215 & 655 & 69.5 & 63.3 & 56.4 & -21.6 & -10.2 \\ 0 & 69.7 & 73.5 & 79.6 & 3.676 & 1409 & 740 & 74.1 & 56.5 & 55.3 & -49.0 & -19.4 \\ 0 & 52.4 & 68.0 & 76.7 & 0.747 & 1204 & 645 & 71.6 & 64.1 & 59.4 & -7.7 & -4.1 \\ 0 & 45.5 & 60.5 & 75.2 & 0.834 & 1630 & 818 & 61.9 & 46.5 & 51.3 & -14.0 & 0.0 \\ 0 & 56.5 & 66.2 & 76.4 & 0.000 & 0 & 0 & 0.0 & 0.0 & 0.0 & 0.0 & 0.0 \\ 0 & 48.0 & 53.2 & 63.4 & 0.000 & 0 & 0 & 0.0 & 0.0 & 0.0 & 0.0 & 0.0 \\ 0 & 47.4 & 49.2 & 53.4 & 0.000 & 0 & 0 & 0.0 & 0.0 & 0.0 & 0.0 & 0.0 \\ 0 & 53.4 & 61.4 & 72.1 & 0.000 & 0 & 0 & 0.0 & 0.0 & 0.0 & 0.0 & 0.0 \\ 0 & 56.7 & 68.1 & 78.6 & 0.000 & 0 & 0 & 0.0 & 0.0 & 0.0 & 0.0 & 0.0 \\ 0 & 61.8 & 70.9 & 79.7 & 4.546 & 1249 & 670 & 72.44 & 56.8 & 56.6 & -55.4 & -15.6 \\ 0 & 51.9 & 57.2 & 63.2 & 0.000 & 0 & 0 & 0.0 & 0.0 & 0.0 & 0.0 & 0.0 \\ 0 & 49.5 & 58.5 & 69.4 & 0.000 & 0 & 0 & 0.0 & 0.0 & 0.0 & 0.0 & 0.0 \\ 0 & 44.6 & 51.8 & 60.9 & 0.000 & 0 & 0 & 0.0 & 0.0 & 0.0 & 0.0 & 0.0\end{array}$

$\begin{array}{rrr}0.0 & 0.0 & 0.000 \\ 0.1 & 7.7 & -0.794 \\ 1.5 & 82.3 & -1.174 \\ 3.2 & 173.7 & -1.106 \\ 0.8 & 42.3 & -1.085 \\ 0.0 & 0.0 & 0.000 \\ 0.1 & 3.8 & -0.641 \\ 1.0 & 53.8 & -1.165 \\ 0.5 & 27.2 & -1.111 \\ 0.0 & 0.0 & 0.000 \\ 0.0 & 0.0 & 0.000 \\ 0.0 & 0.0 & 0.000 \\ 1.4 & 75.2 & -1.082 \\ 1.5 & 76.6 & -1.145 \\ 0.0 & 0.0 & 0.000 \\ 0.0 & 0.0 & 0.000 \\ 1.0 & 50.4 & -1.078 \\ 0.6 & 29.8 & -1.067 \\ 1.2 & 64.6 & -1.059 \\ 0.2 & 11.2 & -1.055 \\ 0.3 & 16.2 & -0.864 \\ 0.0 & 0.0 & 0.000 \\ 0.0 & 0.0 & 0.000 \\ 0.0 & 0.0 & 0.000 \\ 0.0 & 0.0 & 0.000 \\ 0.0 & 0.0 & 0.000 \\ 1.3 & 68.6 & -1.036 \\ 0.0 & 0.0 & 0.000 \\ 0.0 & 0.0 & 0.000 \\ 0.0 & 0.0 & 0.000\end{array}$


Appendix E

Fuel Price Calculations 


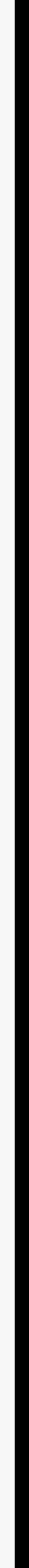




\section{Appendix E}

\section{Fuel Price Calculations}

The fuel prices used in the operating cost analysis are $\$ 0.4257 / \mathrm{ccf}$ and $\$ 0.0581 / \mathrm{kWh}$ for the Triathlon. For the comparison units, a price of $\$ 0.06315 / \mathrm{kWh}$ is used for electricity. These averages are derived from the monthly adjusted costs reported by City Public Service of San Antonio (Table E.1). The averages are calculated over the test period using monthly fuel usage as weights (Table E.2). Monthly electric rates are subject to an additional peak capacity charge of $\$ 0.015 / \mathrm{kWh}$ for electric usage in excess of $600 \mathrm{kWh} / \mathrm{mo}$, applicable from June through September. Individual residential gas and electric bills include a service availability charge of $\$ 4.25 / \mathrm{mo}$ for gas and $\$ 3.85$ for electricity. These charges are not included in the monthly adjusted costs.

Table E.1. Retail Cost of Electricity and Gas During 1994 Cooling Test Period

\begin{tabular}{|c|c|c|}
\hline $\begin{array}{c}\text { Days } \\
516=6 / 1 / 94\end{array}$ & $\begin{array}{c}\text { Electricity } \\
\text { Cost, } \$ / \mathbf{k W h}\end{array}$ & Gas Cost, $\$ /$ ccf \\
\hline $516-545$ & 0.05684 & 0.41198 \\
\hline $546-576$ & 0.05806 & 0.43976 \\
\hline $577-607$ & 0.06141 & 0.43956 \\
\hline $608-637$ & 0.05661 & 0.41012 \\
\hline $638-668$ & 0.05297 & 0.37916 \\
\hline $669-698$ & 0.05482 & 0.40086 \\
\hline
\end{tabular}

Table E.2. Gas and Electricity Usage During 1994 Cooling Test Period

\begin{tabular}{|c|c|c|c|}
\hline $\begin{array}{c}\text { Days } \\
516=6 / 1 / 94\end{array}$ & $\begin{array}{c}\text { Triathlon Monthly } \\
\text { Electricity Usage, kWh }\end{array}$ & $\begin{array}{l}\text { Triathlon Monthly } \\
\text { Gas Usage, MBtu }\end{array}$ & $\begin{array}{l}\text { Unit } 1 \text { Projected Monthly } \\
\text { Electricity Usage, } \mathbf{k W h}\end{array}$ \\
\hline $516-545$ & 80 & 4.2 & 549 \\
\hline $546-576$ & 207 & 10.5 & 1354 \\
\hline $577-607$ & 174 & 8.3 & 1115 \\
\hline $608-637$ & 90 & 4.0 & 482 \\
\hline $638-668$ & 56 & 2.7 & 302 \\
\hline $669-698$ & 15 & 0.8 & 59 \\
\hline
\end{tabular}





\section{Distribution}

No. of

Copies

Offsite

2 DOE/Office of Scientific and Technical Information

18 U.S. Department of Energy

Federal Energy Management Program 1000 Independence Avenue SW

Washington, DC 20585

ATTN: K. Dean DeVine (EE-44) (15)

M. Ginsberg (EE-44)

J. Brodrick (EE-422)

J. D. Ryan (EE-422)

V. Petrolati EE-91

DOE/In-House Energy Management

U.S. Department of Energy

1000 Independence Avenue SW

Washington, DC 20585

M. Carr

Office of the Secretary of Defense

DASD (L) EP

Pentagon

Washington, DC 20301-8000

A. Gillespie

ATTN: FCEN-RDF

FORSCOM

Building 200

Fort McPherson, GA 30330-6000

3 B. Swartz

York International

P.O. Box 1592, Mail Code 191B

York, PA 17405
No. of

Copies

Offsite

3 S. Young

Director of Engineering \& Housing

HQ 5th

U.S. Army at Fort Sam Houston

San Antonio, TX 78334

3 J. Brogan

Gas Research Institute

8600 W. Bryn Mawr Avenue

Chicago, IL 60631

3 P. E. Miles

City Public Service of San Antonio, Texas

Gas Operations Division

P.O. Box 1771

San Antonio, TX 78296

3 R. Sweetser

American Gas Cooling Center 1515 Wilson Boulevard

Arlington, VA 22209

C. Collins

Family Housing

Guidance and Standards Analyst

Naval Facilities Engineering Command 200 Stovall Street

Alexandria, VA 22332-2300

A. Houtzager

Army Housing Divison

Office of the Assistant Chief of Staff for

Installation Management

DAIM-FDH-F

U.S. Army Center for Public Works

7701 Telegraph Road

Alexandria, VA 22315-3862

Distr. 1 
No. of

Copies

Onsite

2 W. G. Atterbury

Battelle Memorial Institute

505 King Avenue

Columbus, $\mathrm{OH} 43201$

E. Lauterstein

Reliable Distributing Company

1952 Shipman Drive

San Antonio, TX 78219

J. Freund

Comfort-Air Engineering Inc.

11403 Jones-Maltsberger

San Antonio, TX 78216

H. Gaberson

NFEFC-code 60

560 Center Drive

Port Hueneme, CA 93043-4328

P. W. Adcock

Oak Ridge National Laboratory

P.O. Box 2008

Oak Ridge, TN 37831-6070

B. Carroll

Lawrence Berkeley Laboratory

1 Cyclotron Road

Berkeley, CA 94720

B. K. Thomas

National Renewable Energy Laboratory

Suite 710

409 12th Street SW

Washington, DC 20024-2125
No. of

Copies

Onsite

DOE Richland Operations Office

P. W. Kruger

A5-54

46 Pacific Northwest Laboratory

P. R. Armstrong

K5-20

D. R. Conover

BWO

J. A. Dirks

K8-18

D. R. Dixon (5)

K8-17

W. D. Hunt (5)

BWO

J. D. Miller (5)

K5-20

G. B. Parker

K9-62

S. A. Parker

K5-08

W. F. Sandusky

K5-08

M. K. Stockmeyer (20)

BWO

D. W. Winiarski

K5-08 